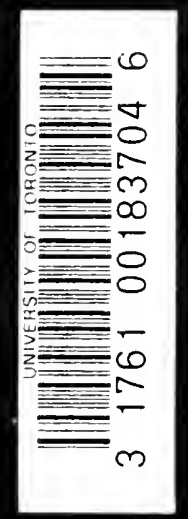


$=\because$

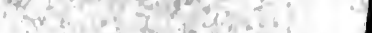


I

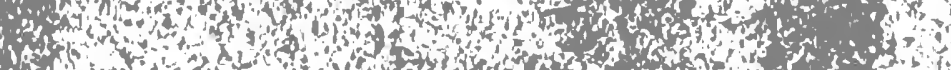
1)

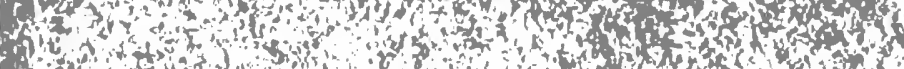

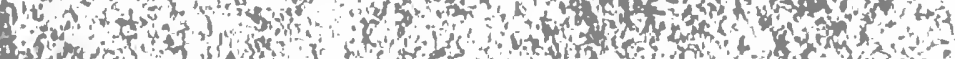
2uto of (1) 3 of s.s.

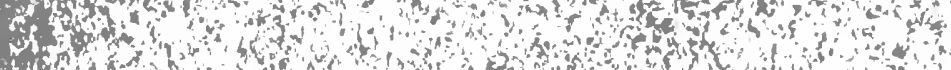

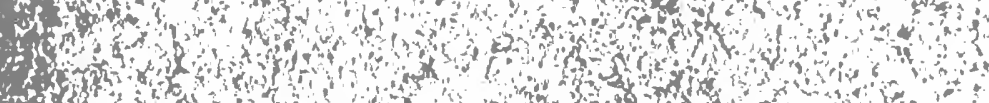
Fonder

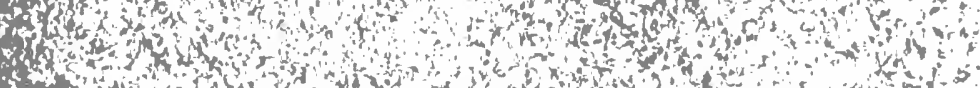

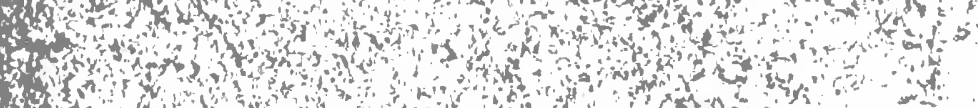

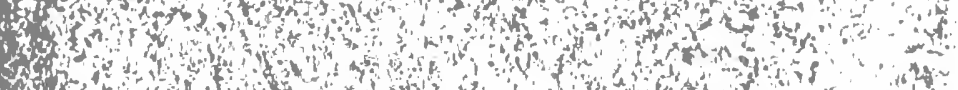
SAt

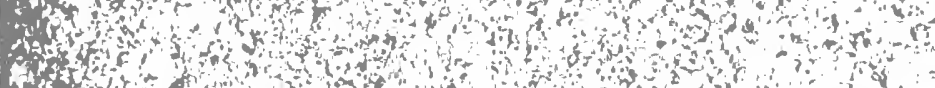

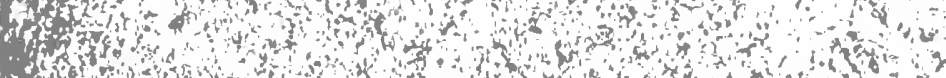
1.3.

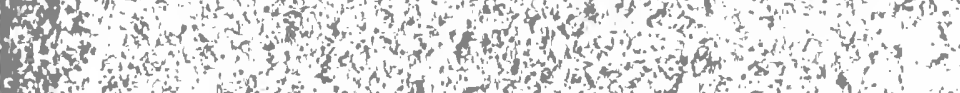
(1) Don

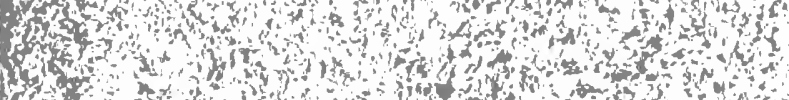

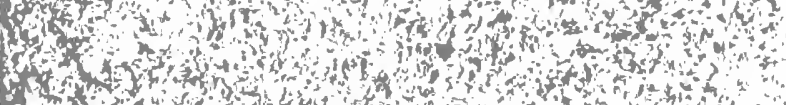

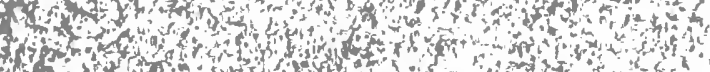

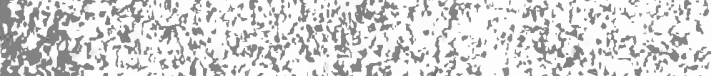
(15)

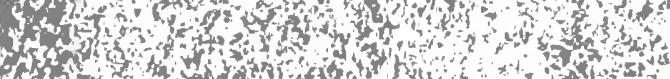
Qfent

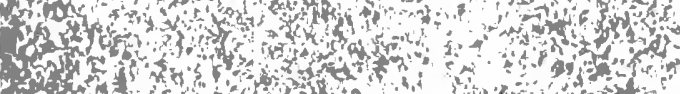
1.

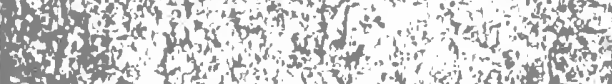

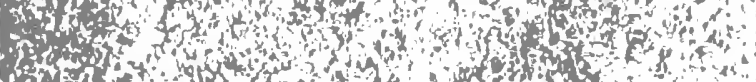
for ontef w 110 en

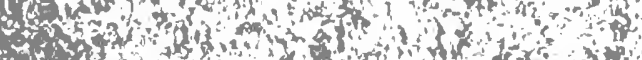

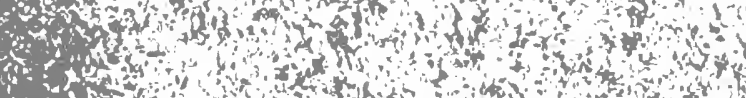
100 b

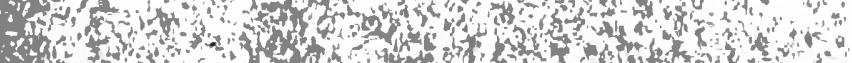


HISTORICAL INTRODUCTION TO MATHEMATICAL LITERATURE 


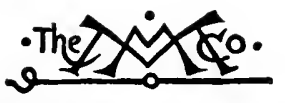

THE MACMILLAN COMPANY

NEW YORK - BOSTON - CHICAGO - DALLAS

ATLANTA - SAN FRANCISCO

MACMILLAN \& CO., Limited

LONDON - BOMBAY - CALCUTTA

MELBOURNB

THE MACMILLAN CO. OF CANADA, LTD.

TORONTO 


\section{HISTORICAL INTRODUCTION TO MATHEMATICAL LITERATURE}

BY

G. A. MILLER

PROFESSOR OF MATHEMATICS IN THE UNIVERSITY OF ILLINOIS

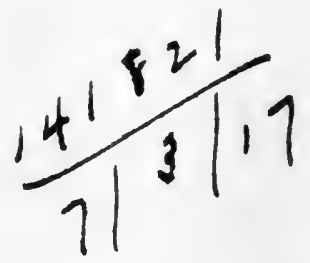

Now igork

THE MACMILLAN COMPANY

1916

All rights reserved 
Cofyright, 1916,

By THE MACMILLAN COMPANY.

Set up and electrotyped. Published January, 1916.

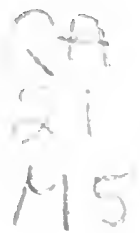

J. 8. Cushing Co. - Berwick \& Smith Co. Norwood, Mass., U.S.A. 


\section{PREFACE}

THE mathematical literature is unusually rich in content and is composed of a great variety of elements. It contains many results that would appeal to every one if they were presented in the proper form and at the proper time. One of the difficult problems which present themselves to those interested in the diffusion of mathematical knowledge is how to establish a proper correspondence between the subject matter and the individual. This problem is especially serious in view of the fact that misfits along this line are often disastrous.

Hence it is very desirable that the mathematical student be led to points from which he can overlook domains of considerable extent in order that he may be able to form a somewhat independent judgment as regards the regions which he might like to examine more closely. The main object of the present work is to guide the reader to such points of observation. These observation points should also appeal to those who are interested in general educational questions but do not have time to enter upon a study of the abstruse developments in this particular field.

Mathematical accuracy should not be confused with mathematical minutiæ. Comprehensive views are often very helpful and fill an important place in mathematical education. The mathematical student needs to use the telescope as well as the microscope, even if the latter 
instrument is the more important for those who desire to become experts along mathematical lines. The training which is best adapted to the needs of the future expert is, however, not always the most valuable for the average student.

Some of the views expressed in the present volume can be more easily understood if it is observed that the volume is based upon a series of lectures which were intended to supplement the work of the regular mathematical courses. The semi-popular lecture style was maintained, and the lecturer's license to exhibit only the main points with a view to special emphasis may explain some statements which should otherwise have been made with greater restrictions. It is hoped, however, that this style may increase the ease of reading the book and that the views presented will always be found correct in a broad way.

In preparing the book for publication the author aimed to meet the needs of a textbook for synoptic and inspirational courses which can be followed successfully by those who have not had extensive mathematical training. It may also be used as a textbook for a first course in the history of mathematics, especially by those teachers who believe with its author that such a first course should largely concern itself with recent mathematical events and developments.

Many of those who have given courses in the history of ancient and medieval mathematics for prospective teachers of secondary mathematics have doubtless experienced that much of the desired literature is found in languages which only a few of their students read with sufficient ease to obtain good results. A course 
in which modern developments and activities are mainly considered presents fewer difficulties along this line. Many of the references in the present volume are to works in the English language, and reports, by the students, on some of these works could be made a very valuable feature of a first course in the history of mathematics. The brief list of biographical sketches given in Chapter VII could also be profitably extended in this manner.

The writer believes that early mathematical courses should be more informational especially along historical lines on the ground that knowledge begets interest in more knowledge. This is especially true of such unifying knowledge as results from a study of mathematics, since unifying knowledge becomes possible only after the elements to be united have been thoroughly grasped; and the more numerous these elements are the greater is the possibility of unification, and the greater is the pleasure to the student. The joy in the study of mathematics increases very rapidly with the number of the theorems which have been completely mastered on the part of the student. This mastery implies that these theorems can be used by the student rather than that they can be only proved by him, for many can repeat proofs of theorems in regard to which they are practically ignorant.

The young student of mathematics is apt to look on this subject as one of solving problems, but the more he advances the more truth he will see in the statement that mathematics is a science which enables one to escape the trouble of solving special problems. Most of us have to solve special problems to become mathe- 
maticians, each special problem being used to emphasize some principle or principles. After the principles are fully comprehended we know how things will come out without going through the details, and the broad underlying principles, which are usually acquired so slowly, are the elements which inspire deep interest and enrich intellectual penetration.

The last few decades have marked a remarkable increase in library facilities of all kinds. The average student is no longer confined to his particular textbook for all the information along the line which he is pursuing, but many other avenues of information are open to him. This naturally makes higher demands on the knowledge of the teacher. The advantages offered by the Summer Sessions of the American Universities have made it possible for the teachers to prepare themselves for these higher requirements. The one-book course should become more and more a matter of the past, especially in the more advanced work. Students should be encouraged to supplement their textbooks and to regard these as the means but not as the end of their study.

A study of the developed parts of mathematics may be compared with tilling of soil which was cultivated before. While rich harvests may bring bountiful returns for the labor involved, yet there are many who prefer the excitement and the hardships of frontier life. In mathematics these frontiers are readily accessible, and it seems unfortunate that limitations of the contemporary mathematical knowledge are not more generally known. A knowledge of some of these limitations endows the study of mathematics with the 
attractiveness of wild and unexplored regions without affecting the attractions due to its fields of known fertility.

To guard against an erroneous impression the author desires to state explicitly that many of the historical statements as well as some of the scientific ones contained in the present volume are based upon what appeared to him entirely reliable authority but are not the fruits of his direct study. In many cases references are given but sometimes it did not appear feasible to do this without marring the presentation. Among the works which the author occasionally accepted as final authority the Encyclopédie des Sciences Mathématiques and the Bibliotheca Mathematica deserve especially to be mentioned. In the spelling of proper names the author aimed merely at adopting forms which are found in some of the best modern literature, without striving to attain uniformity in the spelling of different names.

In plan and scope the present volume may perhaps claim originality. With the enlargement of mathematical knowledge and the increase in mathematical activities there naturally comes the need of new types of mathematical literature. Moreover, with our gradual evolution from the state of barbarism the history of war and bloodshed is being slowly replaced by that of political and intellectual movements. As mathematics holds a prominent place among the latter its history is bound to become more and more a matter of general interest.

Shameless ignorance in regard to such serious intellectual conquests as are embodied in the mathematical literature does not represent a normal condition on the 
part of those interested in the history of the human race. On the contrary, such shamelessness is evidence of the lack of the proper aids to enter this literature. It is hoped that the present volume will be a contribution towards providing more such aids, and towards securing a more common appreciation of the rôle played by mathematics in the civilization of to-day. Much of the mathematical literature needs to be diluted and sweetened before it is served to the masses as an enjoyable and nourishing beverage.

The author desires to acknowledge that he received valuable assistance while the book was in press. Among those whose suggestions and corrections were especially helpful are the following: Dr. A. J. Kempner, Professor R. D. Carmichael, Professor J. B. Shaw, Dr. E. B. Lytle, Dr. W. W. Denton, Mr. C. M. Hebbert, and Mrs. G. A. Miller. If serious defects remain, they are probably due to the fact that the author failed to adopt all the suggestions by these readers. It is with some trepidation that the author sanctions the début of this little volume into a larger and more critical circle of readers. $\mathrm{He}$ hopes, however, that he may receive also from these friendly suggestions and corrections in order that a second edition may be more nearly perfect in case such an edition will appear feasible in the near future.

G. A. MILLER.

OCtOBER, 1915. 


\section{TABLE OF CONTENTS}

\section{CHAPTER I}

\section{GENERAL OBSERVATIONS}

SECTION

1. Changes during the nineteenth century:- . . . . 1

2. History of mathematics . . . . . . $\quad$. 8

3. Developed parts of the history of mathematics . . . 12

4. Periods in the history of mathematics . . . . 15

5. Usefulness of the history of mathematics . . . 17

6. First decade and a half of the twentieth century . . . 22

7. American mathematics . . • • . . . 29

\section{CHAPTER II}

\section{MATHEMATICAL LITERATURE IN GENERAL}

8. Types of recent mathematical literature . . . . . 36

9. Mathematical societies . . . . . . . . 43

10. International mathematical congresses . . . . . 51

11. Periodicals on periodicals and books on books . . . 56

12. Special historical periodicals . . . . . . . 60

13. Encyclopedias and other works of reference . . . . 63

14. Mathematical tables. . . . . . . . . 68

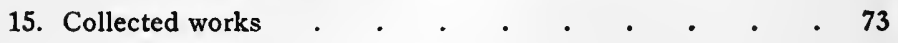

\section{CHAPTER III}

\section{GENERAL HISTORICAL QUESTIONS RELEVANT TO MATHEMATICS}

16. Definitions of the term mathematics . . . . 78

17. Grand divisions of mathematics . . . . . . 81

18. Subdivisions of mathematics . . . . . . . $\quad$. 86

19. Some dominant concepts of mathematics . . . $\quad$. 93 
SECTION

20. Mathematical notation and terminology . . . . . 102

21. Errors in the mathematical literature . . . . 110

22. Living mathematicians . . . . . . . 118

23. Mathematics as an educational subject . . . . . 125

\section{CHAPTER IV}

FUNDAMENTAL DEVELOPMENTS IN ARITHMETIC

24. Existence of an infinite number of prime numbers. . . 129

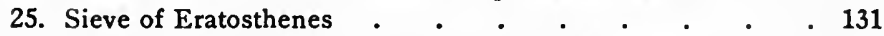

26. Irrational quantities and irrational numbers . . . . 133

27. Significance of irrational numbers and their general introduction . . . . . . . . . . 137

28. Extraction of the square root . . . . . . . . 141

29. Fundamental operations of arithmetic . . . . . . 144

30. Systems of notation. . . . . . . . . . . . 149

31. The greater Fermat theorem . . . . . . . 153

\section{CHAPTER V}

FUNDAMENTAL DEVELOPMENTS IN GEOMETRY

32. The Pythagorean theorem . . . . . . . 159

33. The area of the circle . $\quad . \quad$. $\quad . \quad . \quad . \quad . \quad . \quad 163$

34. Area and volume of the sphere . . . . . . . 168

35. Regular figures . . . . . . . . . . 171

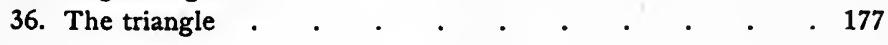

\section{CHAPTER VI}

FUNDAMENTAL DEVELOPMENTS IN ALGEBRA

37. Introduction . . . . . . . • . . 182

38. Fundamental theorem of algebra . . . . . . 185

39. Determinants . . . . . . . . . . 191

40. Numerical equations . . . . . . . . . . 195

41. Domain of rationality . . . . . . . . . . $\quad$. 202

42. Invariants . . . . . . . . . . 206

43. Binomial theorem . . . . . . . . . 209 


\section{CHAPTER VII}

TWENTY-FIVE PROMINENT DECEASED

\section{MATHEMATICIANS}

SECTION

44. Introduction . . . . . . . . . . 214

45. Euclid . . . . . . . . . . . 216

46. Archimedes . . . . . . . . . . . . 219

47. Apollonius . . . . . . . . . . . . 221

48. Diophantus of Alexandria . . . . . . . 224

49. Vieta . . . . . . . . . . . . 226

50. Descartes . . . . . . . . . . . . 228

51. Fermat . . . . . . . . . . . 230

52. Newton . . . . . . . . . . . 231

53. Leibniz . . . . . . . . . . . . 235

54. Euler . . . . . . . . . . . . 236

55. Lagrange . . . . . . . . . . . . 239

56. Gauss . . . . . . . . . . . . 241

57. Cauchy . . . . . . . . . . . . 243

58. Steiner . . . . . . . . . . . 245

59. Abel . . . . . . . . . . . . 247

60. Hamilton. . . . . . . . . . 248

61. Galois . . . $\quad . \quad . \quad . \quad . \quad . \quad . \quad .251$

62. Sylvester . . . . . . . . . . . 253

63. Weierstrass . . . . . . . . . . 255

64. Cayley . . . . . . . . . . . 257

65. Hermite . . . . . . . . . . . 260

66. Kronecker . . . . . . . . . . . 262

67. Cremona. . . . . . . . . . . . 264

68. Lie. . . . . . . . . . . . 265

69. Poincaré . $. \quad . \quad . \quad . \quad . \quad . \quad . \quad 268$

\section{APPENDIX}

\section{LISTS OF IMPORTANT WORKS}

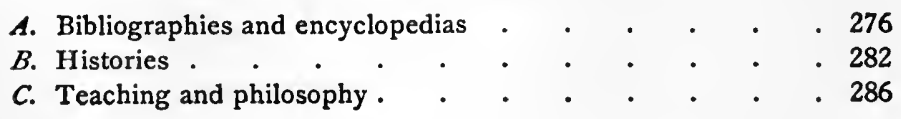




\section{HISTORICAL INTRODUCTION TO MATHEMATICAL LITERATURE}

\section{CHAPTER I}

\section{General Observations}

1. Changes during the nineteenth century. - The nineteenth century witnessed a marvelous increase in general mathematical intelligence. At the beginning of this century the elements of mathematics were still regular university subjects. According to Gebhardt the function of teaching elementary mathematics in Germany was assumed by the Gymnasiums during the years from I810 to 1830.* Before this time this function had been performed by the universities. In our own country this transition was made about the same time, as may be inferred from the following statements in regard to the oldest Ar erican university.

"In I802 the standard for admission to Harvard College was raised. In mathematics a knowledge of arithmetic to the 'rule of three' was required. Thus, in 1803 , for the first time had it become necessary, according to regulations, for a boy to know something about

*Internationale Mathematische Unterrichtskommission, Vol. 3, No. 6 (19r2), p. 2. 
arithmetic before he could enter Harvard. We surmise, however, that the requirements in arithmetic were very light, for we know from the diary of a student in the Freshman class in 1807 that arithmetic continued to be taught during the first year at college. After 1816 the whole of arithmetic was required for admission." *

Although the general mathematical intelligence was very low at the beginning of the nineteenth 'century, it should not be inferred that there were no great mathematicians at that time. While there were then no American mathematicians who contributed to the advancement of higher mathematics, the establishment, in I804, of the first American mathematical periodical, entitled, "The Mathematical Correspondent ; containing new elucidations, discoveries and improvements in various branches of the mathematics," is evidence of considerable mathematical interest, even if the support was insufficient to continue the publication of this journal for a long time. In fact, only nine numbers of this quarterly were ever published. On the other hand, there were then some very eminent mathematicians in Europe, especially in France, as is evident from the fact that Lagrange, Monge, Laplace, Legendre, and Fourier were then making discoveries which have made their names familiar to all later students of our subject. In Germany Gauss was practically the only eminent mathematician at this time.

The wonderful increase in mathematical intelligence during the nineteenth century was largely due to the progress made during this period in training the youths in the schools for service along technical lines. The French p. 60.

* F. Cajori, Teaching and History of Mathematics in the United States, 1890, 


\section{Fundamental Concepts of Algebra and Geometry}

\section{BY JOHN WESLEY YOUNG}

Professor of Mathematics in Dartmouth College

With a note on "The Growth of Algebraic Symbolism," by W. G. MITchell, Professor of Mathematics in the University of Kansas.

247 pp., $12 m 0, \$ 1.60$

An elementary account of the logical foundations of algebra and geometry-elementary in the sense that the technical mathematical equipment presupposed on the part of the reader has been reduced to a minimum. Except in a very few instarces no knowledge of mathematics beyond the most elementary portions of algebra and geometry has been assumed. The author gives a general exposition of the abstract formal point of view developed during the last few decades, rather than an exhaustive treatment of the details of the investigations. The results of recent work on the logical foundations are of vital interest alike to the teachers of mathematics in our secondary schools and colleges and to philosophers and logicians. It is hoped that both these classes will welcome a concise statement of some of the more fundamental of these results and an elementary exposition, free from all involved details, of the point of view which governs all present work on the foundations. The book should be available also as a text in Teachers' Courses in colleges and universities.

\section{THE MACMILLAN COMPANY}




\title{
A Short History of Mathematics
}

BY W. W. ROUSE BALL

$498 \mathrm{pp} ., 12 m 0, \$ 3.00$

An historical summary of the development of mathematics. It gives a popular account of those leading facts in the history of mathematics which many who are unwilling, or have not the time, to study it systematically may yet desire to know.

\section{A Primer of the History of Mathematics}

\author{
BY W. W. ROUSE BALL
}

Fellow and Tutor of Trinity College, Cambridge

I62 pp., I6mo, $\$ .75$

A brief and popular account of the history of mathematics, including some notice of the lives and surroundings of those to whom this development is mainly due.

\section{A History of Mathematics}

\section{BY FLORIAN CAJORI}

Professor of Mathematics in Colorado College

422 pp., 8v0, \$3.50

The increased interest in the history of exact sciences manifested in recent years led the author to the preparation of this history of mathematics, which will be found accurate, reasonably complete and most useful.

\section{A History of Elementary Mathematics, with Hints on Methods of Teaching}

\author{
BY FLORIAN CAJORI
}


Revolution at the end of the preceding century had awakened a keen appreciation of the importance of a more practical education for the young people, and with the emphasis on scientific and technical education there naturally came an increase of emphasis on mathematics, which furnishes ideals as well as aids for scientific and technical progress. Mathematics deals mainly with realities and stern facts, and it arms those whose life work is beset with physical difficulties. Hence it appeals especially to the leaders of the common people, and it performs a fundamental function in the education of those who aim to excel in overcoming material difficulties.

The nineteenth century witnessed also a great increase in our knowledge as regards mathematical developments in very ancient times. Two facts are especially important in this connection; viz., the discovery of a key to the cuneiform inscriptions of the ancient Babylonians and the discovery of a key to writings of the ancient Egyptians. According to E. Löffler's Ziffern und Ziffernsysteme der Kulturvölker, I9I2, page 22, the first one to decipher a cuneiform inscription was G. F. Grotefend, a German Gymnasium teacher, who deciphered a part of such an inscription in I802. It was, however, not until the last quarter of the nineteenth century that systematic explorations in the Babylonian country were inaugurated. These explorations have led to the discovery of many thousands of clay writing tablets, both burnt and unburnt, which have enabled us to learn many facts in regard to the mathematical attainments and the mathematical instruction in this country three or four thousand years B.C. 
Attempts were made as early as the seventeenth century to read Egyptian hieroglyphs, but no promise of success appeared until the discovery of the famous Rosetta stone, in I799, by a French engineer attached to Napoleon's Expedition. This discovery furnished a key to the considerable treasure of ancient Egyptian writings and was soon followed by translations of some of these writings into modern languages. The nineteenth century was thus enriched mathematically not only by its own advances, but also by stores of knowledge which became available through the development of the branches of science known as Assyriology and Egyptology. While the mathematical knowledge gathered from these ancient writings has been of no value whatever from the standpoint of new mathematics, since the mathematical attainments at the beginning of the nineteenth century were far beyond those reached in these early centers of learning, yet the mathematical literature has been greatly enriched by definite information in regard to these early attainments.

The latter half of the nineteenth century witnessed a great change of view in regard to the value of the histor" of mathematics. In the opening article of the this series of the important journal on the history of mathe matics, entitled Bibliotheca Mathematica, G. Enestr stated that he had good reasons to believe that in abc. I870 the majority of mathematicians had very litt confidence in the value of the history of mathematics. It seemed to them that if any of the older mathematical works involved real progress, the results would be found in better form in the later treatises. If, on the other 
hand, such an older work did not involve any real advances, its study would not only be unnecessary but it would even be harmful. Referring to about the same period, Felix Müller observed that one of his teachers told him truly that it was no longer customary, in scientific works, to mention those who had previously considered the same questions.*

At the end of the nineteenth century the value of the history of mathematics was much more generally appreciated in view of the fact that mathematics was then more generally regarded as an increasing variable instead of as a fixed constant. The dynamic elements of mathematics received more attention. $\dagger$ The large German and French mathematical encyclopedias, which were started about this time, bear evidences, by their extensive references, of the growing historical interest. This is especially true of the French edition, whose publication began in 1904 and which contains a very large number of historical notes. The increasing interest in the history of mathematics towards the end of the nineteenth century was also largely due to a constantly growing interest in the teaching of mathematics, which culminated near the beginning of the present century in the appointment of an International Commission on the Teaching of Mathematics.

The increase of interest in the history of mathematics has resulted in a more careful study of the evidences upon which various historical statements rest, and it has

* Felix Müller, Bibliotheca Mathematica, Vol. 4 (r903), p. 27 r.

† Cf. C. H. Müller, Studien zur Geschichte der Mathematik, I903, p. 6; G. W. Myers, Mathematical Supplement of School Science, Vol. I (1903), p. 85. 
been found that a large number of these statements had very little foundation. One of the most striking illustrations of this fact is furnished by the 2000 corrections which were made before I9I5 with respect to the wellknown Cantor's Vorlesungen über Geschichte der Mathematik.* This important history confines itself to the developments which precede the nineteenth century, and hence one might have supposed that it would be comparatively free from errors, since it could confine itself to well-seasoned facts. The given large number of corrections is evidence of the great difficulties involved in the history of mathematics. These difficulties have been greatly increased by the fact that so many mathematical writers who were scrupulously careful about their other work did not look seriously on shortcomings along the line of historical notes.

Notwithstanding the great advances during the nineteenth century, the beginning of the twentieth century found most of the civilized world practically indifferent in regard to advanced mathematics. The center of mathematical activity not only remained in Europe during the nineteenth century but it was also not decidedly shifted among the European countries. During the latter part of the century Italy made very rapid advances and gradually assumed a position among the leading mathematical countries; in fact, Italy became the leading country along geometric lines, while France continued to lead in analysis, and Germany maintained her leadership in the theory of numbers, a leadership which was gained by Gauss. England maintained her

* G. Eneström, Bibliotheca Mathematica, Vol. I4 (I914), p. 28r. 
eminence in mathematical physics, while the United States became the leading mathematical country outside of Europe, making more and more rapid progress towards the close of the century. On the other hand, the peoples of Asia, Africa, and South America continued to do very little to increase mathematical knowledge or even to utilize the more advanced results reached in the leading mathematical countries.

The most important single guiding motive in the rapid advances made during the nineteenth century was doubtless the general introduction of the ordinary complex numbers. At the beginning of the century these numbers were still commonly regarded as mathematical curiosities, notwithstanding the beautiful results which Euler and others had already obtained by means of them. Even Gauss did not express himself clearly, in his earliest publications, in regard to the legitimacy of these numbers, although he objected to calling them impossible numbers, as was then still done. On the other hand, at the end of the century these numbers were commonly used not only in pure mathematics but also in various subjects of applied mathematics, and the domain of known mathematics was greatly extended thereby.

Some of the mathematical changes during the nineteenth century are described more fully in the following articles: The history of mathematics in the nineteenth century by James Pierpont, Bulletin of the American Mathematical Society, volume I I (1905), pages I56-159; The century's progress in applied mathematics by $\mathrm{R}$. S. Woodward, ibid., volume 6 (1900), pages 133-ז63; 
Mathematical productivity in the United States by C. J. Keyser, Educational Review, volume 24 (I902), pages 346-35०; L'auvre mathématique du $\mathrm{XIX}^{e}$ siècle by R. d'Adémar, Revue des questions scientifiques, series 2, volume 20 (I90I), pages I77-218; Die Mathematik im neunzehnten Jahrhundert by S. Günther, Zeitschrift für mathematischen und naturwissenschaftlichen Unterricht, volume 32 (1902), pages 227-233.

2. History of mathematics. - In 1640 Descartes wrote as follows: "I am accustomed to distinguish two things in the mathematics, the history and the science. By history I mean what is already discovered, and is committed to books. And by the science, the skill of resolving all questions." * This statement by Descartes may serve to direct attention to the fact that the term history of mathematics is used with very different meanings by different writers. According to Descartes the entire mathematical literature, at least as far as it does not involve duplication, is history of mathematics. Hence the history of mathematics and the history of the mathematical literature would appear to be equivalent. In fact, these two terms are equivalent under a more restrictive definition of history. On the other hand, most writers would probably agree that mathematics is much more extensive than the mathematical literature. It may reasonably be assumed that only an infinitesimal part of mathematics is known.

The term history of mathematics is commonly used with a very narrow and indefinite meaning, implying that

* Philosophical Transactions of the Royal Society of London (Abridged), Vol. 2 (1809), p. 533. 
a comparatively small number of mathematical results are exhibited with the dates of their discovery, the names of their discoverers, and some of the circumstantial factors which may have been influential in leading to their discovery. A treatment of this history therefore usually involves a great extension of the literature in which these results were first established, and it may be regarded as an effort towards popularizing a comparatively small number of known mathematical results by exhibiting their contact with matters of common interest. The results selected for such popularization are usually those which were discovered early in the development of mathematics and hence they are of a very elementary nature. Sometimes a few of the unusually fundamental results of more advanced mathematics have been treated in a similar way.

It is of interest to inquire what distinguishes the history of mathematics from other mathematical writings, in case we assume that there is a difference, as is commonly done. According to the view of Descartes practically all the literature which appears in our better journals of mathematics should be regarded as historical, while many others would probably contend that only a small part of this literature should be classed with history. All might agree on the statement that every mathematical advance is making mathematical history, but some might hold that it would become history only through some undefined process of maturing. Judging from the writings which are now usually classed under mathematical history, it would appear that the chronological element was considered an essential in a direct historical 
paper. In an indirect historical paper, for instance, one discussing how mathematical history should be written, this element would not need to be explicitly present.

Next in importance to the chronological element in the usual historical presentation of a mathematical subject is the human element. Even the mere names of those who enriched mathematical thought by pointing out logical steps leading to views of unusual beauty or to regions of unusual fruitfulness serve to establish a sense of comradeship. This sense is intensified by more or less complete biographical notices. It should, however, be observed that these names and these biographical sketches serve other useful purposes. The names of the great mathematicians may be employed to unify varied mathematical results, while the biographical notices serve to unify mathematical knowledge and knowledge relating to other lines of thought.

Another important element in the history of mathematics is a study of the external factors which tend to retard or to expedite mathematical development. Influences of libraries, of meetings, of journals, of prizes, etc., are now at work among us. Some of these have been inaugurated in recent times while others are quite old but have varied from time to time in their intensity. Various stipends have contributed to the relief from other duties and to the prolonging of student days. While most of these factors are not restricted to mathematics, they have been of great importance in the development of mathematics, and hence their study is naturally of interest to those who enter deeply into the mathematical activities of their day. 
It is evident that the main elements which are present in works on the history of mathematics are usually also present, but in a smaller degree, in mathematical writings which are not classed with history. Like some other commonly used terms in mathematics, the term history of mathematics should probably always remain an undefined term. Usage of this term could probably not be wisely restricted along the lines prescribed by a definition, in view of the fact that the various types of mathematical literature tend more and more towards continuity. In fact, this tendency towards continuity is not confined to the subjects within the domain of mathematics, but it applies fortunately to all scientific knowledge. The histories of these sciences are strong factors tending towards establishing this continuity.

Since thousands of new mathematical results and many new methods are being discovered annually, it is clear that when one man writes a work of one or more volumes, and calls it a history of mathematics, this term must be used in a very restricted sense. In a broad sense there is no such work as a complete history of mathematics extant, and it is to be hoped that such a work will never be written, for its existence would imply mathematical stagnation.

Works on history of mathematics, as well as courses on this subject, commonly begin with the developments in the most ancient times. The question may be raised whether it would not be better to begin with modern developments and with modern conditions. There are too many students of mathematics who could give an account of the Pythagorean school, but who know 
nothing about the modern international mathematical congresses, or the other great mathematical undertakings of the present day. There are those who could give the names of a dozen ancient Greek mathematicians but could not name half that number of eminent living European mathematicians. The present work aims to consider some of the modern developments before considering those of the earlier periods.

3. Developed parts of the history of mathematics. Mathematical history and mathematics have in common the property that they inspire with awe and amazement those who approach them as humble disciples with a view to learning all that is known. On the other hand, they are apt to appear glaringly lacking and feeble to those who approach them from various directions with a view to getting information as regards particular important questions, properly belonging to these domains of knowledge. The former are apt to be surprised by the large amount that is known, while the latter are equally surprised to find that so many things, which appear easier than many other things which are well known, are still classed among the unknowns.

A complete knowledge of mathematical history implies that every symbol, every theorem, and every method employed in our mathematical work suggests the various stages of its development and the tendencies of the ages in which these developments culminated. Just as the stars speak with increasing clearness and effectiveness to the growing astronomer, or as the plants have added interest to the advanced botanist, so does mathematical history convert the narrow mathematical logician into a 
man who sees in his symbols, in his theorems, and in his methods, useful guide posts to the intellectual history of the race. The dignity of the human mind stands forth more clearly when viewed from these heights of permanent triumphs, and the various falterings and shortcomings in advancing towards simplicity and generality in mathematical results, tend to cultivate a true attitude of mind towards the various intellectual weaknesses so noticeable in our surroundings.

While a complete knowledge of mathematical history seems out of question, it is clear that a historical knowledge of a few of the most useful developments may serve not only as a starting point for deeper penetration but also as a source of pleasure and of clearer vision. The desire to know the sources of intellectual progress is not confined to modern times. The noted Peripatetic School founded by Aristotle (384-322 B.c.) aimed to find the origin of every idea, and the members of the Alexandrian School sought to trace the teaching of Greek philosophers to their sources in other lands.

As many of the early developments of mathematics antedate history, there have naturally arisen numerous theories, not founded on historical evidence, to explain particular facts. As instances of this kind we may cite the fanciful arrangements of vertical and horizontal strokes, equal in number to the various digits from I to 9 , as possible sources of our so-called Arabic number symbols. Such a conjectural explanation appeared even in the first edition of Ball's History of Mathematics, I888, page I47, but it was omitted in the later editions of this popular work. A less fanciful conjecture which 
appeared for a long time in the histories of mathematics was that the ancient Babylonians divided the circle into 360 equal parts, called degrees, because they thought that there were exactly 360 days in the year. Fortunately, modern histories of mathematics are less inclined to deal with fanciful conjectures.

A very serious difficulty in mathematical history is presented by the fact that many subjects were developed very slowly and were based upon various related developments. When we are told, for instance, that the differential and integral calculus was founded by Newton and Leibniz during the latter part of the seventeenth century, but that in the third century before Christ the great Greek mathematician Archimedes employed the elements of integral calculus, and that an early Hindu mathematician used elements of differential calculus, there is evidently need of explanations. The statement that a subject was founded at a certain time and by a certain man is simple, and may convey important information, but it generally does not convey the whole truth. Some of the simple historical statements are similar to some simple hypotheses about the laws of nature, - they serve as convenient first approximations to the truth.

In order to emphasize certain facts it may be desirable to think of mathematics as consisting of three divisions. One of these is composed of the published results which may be found in books and periodicals. Another consists of those facts which are known but have not yet found their way into the literature; while the third division is composed of what is still unknown. This 
last division may reasonably be assumed to be of infinite extent and it is of chief interest to the investigator. It is the direct source of accretion of the second division, which, in turn, is the source of the first.

The second of these divisions is perhaps mostly in the minds of those university professors who would rather enrich their lectures than publish their results. It is well known, for instance, that Weierstrass presented many new results in his lectures at Berlin, which he never offered for publication, and it often happens that the interest in investigation becomes so absorbing as to prevent publication. On the other hand, many investigators delay publication in the hope that they may at some time arrive at more perfect new results, and this hope may be the most fruitful source of growth of the second division. Naturally, very few important results remain for a long time in this division.

4. Periods in the history of mathematics. - For the sake of emphasizing certain fundamental facts it is convenient to divide the history of mathematics into a small number of periods. Various divisions have been made which usually differ from those adopted in the common histories. A natural division seems to be as follows: To the first period belong those mathematical developments which preceded the founding of the universities of central and western Europe, about the thirteenth century. The second period extends from the beginning of these universities to the establishment of permanent mathematical periodicals, about the beginning of the nineteenth century. The third period includes all the 
developments made from the founding of these periodicals to the present time.

The most noteworthy feature of the first of these three periods is the magnificent work which was done by the ancient Greeks, especially during the time of the First Alexandrian School, about 300-30 B.c. The names of Euclid, Archimedes, and Apollonius, which are associated with this School, are still well known to all students of mathematics, and they stand out as high peaks in the early development of our subject. Other important features of this first period are the mathematical achievements of the ancient Babylonians and the ancient Egyptians, and their influence on the development of mathematics among the ancient Greeks.

The second period is especially graced by the founding of analytic geometry and the differential and integral calculus. The early part of this period is marked by the recovery of some of the earlier Greek mathematical developments, and the great interest in Greek learning is partly exhibited by the efforts to restore lost Greek works from scattered references and circumstantial evidences. During the latter part of this period the new life which had been brought to mathematics by the discovery of analytic geometry and the differential and integral calculus began to bear rich fruit and led to the founding of modern mathematics by Euler, Lagrange, Gauss, and others.

The third of these periods has been the most fruitful, and was inaugurated by a tangible expression of the spirit of coöperation in the form of periodic literature. During this period, as was noted in $\S \mathrm{I}$, there has been 
a growing tendency towards the democratization of mathematical education; that is, the great usefulness of mathematics in the development of technical subjects was more and more generally recognized, and this has led to a general introduction of mathematics into the educational work, which has given rise to an extensive literature, aiming solely to make known developments more easily accessible. This is the only kind of mathematical literature with which most students become acquainted.

5. Usefulness of the history of mathematics. - The history of elementary mathematics is useful for establishing contact between mathematicians and other scholars. The names for numbers and the various ancient practices as regards the performance of elementary mathematical operations tend to disclose relations between the civilizations of various countries, and hence they also tend to establish scholarly contact between the mathematicians, the philologists, and the historians. The fact that mathematics and philosophy were united by the early Greeks under the single term mathematics, having been first separated into two fields by the Peripatetics, ${ }^{*}$ tends to establish scholarly contact between mathematicians and philosophers.

This restricted use of the term mathematics, introduced by the Peripatetics, was the first step towards confining the use of this term to what is relatively easy, and hence to what can be definitely established. Therefore a number of mathematical results of permanent value could be established by the early thinkers. Mathematics is the only one of the sciences to possess a considerable body of

* Cantor, Vorlesungen über Geschichte der Mathematik (3), Vol. x, 1907, p. 216. 
perfect and inspiring results which were proved two thousand years ago by the same thought processes as are used to-day. The history of mathematics is therefore also useful for directing attention to the permanent value of scientific achievements and to the great intellectual heritage which these achievements present to the world.

The history of the fundamental interplay between mathematical concepts and those of physics and astronomy tends to create a common ground for the devotees of these sciences. The gradual entrance of mathematical concepts and mathematical formulas into the theories of various other sciences is a matter of common interest, and hence a knowledge of this movement is very desirable on the part of those who seek broad views about intellectual matters.

The history of mathematics is alsu useful to those who seek only a complete mastery of mathematics itself, since it enables the student to go to original sources. "The student of mathematics should trust no middleman, but go with his own head to original sources, to the masters themselves. Second-hand ideas are as full of bacteria as second-hand books and clothing."* The masters who first developed a subject have, in many instances, left traces of much deeper insight than their interpreters transmitted. To go to original sources the student usually needs to know the important steps in the history of the development of his science.

Probably the greatest usefulness of the history of mathematics is due to the fact that it puts more life into

- E. O. Lovett, Bulfetin of the American Mathematical Society, Vol. 4 (1898), p. 552 . 
the study of this science. It changes the concepts of mathematics from the domain of statics to that of dynamics. Moreover, it humanizes mathematics by noting the influence of unusually forceful men in shaping the current of mathematical thought. It politicizes mathematics by showing the influences of particular schools, such as the ancient Pythagorean School, or, in more recent times, English and the continental schools using different notations in the calculus. It clarifies mathematics by directing attention to the fact that the individual student is a miniature world, and the experiences which the world has had with various concepts are portrayed more or less clearly in the development of the individual. The fact that many important concepts entered so slowly into the intellectual life of the world and met with much opposition, is full of meaning to those who are meeting these concepts for the first time, or are trying to teach them to others.

A study of the history of mathematics exhibits also many interesting phases of mathematics which are not generally presented in our regular courses for want of time or because they do not appear to be a necessary part of the mathematical machinery. To illustrate, we may refer to the subject of magic squares; that is, squares formed by the natural numbers $1,2,3, \ldots, n^{2}$, which are such that the sum of the numbers in each row, in each column, and in each diagonal is the same. The following may serve as illustrations :

$\begin{array}{lll}2 & 9 & 4 \\ 7 & 5 & 3 \\ 6 & 1 & 8\end{array}$

$\begin{array}{rrrr}1 & 14 & 15 & 4 \\ 12 & 7 & 6 & 9 \\ 8 & 11 & 10 & 5 \\ 13 & 2 & 3 & 16\end{array}$


The subject of magic squares has always had a peculiar fascination for many people, some of whom were not mathematicians. In our own country we may. refer, by way of illustration, to the work of Benjamin Franklin, which he himself explains in a letter to Peter Collinson in the following words : "I had amused myself in making these kinds of magic squares, and at length had acquired such a knack at it, that I could fill the cells of any magic square of reasonable size with a series of numbers as fast as I could write them, disposed in such a manner that the sums of every row, horizontal, perpendicular, or diagonal, should be equal; but, not being satisfied with these, which I looked on as common and easy things, I had imposed on myself more difficult tasks, and succeeded in making other magic squares with a variety of properties, and much more curious." *

The large number of possible squares when $n$ is large has been a matter of great astonishment to many people. As early as 1640 the great French mathematician Fermat claimed that he possessed a method by which he could determine the number of such distinct squares, and, in a letter to Mersenne, he stated that with the first 64 natural numbers the number of these squares was the enormous number $1,004,144,995,344$, but in a later letter he acknowledged that his method did not really give all such possible squares.

Even at the present day we do not know much about the number of such possible distinct squares. A list of 880 such squares with the first 16 natural numbers was published by B. Frenicle de Bessy in 1693 in Divers

*The Works of Benjamin Franklin, Vol. 6 (1838), p. ror. 
ouvrages de mathématique et de physique. Par Messieurs de l'Academie royale des sciences, and no additional squares of this kind have since been found. On the other hand, no simple proof has been given that no more exist. It is very easy to obtain eight magic squares from any given magic square by subjecting this square successively to the eight movements of its group, consisting of four movements through $180^{\circ}$ around the lines of symmetry, and four rotations in the plane through $0^{\circ}, 90^{\circ}, 180^{\circ}$, and $270^{\circ}$. These eight squares are usually regarded as the same magic square. If this is done only one such square can be formed when $n=3$, but there are 880 when $n=4$, as was noted above.

Even the next case, when there are 25 natural numbers, presents great difficulties. According to Nature, volume 65 (I902), page 448, P. A. MacMahon stated that the number of such possible squares is certainly beyond 60,000 . The actual number may be more than $600,000,{ }^{*}$ which shows that we are dealing here with a problem of great complexity notwithstanding the fact that it relates simply to arrangements of the first twenty-five natural numbers so as to bring about results that can be clearly understood by those having only a slight knowledge of numbers.

Although the number of the possible magic squares even for a comparatively small number of natural numbers is extremely large, yet special cases of these squares have appeared so wonderful that the superstitious of early times attributed to them mysterious properties.

*W. Ahrens, Zeitschrift für mathematischen und naturwissenschafllichen Unterrichl, Vol. 45 (1914), p. 528. 
They were often inscribed on amulets during the middle ages, and hence they serve as an instance of how the development of mathematics was influenced during the earlier ages by number mysticism. In later times, the same marvelous number relations served as an inspiration from a sense of beauty and harmony rather than from a sense of mystery.

A great variety of motives - religious, economic, æsthetic, and philosophic - have contributed to the development of mathematics, and the influences exerted by these various forces constitute an interesting element in the study of the history of our subject.

6. First decade and a half of the twentieth century. The opening of the twentieth century shows a marked contrast when compared with the opening of any previous century as regards mathematical activity and mathematical achievements. While it is very difficult to measure mathematical values and while quantity is one of the least reliable standards of measurement, yet it is interesting to note that as regards the amount of mathematical literature it would be very conservative to state that the first decade and a half of the present century produced at least one fifth as much as all the preceding centuries combined. Hence it appears likely that the twentieth will produce, as the nineteenth century has done, much more new mathematical literature than the total existing mathematical literature at its beginning.

During the decade and a half under consideration, a number of new periodicals were started, some of which have already taken a prominent place in the periodical literature of our times. In our own country, the Trans- 
actions of the American Mathematical Society were commenced at the beginning of this period, and they have enjoyed the support of leading American mathematicians from the start. The high standards and careful editorship of this periodical have been of the greatest value in the development of research activity of a high order in our midst.

Towards the close of the period under consideration an important general scientific journal, devoting considerable space to mathematics, was started in our country; viz., the Proceedings of the National Academy of Sciences. The first number of this periodical appeared in January, 1915 , and the periodical at once received the support of leading investigators in various scientific fields. It has for its object the publication of important short articles and of abstracts of longer articles, thus giving brief but clear accounts of the research results obtained by its members and other American investigators. It should render a very useful service in bringing together important investigations in various fields and thus establishing a closer acquaintance among the various investigators of our country.

In May, I9II, there was started at Madrid, Spain, a new mathematical journal entitled Revista de la Sociedad Matematica Española, which is of especial interest to Americans in view of the fact that the Spanish language is used in large parts of our continent. This periodical is the official organ of the national mathematical society of Spain, which was formally organized about a month before the said periodical was started. It is to be hoped that this society and its periodical will do much 
towards organizing the mathematical work among the people using the Spanish language, especially since they have not taken an active part in the development of mathematics during recent centuries, having remained far behind the Italians in this respect.

Another important mathematical periodical, entitled The Tôhoku Mathematical Journal, was started in $19 \mathrm{rr}$ at Sendai, Japan, under the editorship of T. Hayashi. It invited from the beginning contributions in English, French, German, Italian, and Japanese, but most of its articles in the first few volumes were in English. This is the first journal, devoted mainly to modern advanced mathematics, which has been published in Japan, and its international character should do much to advance the interests of higher mathematics in that country.

In view of the fact that Asia took practically no part in the development of mathematics in modern times up to the beginning of the twentieth century, it is interesting to note another thriving mathematical journal which was started within its borders during the period under consideration. This periodical is entitled The Journal of the Indian Mathematical Society, and it was started at Madras, India, in February, r 909 . The fact that it is the official organ of a society founded in 1907 for the advancement of mathematical study and research in India, makes this journal the more interesting, and increases its opportunities for usefulness. Another Indian mathematical periodical was started in 1909 under the title Bulletin of the Calcutta Mathematical Society. The first three numbers of this journal, which was expected to appear quarterly, were published in April, July, and October of 
I909, but the fourth number bears the date January, I9I3.

The new mathematical periodicals which have been named thus far were started at a considerable distance from the greatest centers of mathematical research activity. It is therefore interesting to note a new periodical which was commenced at one of these centers during the period under consideration; viz., the Sitzungsberichte der Berliner Mathematischen Gesellschaft, which was started in 1902 by a society organized on October $3 \mathrm{I}$, I90I. This periodical has also been published in connection with the older journal entitled Archiv der Mathematik und Physik.

The most noteworthy mathematical publication started during the period under consideration is the Encyclopedie des Sciences Mathematiques, the first part of which appeared in August, r904. A circular which was mailed with this part stated that the entire encyclopedia would be published in about 50 parts, each part containing 160 pages, appearing as near as possible at intervals of three months. If this original plan could have been carried out, the entire work would have contained about 8000 pages and would have been completed in about twelve and a half years. As the publication progressed the plans were enlarged, and, at the end of the first ten years, during which about 5000 pages appeared, the parts which had not yet been published promised to become more extensive than the entire work was expected to be at the beginning of the publication. Further data in regard to this very important publication will be given in $\S \mathrm{I} 3$.

Another very noteworthy undertaking inaugurated 
during the period under consideration is the study of methods and materials of mathematical instruction in various countries, under the general direction of the International Commission on the Teaching of Mathematics, which was created during the fourth International Congress of Mathematicians held at Rome, Italy, in April, 1908. At first it was intended that this commission should confine its work to secondary mathematics, but it soon appeared desirable to include all mathematical instruction in the scope of its investigations. Additional commissioners were appointed in various countries; the American commissioners being W. F. Osgood, D. E. Smith, and J. W. A. Young. Under the direction of sub-committees appointed in various countries a vast amount of material relating to the mathematical instruction in the countries concerned has been published. In our own country this material was published by the United States Bureau of Education in the form of reports, which are of great historic value, especially to those engaged in the teaching of secondary mathematics.

In addition to securing these valuable reports the central committee of the International Commission organized various meetings for the discussion of fundamental questions relating to mathematical instruction. At the meeting held in Paris, France, during April, I9I4, it was reported that the total publications, under the direction of the various committees, aggregated 10,293 pages. As this meeting was held only about six years after the work of the Commission was started, it furnishes evidence of the vigor with which the under- 
taking had been prosecuted in the sixteen different countries which had contributed to these publications. In Germany these publications became so popular as to give rise to the common special word $I M U K$ composed of leading letters in Internationale mathematische Unterrichtskommission. Details in regard to the work of the Commission appeared from time to time in the periodical entitled L'Enseignement Mathématique, which was selected as its official organ.

One of the most noteworthy features of the period under consideration is the great interest in questions relating to the teaching of mathematics, and the great success of the International Commission on the Teaching of Mathematics was doubtless largely due to the fact that the time was ripe for vigorous advances along this line. Reforms of various kinds and of far-reaching significance received a great deal of attention. A number of new journals devoted mainly to methods of teaching were also established. In our own country School Science and Mathematics, and The Mathematics Teacher may serve as illustrations. The former of these was a continuation of School Science, the first number of which appeared in March, Igor ; while the latter began to appear as a quarterly in September, 1908.

Perhaps no other undertaking started during the period under consideration exhibits the spirit of this period so forcibly as the commencement of the publication of the collected works of the great Swiss mathematician Leonard Euler. Various efforts had been made earlier to publish his very extensive works, but these efforts had failed on account of the large amount of money required for the 
publication. In September, I909, the Swiss Society of Naturalists, having secured through national and international subscriptions, and through donations, about one hundred thousand dollars for this purpose, announced that it would undertake this great publication. Two years later the first volume was published, and several other volumes followed in rapid succession, but it soon appeared that the entire publication would cost much more than the original estimate called for. This led to the formation of a unique international mathematical society whose main purpose was to aid the publication of these collected works, which were expected to aggregate more than 45 large volumes.

The developments which have been noted are of a general nature and constitute merely evidences of the fact that there was real mathematical growth during the period under consideration. The matters of main interest relate to the new discoveries and the new developments in mathematics itself. These are, however, too numerous to be considered here. In fact, the Jahrbuch über die Fortschritte der Mathematik fills annually a volume of more than a thousand pages in giving titles and brief reviews of the new literature. For the period under consideration this would involve more than fifteen thousand pages, and hence it is clear that in such a brief sketch as the one here presented it is impossible to enter deeply into a discussion of the nature and the bearing of the various direct mathematical advances.

The preceding observation may serve to show that the beginning of the twentieth century found Mathematics alive and growing as never before, notwithstanding her 
age and her repugnance to amputations. While some other sciences grow new branches to replace those which had to be removed, real mathematical growth is of a permanent nature, and hence its continued vigor is full of meaning and of promise. Most of the developments of the period under consideration will be treated incidentally in what follows, but the few which have been mentioned may illustrate the fact that the most interesting part of mathematical history is the history of to-day, and the surest way to understand the mathematical developments of the past is to consider them in relation to the most recent developments.

7. American mathematics. - In 1898 a well-known French mathematician wrote as follows in reference to the mathematical situation in America: "Mathematics in all its forms and in all its parts is taught in numerous universities, treated in a multitude of publications, and cultivated by scholars who are in no respect inferior to their fellow mathematicians of Europe. It is no longer an object of import from the old world, but it has become an essential article of national production, and this production increases each day both in importance and in quantity." * It is probable that most American mathematicians would say that this quotation, taken by itself, is apt to create a more favorable impression in regard to American mathematics than the facts justified at the time it was written. It is given here mainly to point out that by the end of the nineteenth century America had assumed a position of respect among the mathematical countries of the world, and there are good reasons

* Laisant, La Mathematique, Philosophie-enseignement, I898, p. 143. 
for believing that this respect has increased rapidly during the first decade and a half of the twentieth century.

Up to the middle of the nineteenth century there was very little advanced work in mathematics in America. During the periods in which mathematics in Europe was enriched by the works of Euler, Cauchy, Gauss, Lagrange, Galois, and Abel, there was no one in America whose work contributed materially towards aiding the advancement of pure mathematics. One of the earliest important contributions in this direction was the memoir on "Linear associative algebra," read in 1870 by Benjamin Peirce before the National Academy of Sciences in Washington, which had been established seven years earlier. This memoir, of which only a small number of copies in lithograph were taken in the author's lifetime, was published later in volume 4 of the American Journal of Mathematics.

Beginning with the middle of the nineteenth century the interest in advanced mathematics in our country began to increase fairly rapidly. During the fifties and the early sixties of this century a small number of young men studied higher mathematics at Harvard under the guidance of Benjamin Peirce, and at Yale the Ph.D. degree was established as early as 1860 . In about 1880 there began a steady stream of American mathematical students to Europe, especially to Germany, and to the young men who returned from Europe, with the ideals of research which they found there and with the equipment for advanced work which they had acquired while abroad, we probably owe more than to any other one 
cause the rapid mathematical development which our country began to experience at that time.

About the time that many Americans began to go to Europe to study mathematics, Johns Hopkins University opened its doors ( 1876$)$ and began at once to wield at home a powerful influence in starting young men in mathematical research. This influence was largely due to the enthusiasm and ability of J. J. Sylvester, who was called from England to start the mathematical work at this institution, and who succeeded in communicating his enthusiasm to some of his students. A very important element in the influence of Johns Hopkins University was the establishment in 1878 of the American Journal of Mathematics, under the editorship of J. J. Sylvester; but a still more important element in this influence was the fact that undergraduate instruction was regarded as a subordinate function of this university from the start. This fact greatly strengthened the hands of those members of the faculties of the older universities who had been working to establish graduate instruction in their own institutions.

Two other institutions founded towards the end of the nineteenth century had a large influence in furthering the interests of advanced mathematics, even if these institutions were established after the idea of graduate work had taken a strong hold on some of the older universities. Clark University was established at Worcester, Massachusetts, in 1889 , and was devoted exclusively to graduate work in a small number of departments, including mathematics. Chicago University opened its doors three years later and exercised from the beginning a 
remarkable influence on the development of mathematics in the Middle West. While the direct influence of these institutions has been very considerable, their indirect influence has been still more important. For example, the magnificent equipment of Chicago University has been a strong factor in the material development of the neighboring state universities; the equipment along the line of library facilities being especially significant.

An important factor in the development of graduate work in our country has been the financial aid given to graduate students in the form of scholarships and fellowships.* Many students have been enabled by scholarships and fellowships to get started towards careers of much greater usefulness than would otherwise have seemed possible for them, but others have been attracted by these inducements to institutions or to departments which could offer very few other advantages to their graduate students. It has too often happened that weak institutions used money for scholarships and fellowships which was sorely needed to increase their facilities for graduate work of a high order. The best interests of graduate work seem to require that institutions should attract graduate students by the superiority of their faculties and their other equipment rather than by fellowships and scholarships, and this will doubtless be more and more the case as the true conditions become better known.

The student who is just entering upon graduate work should keep in mind the rapid changes which have taken place in recent years as regards the relative advantages

* Cf. G. Stanley Hall, Forum, Vol. I7 (I894), p. 443. 
at the various institutions. The fact that a given institution was in the lead as regards mathematical advantages ten or twenty years ago is no guarantee that these conditions prevail to-day. By way of illustration, we may cite the fact that in November, r9ro, Professor Cattell published in Science, page 685 , a statistical study in which he gave some data in regard to the ten strongest American departments at that time, in various sciences, including mathematics. It is interesting to note that several institutions in this list had no mathematical standing ten years earlier, and that several of those which stood relatively high ten years earlier were not included in the list.

While scholarships and fellowships were a very strong factor in the inauguration of research work among American students, the American Mathematical Society has probably been the strongest single factor in organizing and developing research activity, especially among the instructors in the stronger institutions. This Society grew out of the New York Mathematical Society, which was organized in 1888 and was at first not much more than a mathematical club, meeting at Columbia University. In I89r it began the publication of a periodical called the Bulletin of the New York Mathematical Society, "a historical and critical review of mathematical science." Three years later the name of this periodical was changed to Bulletin of the American Mathematical Society, which more fully described its character. Although the main object of this periodical was the publication of critical reviews and reports, yet it included, even in its earlier volumes, a number of research articles; and 
the meetings of the society were from the beginning very largely devoted to the consideration of new research results obtained by its members.

In view of the desire of the mathematicians in various parts of the country to be able to attend meetings for the discussion of mathematical questions, and the inconvenience and expense involved in traveling great distances to attend such meetings, the American Mathematical Society authorized the organization of sections, which have selected their own places of meeting and arranged their own programs. The first section to be organized in accord with this authorization was the Chicago Section, which held its organization meeting in Chicago on April 24, I897, under the chairmanship of E. H. Moore. About five years later a second section was organized under the name San Francisco Section, the organization meeting having been held in San Francisco on May 3, I902, under the chairmanship of Irving Stringham. A third section, called the Southwestern Section, was authorized by the Council of the Society on December 28, I906, and held its first regular meeting at St. Louis, Mo., on November 30,1907 , under the chairmanship of E. R. Hedrick.

By means of these sectional meetings, which have been somewhat migratory, and the migratory summer meetings, the American Mathematical Society has made it possible for most of its members to attend meetings, at least occasionally, without traveling far. There are, however, still large sections of the country which are rarely represented at these meetings. This is especially true of the South, where the number of investigators in advanced mathematics has thus far been very: small. 
The usefulness of the American Mathematical Society has not been restricted to stimulating mathematical activity by means of these meetings and the publication of its Bulletin. As noted in the preceding section it began in 1900 the publication of a regular research journal, and it has also published several separate books. These direct services are, however, overshadowed by indirect ones; prominent among which are the setting of high standards and the encouragement of coöperation among the various investigators.

As mathematical research has been inaugurated in America very largely by those who obtained their start in investigation while studying abroad, it is natural that American mathematics is very closely connected with the mathematics of foreign countries. In fact, a considerable number of American investigators have published some of their best work abroad, and sometimes even in foreign languages. Hence it might be somewhat difficult to define the term American Mathematics. In fact, mathematics is unusually cosmopolitan and some mathematical societies are very cosmopolitan. The great mathematical advances soon become world movements, and, while the study of the relative contributions by various nations is of interest, the main interest should always center in the movements themselves. 


\section{CHAPTER II}

\section{Mathematical Literature in General}

8. Types of recent mathematical literature. - The recent mathematical literature consists mainly of printed matter in the forms of books, pamphlets, and periodicals. Each of the separate books and pamphlets is commonly due to an individual writer, while the separate journals generally result from coöperation. Most of the books are written with a view to presenting the main elements of a more or less extensive field in such a manner that the various steps can be followed by a considerable number of readers. In many cases, the sole object of the authors is to present known results in an unusually clear form. This is especially true as regards the textbooks relating to subjects pursued by a very large number of students.

The literature of this type is very extensive but it is of interest mainly from the standpoint of the history of methods. It should be observed that the paths which lead from one mathematical theorem to another can usually be varied without limit. That is, mathematics is not a linear sequence of facts, such that just one fact must be understood before the following one can be comprehended. If this were the case, methods in mathematics would relate only to the lengths of the various possible steps in this linear sequence. 
Even if mathematics consisted of such a linear sequence of theorems, there would be room for an unlimited variation as regards methods, in view of the fact that the lengths of the steps by which the results are established could be varied without limit. If we observe, however, that there appears to be no upper limit to the number of dimensions in mathematics, it is clear that the literature relating to methods is potentially infinitely more extensive than that which relates to the first proofs of mathematical facts or theorems. In the present Introduction we shall devote most attention to the mathematical history relating to the first establishment of important results, and hence we shall aim to consider only a very small part of the literature relating to our subject. We shall, however, not exclude entirely the literature relating to methods and to teaching.

Since the literature in which advances in knowledge have been made will mainly concern us, the periodic literature will be of most interest in the study of the mathematical development of recent times. The extent of this literature is very great. According to Felix Müller (Jahresbericht der Deutschen MathematikerVereinigung, volume 12 , 1903 , page 439 ) there were only I7 periodicals containing mathematical articles, up to I700, the first having appeared in 1665 . During the eighteenth century 210 such periodicals appeared, while the number of such new journals during the nineteenth century was 950 , including those which were continued under new titles.

Most of these journals contained comparatively little 
relating to pure mathematics. The oldest among the current journals devoted mainly or entirely to advanced mathematics is Journal de l'Ecole Polytechnique, which was started in I794, but a considerable number of more elementary mathematical journals were started earlier in the eighteenth century. Some of these contained mathematical problems which aimed to entertain the reader rather than to advance mathematical knowledge. In England, the early numbers of The Ladies' Diary (I 704-1840) contain a number of problems which were often stated in rhyme, especially in the initial numbers. The answers are also frequently given in this form. By way of illustration we give below questions I3 (I 7IO) and I7 (I7II), and their answers.

\section{QUESTION 13}

"A farmer with a plowman doth agree, That thirty days his servant he should be. Each day he wrought the farmer is to pay Him sixteen-pence; but when he was away Five groats he is for each day to abate. The time expir'd; they their accounts do state. Whereby the master nothing is to give, Nor has the servant any to receive. How many days he wrought I do demand, And how many he play'd I'd understand."

\section{ANSWER}

"That lazy drone who squander'd away Thirteen days and one third in sleep and play, In thirty days (for all he nothing got)

Deserv'd to have his bones broke, for an idle sot." 


\section{QUESTION I7}

"I happen'd one evening with a tinker to sit, Whose tongue ran a great deal too fast for his wit. He talk'd of his art with abundance of mettle I ask'd him to make me a flat bottom kettle, That the top and the bottom diameters be In just such proportion as five is to three; Twelve inches the depth I would have, and no more, And to hold in ale-gallons seven less than a score, He promis'd to do it, and to work he strait went ; But when he had done it, he found it too scant. He alter'd it then, and too big he had made it, And when it held right the diameters fail'd it : So that making it so often too big or too little, The tinker at last had quite spoiled the kettle: Yet he vows he will bring his said purpose to pass, Or he'll utterly spoil every ounce of his brass. To prevent him from ruin, I pray help him out, The diameters' length else he will never find out."

ANSWered By Mrs. Barbary StDway

"Well, bonny brave tinker, to save thee from ruin, The kind British lasses are active and doing; Because that thou art a brave fellow of mettle, Take here the diameters both of thy kettle; One's twenty-four inches four-tenths, very near, T'other fourteen, and sixty-four cents doth appear."

In later numbers of this journal many more important mathematical questions appeared, especially questions relating to geometry. The Gentleman's Diary or the Mathematical Repository ( $\mathrm{I} 74 \mathrm{I}-\mathrm{I} 840$ ) may be regarded as a scientific mathematical journal and it contains a number of important problems and solutions 
relating to elementary mathematics. These journals did much to keep alive in England a general interest in mathematics, and they contain a number of theorems relating to elementary mathematics which were rediscovered in later times.

Several of the current mathematical periodicals of high grade were started during the first half of the nineteenth century. The two most important ones are: the German journal entitled Journal für die reine und angewandte Mathematik, which began publication in 1826 under the editorship of A. L. Crelle, and the French journal entitled Journal de mathématiques pures et appliquées, the first volume of which appeared in 1836 under the editorship of J. Liouville. These two journals are frequently referred to under the names of their founders, Crelle and Liouville respectively, and they have been very potent factors in the development of mathematics in their respective countries, which were the two foremost countries along mathematical lines during the nineteenth century. As evidence of the coöperation involved in such publications we note that the first hundred volumes of the former of these two journals contain more than two thousand articles by 427 different authors.

In England the Cambridge Mathematical Journal was founded in 1839 , and it was continued from 1846 to 1854 as the Cambridge and Dublin Mathematical Journal. In I855 this periodical was followed by the well-known Quarterly Journal of Pure and Applied Mathematics under the editorship of J. J. Sylvester and others. During the latter half of the nineteenth century this journal became almost as influential in England as Crelle and 
Liouville were in their respective countries. The need of periodicals of various grades made itself felt very early. The purely research journals did not satisfy the needs of those whose main energies were devoted to teaching and to finding the simplest methods of presentation. Even during the first half of the nineteenth century this need found expression in the starting of two permanent periodicals devoted to the interests of teachers of mathematics.

The first of these was founded in I84I, under the title Archiv der Mathematik und Physik, by J. A. Grunert, and the second was founded a year later under the title Nouvelles Annales de Mathématiques. Both of these periodicals were modeled after an earlier French periodical founded by J. D. Gergonne in I8ro under the title Annales de Mathématiques pures et appliquées, which was discontinued in r83r. These periodicals have been strong factors in leading to higher attainments on the part of the mathematics teachers of France and Germany. They include also many articles which are of value to the investigators, especially along the line of elementary mathematics.

The beginner is frequently annoyed by the fact that writers do not always refer to a given journal by means of the same name. Some authors are inclined to refer to a journal by the name of the editor. As has been noted above it is quite common to designate the Journal für die reine und angewandte Mathematik by Crelle or by Crelle's Journal. Some authors have also referred to this periodical as Borchardt's Journal, since C. W. Borchardt succeeded A. L. Crelle as editor, begin- 
ning with volume 53. In view of the fact that the number of the mathematical journals is becoming so large, it appears very fortunate that the number of those writers who refer to journals under the name of the present editor seems to be decreasing. In a few cases the names of the original editors persist, but this is not a very serious matter, as there is usually only one original editor, while the number of later editors of the same journal may increase without limit.

A mathematical journal extending through a long period of years constitutes a kind of mathematical section of this period, since its various volumes are characterized by the developments which were in progress at the time these volumes appeared. For instance, the hundred and forty volumes of Crelle's Journal exhibit numerous more or less distinct strata of mathematical progress in Germany. It is an interesting thought that some of these journals will probably continue, through all future ages, to contribute to the development of our subject and to record the most important achievements, which, in turn, will serve as new starting points for those which follow. The permanent periodicals founded in the second half of the nineteenth century are too numerous to note here. Some of the most important of them will, however, be noted incidentally in the following section.

Next to journals, the mathematical monographs and pamphlets are perhaps the most common channels for new developments to move from place to place. In some countries this form of publication is commonly employed for doctors' dissertations. It is also largely used to develop the subject matter of the newer fields, 
where brief introductions are desired by many who do not have the time to enter deeply into a field. Examples of this kind of literature are the "Cambridge Tracts in Mathematics and Mathematical Physics," which were begun in 1905, and the "Collection de monographies sur la théorie des fonctions" published under the direction of E. Borel. In America the "Mathematical Monographs," edited by Merriman and Woodward, represent the better type of pamphlet literature.

There is no sharp line between pamphlets and books, although the latter term is commonly used for the more extensive presentations. Books dealing with modern mathematical subjects frequently contain much that is new and are of great service in extending the boundaries of mathematical knowledge. By usually exhibiting broader fields than are represented by the pamphlets or the journal articles, they tend to direct attention to the more important phases of the subjects under consideration. Such books are useful not only because they advance our knowledge, but also because they aid in directing attention to the difference in importance as regards various developments. One of the most important functions of books is to bring scattered results together in a connected form and to provide easy avenues of approach to the results which are most far-reaching and vital.

9. Mathematical societies. - The second half of the nineteenth century witnessed the inauguration of another strong factor in the mathematical literature, viz., the starting of large mathematical societies having regular periodicals as their official organs. In some cases 
these periodicals have become the leading mathematical journals in the country concerned, and these societies play a more and more important rôle in the development of the mathematical literature. The earliest of these influential societies was the London Mathematical Society, organized in 1865 under the presidency of A. De Morgan.* It began at once to publish a journal under the name Proceedings of the London Mathematical Society, which contains brief accounts of the meetings but is mainly devoted to the publication of articles presented at the meetings of the society. Although this society had a local name it soon became really the national mathematical society of England, and it elected - also a number of foreign members.

Seven years after the London Mathematical Society was founded a similar organization was established at Paris under the name La Société Mathématique de France, holding its first meeting on November 6, 1872. Its

* Mathematical societies without regular periodicals were organized much earlier. The oldest among these which survived is the Mathematische Gesellschaft zu Hamburg, organized in 1690 . In volume 64 of Nature, P. A. MacMahon gave an interesting sketch of the history of a noted early English mathematical society known as the Mathematical Society of Spilalfields which was founded in I 7 I 7 and was taken over by the Royal Astronomical Society in 1845 . At first it was little more than a workingmen's club at which questions of mathematics and natural philosophy were discussed every Saturday evening. According to the constitution of the Society it was the duty of every member who was asked a mathematical or philosophical question by another member to answer the question to the best of his ability. It is interesting to note that each member present at a meeting was entitled to a pint of beer at the common expense. The Society accumulated a valuable library and its rooms became headquarters for lectures on various scientific subjects. In about 1800 it included a number of the leading mathematicians of the day among its members, but it should be observed that England did not have any very prominent mathematicians at that time. 
official organ is entitled Bulletin de la Sociêté Mathématique de France and this Bulletin is sent free to all of the members of the society. In scope this Bulletin is similar to the Proceedings of the London Mathematical Society, which are also sent free to all the members of the society, the annual dues being used mainly to defray the expenses of the official publication. In fact, one of the chief advantages of most of the modern mathematical societies is due to the increase of mathematical intelligence secured through the circulation of their official organs among all their members. In this respect the London society has served as a prototype for many of the later mathematical organizations.

One of the most noteworthy mathematical societies was organized in Italy in I884 under the name Circolo Matematico di Palermo. This organization was unusually successful in securing a large number of foreign members and hence it soon became more decidedly an international society than any of the other mathematical societies. It also surpassed the others in membership, having, in May, I914, 932 members, including I4I from the United States and the same number from Germany. In July, I885, this society began the publication of a periodical under the title Rendiconti del Circolo Matematico di Palermo, but the first volume was not completed until September, 1887 . This periodical soon became one of the leading mathematical journals of the world. In fact, during the celebration of the thirtieth anniversary of the founding of this society, held at the University of Palermo in April, r914, Professor E. Landau of Göttingen, Germany, said in a public address that the Rendiconti 
were then the best mathematical journal of the world.* This success was largely due to the great liberality and devotion of G. B. Guccia, who was the founder and director of this publication for thirty years, and who secured for it contributions from many of the leading mathematicians of various countries.

About the same time that the Circolo Matematico di Palermo was organized in Italy a similar society was formed at Edinburgh, Scotland, under the name Edinburgh Mathematical Society. While this society has not been quite as successful as those which have been noted above, it has maintained a good periodical, known as Proceedings of the Edinburgh Mathematical Society and devoted mainly to questions in elementary mathematics. As noted in $\S 7$ the American Mathematical Society was organized in 1888 under a different name, and it soon became one of the leading mathematical societies of the world. The members received the Bulletin free of charge and were thus supplied with an unusually large amount of general mathematical information, since this periodical was more largely devoted to reviews and reports than the official publications of the other mathematical societies. Through the publication of the Transactions in 1900 the American Mathematical Society became the most prolific mathematical society of the world as regards the extent of its publications. Its great influence on the development of mathematics in our country was noted in the section cited above.

It is a somewhat singular fact that Germany was the

* Supplemento ai Rendiconti del Circolo Matematico di Palermo, Vol. 9 (19I4), p. 12 . 
last one among the leading mathematical countries to organize a national mathematical society, having organnized such a society in 1890 under the name Deutsche Mathematiker-Vereinigung. It thus happened that each of the five leading mathematical countries of the world France, Germany, Italy, England, and the United States - organized national mathematical societies during the quarter of a century extending from 1865 to 1890 . While these organizations were very powerful in stimulating mathematical activity, they themselves were expressions of the wonderful mathematical awakening during the quarter of a century which gave them birth. We are still too close to the dates of these births to be able to measure fully the influences going out from these organizations, but that they have been great and will be greater in the future no one can doubt.

The official publication of the Deutsche MathematikerVereinigung is called Jahresbericht der deutschen Mathematiker-Vereinigung, the first volume of which bears the date 1892 . Characteristic features of the early volumes of this publication were the extensive reports on modern developments in various fields of mathematics, beginning with the report by W. F. Meyer on the theory of invariants. The most extensive of these reports covers I800 pages and was prepared by $\mathrm{H}$. Burkhardt under the general title, "developments in oscillating functions and integration of the differential equations of mathematical physics." These reports may be regarded as forerunners of the large mathematical encyclopedia whose inauguration was greatly promoted by the Deutsche Mathematiker-Vereinigung. 
In one respect this society differs widely from the other leading mathematical societies mentioned above; viz., its members do not receive the official periodical free of charge and hence the annual membership fee is unusually small. While in the other societies the annual dues vary from about two dollars to about five dollars, those of Deutsche Mathematiker-Vereinigung are only about fifty cents. Notwithstanding this fact, the Jahresbericht has been able to maintain very high standards, and, among the society publications, it stands next to the Bulletin of the American Mathematical Society in regard to the amount of space devoted to reviews, reports, and matters of general interest. With respect to number of members the Deutsche MathematikerVereinigung stood next to the Circolo Matematico di Palermo in I9I5, among the leading mathematical societies, having then 780 members. The American Mathematical Society held then the third place as regards membership, having 709 members.

Those who are looking forward to mathematical careers are naturally interested in the advantages which appertain to membership in a leading mathematical society. They may have observed that some mathematicians belong to several such societies, and they are naturally led to inquire whether the young mathematician ought to strive to enter as many of the leading mathematical societies as possible. In particular, they might be interested in the motives which actuated the given I4I Americans and the same number of Germans, as well as numerous other foreigners, to join the Circolo Matematico di Palermo. 
In answer to questions raised by these interests it may be said that doubtless various motives actuated those who either sought or accepted memberships in the leading mathematical societies. Such memberships serve as evidences of some distinction. Even if many of the mathematical societies have been very liberal in the election of their members, yet it is true that a large majority of those living in any particular community were usually regarded as ineligible. It is, however, also true that mathematical societies have generally been glad to increase their memberships and have been willing to elect as members persons who held certain positions or who fulfilled certain formal conditions, without entering into a direct consideration of their abilities.

Probably most of those who accepted memberships in such societies did so because of the direct advantages in the form of publications or meetings which such memberships afford. For instance, although the Deutsche Mathematiker-Vereinigung does not send its Jahresbericht free of charge to its members, these members can secure this as well as other publications at a reduced price. The publications of the Circolo Matematico di Palermo have been so valuable and extensive that many members have regarded these as being worth much more to them than the small annual dues of this society. The active mathematicians have thus been often led to join mathematical societies by a sense of the fact that union is economy rather than by the feeling that union is strength.

It is likely that many have joined societies from a sense of loyalty to their own subject and its development. 
This is especially true as regards the societies of one's own country. The fact that the mathematical societies have been such strong factors in the recent past naturally awakens in many the feeling that they would like to have a part in the good work which these societies are doing. Moreover, the meetings afford opportunities of acquaintance and inspiration which are prized very highly by most of those who are in position to attend them frequently. It is, however, also true that these society activities demand time and energy, and that there is always danger of excessive socialization in scientific movements.

The advantages of membership in a foreign society are generally less than those connected with membership in a native organization, but in many instances the former are also very considerable. The fact that so many of those who secure such memberships maintain them for a long period of years is evidence of their intrinsic value to a number of mathematicians. The entire question is so much a matter of taste and mathematical enthusiasm that it is somewhat difficult to give advice along this line to those just entering on their mathematical careers, but it is probably true that more young people err by being too conservative in this direction than by joining too many mathematical organizations.

The great success of the mathematical societies organized during the latter half of the nineteenth century has probably been largely due to the fact that these societies led many to recognize the great value of mathematical periodicals. In a certain sense these periodicals may be regarded as the blood vessels of a living mathemat- 
ical body, conveying promptly important discoveries and important new points of view from one part of this body to another. The need of these journals becomes more and more pronounced as the number of investigators and the number of new results increase. Moreover, these journals are very economical for the reader since they save the time and the expense of traveling long distances to become acquainted with what others are doing.

Sumarary of Leading Nattonal Mathemattcal Socteties

\begin{tabular}{|c|c|c|c|}
\hline Country & & Name of the Society & WHEN FOUNDED \\
\hline England . & & London Mathematical Society & 1865 \\
\hline France . & & Société Mathématique de France & 1872 \\
\hline Scotland & & Edinburgh Mathematical Society & I883 \\
\hline Italy . . & 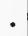 & Circolo Matematico di Palermo & I884 \\
\hline America . & - & American Mathematical Society & I888-94 \\
\hline Germany & & Deutsche Mathematiker-Vereinigung & I890 \\
\hline India . & . & Indian Mathematical Society & I907 \\
\hline Spain . • & & Sociedad Matemática Española & I9II \\
\hline
\end{tabular}

10. International Mathematical Congresses. - Towards the end of the nineteenth century there was inaugurated a type of literature of unusual interest in the form of reports of international mathematical congresses. It is commonly said that the first of these congresses was the one held at Zürich, Switzerland, in August, I897, but there were at least two earlier international meetings of mathematicians which were of a somewhat similar nature. The first of these was the Congrés international de bibliographie des sciences mathé- 
matiques, held in Paris in July, 1889, and the second was the International Mathematical Congress, held in connection with the World's Columbian Exposition at Chicago, in August, I893. The papers read at the latter meeting were published in 1896 by the American Mathematical Society in a volume entitled, Mathematical Papers read at the International Mathematical Congress.

Notwithstanding these facts, the congress held in Zürich in 1897 has, by general agreement, been called the first international mathematical congress, and its proceedings were published in 1898 in a volume entitled, Verhandlungen des ersten Internationalen MathematikerKongresses. In the Rules for this meeting the objects of the congress were formulated as follows: $(a)$ to promote personal relations among the mathematicians of different countries, (b) to give a survey of the present state of various mathematical branches and to offer an occasion to treat certain questions of special importance, (c) to deliberate and to decide on the problems and the organization of future congresses, and $(d)$ to discuss questions of bibliography, terminology, etc., in regard to which an international understanding seems necessary.

This first international mathematical congress was entirely successful. Sixteen different countries were represented and 242 people took part in its proceedings. It was decided to hold future international congresses in various countries at intervals of from 3 to 5 years, the second one to be held at Paris in 1900 . A large number of scientific papers representing advances in various fields were presented at the general and the sectional meetings of this congress. These appeared in the vol- 
ume noted above and they constitute the most valuable feature of the congress.

From the standpoint of the student of the history of mathematics this congress offers another element of considerable interest, in view of the fact that it has been generally agreed to call it the first international congress. It is doubtless true that it was more intensely international than those which preceded it; yet, without any change in the circumstances, it is easily conceivable that the contemporaneous mathematicians might have decided to call it the second or the third international mathematical congress instead of the first. It thus exhibits very clearly a kind of fortuitous element which often enters into the consideration of questions of history and which affects many historical statements. Hence the naming of this congress furnishes an illustration of the advantages secured by beginning a study of the history of mathematics with recent developments. where the original sources are easily accessible.

According to the resolution noted above, the second international mathematical congress was held in Paris, France, after an interval of about three years, but the three congresses which immediately succeeded this one were held at intervals of four years, as follows. Heidelberg, Germany, in 1904; Rome, Italy, in 1908; and Cambridge, England, in I912. The growing interest in these congresses is partly exhibited by the increase in attendance. As noted above, the first congress showed an attendance of 242 , representing I 6 different countries, while the fifth was attended by 708 , including the 574 members of the Congress, representing 28 different coun- 
tries. In view of the fact that mathematics is the same over the entire world it might at first appear that international mathematical congresses could offer relatively few advantages. Geologists, botanists, zoölogists, etc., can bring useful local scientific information to their national and international meetings, while the mathematicians live above local conditions.

On the other hand, the fact that the study of mathematics is unaffected by the natural local conditions makes it more decidedly a cosmopolitan science and calls for hearty international coöperation. From this point of view mathematics is especially well suited as a subject for international conferences and for international movements. It was noted in $\S 6$ that the great movement under the direction of the International Commission on the Teaching of Mathematics was inaugurated at the fourth international congress, held at Rome in April, I908. At first only three members were appointed; viz., F. Klein of Germany, G. Greenhill of England, and H. Fehr of Switzerland. These three men were appointed on April Ir, I908, and they later organized as a Central Committee and appointed a large number of additional commissioners in various countries, who, in turn, appointed various committees and subcommittees.

At the Cambridge congress the Central Committee was enlarged by the addition of D. E. Smith of the United States, and during the following year this committee was further enlarged by the addition of three new members, as follows: G. Castelnuovo of Italy, E. Czuber of Austria, and J. Hadamard of France. The extensive and important work resulting from this enterprise is well 
known and was outlined in $\S 6$. It is the most conspicuous example of the usefulness of the international mathematical congresses, even if it exhibits only one phase of this usefulness. "The objects as outlined at the Zürich congress are doubtless still more important even if the results along these lines are less tangible.

It is a rather singular fact that when mathematical periodicals became more numerous and seemed to remove the greatest need of mathematical meetings, since they established improved means of communication between the various mathematical investigators, these meetings became more numerous and more popular. This seems to indicate that the periodicals have been of the greatest value in arousing interest, for when men travel hundreds and even thousands of miles to attend mathematical meetings there must be considerable interest. This is especially true if one remembers that the most important scientific results announced at the meetings will soon become accessible in the publications.

While many of the leading mathematicians have taken part in the national and the international meetings, there are others of equal prominence who have seldom attended such meetings. It should always be remembered that there is no royal road to deep mathematical insight, and that those who would accomplish important work should realize the great importance of utilizing their time to the utmost. A Gauss, who never slept away from his observatory after he came to Göttingen, except once when he attended a scientific congress in Berlin, ${ }^{*}$ is a constant reminder of the importance of serious and

*W. W. R. Ball, A History of Mathematics, rgr 2, p. 499. 
continuous work. Meetings, however, frequently enable one to combine recreation and work in a most profitable way.

Summary of International Mathematical Congresses

\begin{tabular}{|c|c|c|c|c|c|}
\hline No. & HELD AT & & Date & MeYBers & $\begin{array}{l}\text { No. or CoUN- } \\
\text { TRTES REPRE- } \\
\text { SENTED }\end{array}$ \\
\hline $\mathbf{I}$ & Zürich, Switzerland & August & $9-11,1897$ & 242 & I6 \\
\hline 2 & Paris, France & August & $6-12,1900$ & 273 & 29 \\
\hline 3 & Heidelberg, Germany & August & $8-13,1904$ & 336 & I9 \\
\hline 4 & Rome, Italy & April & $6-11,1908$ & 535 & 22 \\
\hline 5 & Cambridge, England & August & $22-28$, I912 & 574 & 28 \\
\hline
\end{tabular}

11. Periodicals on periodicals and books on books. The rapid and steady growth of the mathematical literature (periodical and non-periodical) has made it desirable to have special aids to enable investigators and scholars to make rapid surveys not only of the main results but also of the main advances along various lines. The latter need has been partially met by the publication of periodicals on periodicals, - a kind of periodical squared literature. On the other hand, the great accumulation of results which have been embodied in books during long periods of years has made it increasingly desirable to have books on books, bringing together the main results of earlier times in the light of the more comprehensive modern theories. These periodicals on periodicals and books on books should not be regarded as a kind of second-hand mathematical literature. On the contrary, this kind of literature often makes the highest demands for scholarship and ability 
on the part of its authors, and it renders a more and more needed service to the progress of our subject.

Among the periodicals on periodicals the German periodical entitled Jahrbuch über die Fortschritte der Mathematik is probably the most noteworthy. As the title implies this is a yearbook, and it aims to give a brief account of the advances made from year to year in various fields of pure and applied mathematics. The first volume appeared in $187 \mathrm{I}$ and is devoted to a review of the literature (articles, pamphlets, and books) which appeared during the year I868. It thus appears that these reviews were published from two to three years after the publication of the original works. To diminish this gap the second volume, which was published about a year after the first, included reviews of work appearing during the two years 1869 and 1870 .

At the present time this work reviews the main books and pamphlets, together with the articles appearing in about 200 different periodicals, noting in all about 2000 publications annually. It is evident that such an extensive survey calls for coöperation on a large scale, since these reviews would be of little value unless they were written by specialists in the various subjects under review. As a matter of fact, these reviews are of very unequal merit, as might be expected since they are prepared by so many different authors with different views. The reviews in the first volume were written by about thirty different men, mostly Germans, but the number of reviewers has since been considerably increased. It is a great credit to the perseverance and devotion of those who have guided the periodical, that it has maintained 
such high standards and has been able to render such an important service to all interested in the new advances of our subject. Comparatively few able men are willing to perform such altruistic and difficult service for a long period of time.

An important indirect advantage of such a periodical is due to the fact that it often directs special attention to work of an unusually high order, as well as to work of an unusually low order. The progress of science is the progress of truth and demands perfect sincerity of its devotees. As the honors and emoluments attending scientific achievements have increased, the temptations to try to appear more successful scientifically than the merits of the case warrant have also increased. Hence it is very fortunate that all mathematical articles which propose to achieve real advances are exposed to a critical examination by experts who are expected to express their opinions in such a public manner. Unfortunately the rapid changes in the personnel of these reviewers has led to such a great variety in the styles of these reviews as to impair greatly the value of the Jahrbuch from this point of view.

While the Jahrbuch has been the largest and the most valuable periodical on periodicals during almost half a century, it is not the only journal in this field. In 1893 the Amsterdam Mathematical Society started a periodical called Revue semestrielle des publications mathématiques, which furnishes short abstracts of articles published from half year to half year. These abstracts do not aim to be critical, but they aim to give, in brief, the main results which the author claims to have estab- 
lished. The main advantage of this journal over the $J a h r b u c h$ has been that it has published these abstracts soon after the appearance of the article, while the publications in the Jahrbuch have generally appeared from two to three years after the publication of the articles concerned.

The need of books on books was felt very early. In No. 5 of the Philosophical Collections, J. Pell (16ro-85) suggested that the following works be published:* "Mathematical Pandects, containing, as clearly, methodically, concisely, and ingeniously, as it can be done, whatever may be collected, or deduced by way of corollary, from mathematical books and discoveries made before our time; quoting the most ancient authors in which they are found, and noting in all following authors where they have pilfered from others without acknowledgement; or, what is worse, have arrogated to themselves the inventions of others. By this means, that large library would be contracted into a much narrower compass, to the great saving of labour, time, and expence, for those that come after."

In commenting on this and other views, Descartes published a note in the same periodical, February, r6 40 , which reads as follows: "Now it is much to be wished, that this mathematical history (i.e., whatever is already discovered, and is committed to books) which lies scattered through many volumes, and is not yet intire and complete, were to be all collected into one book. And for this purpose, there would be no occasion to be at the charge of seeking or purchasing many books.

* Philosophical Transactions (Abridged), Vol. 2 (1809), p. 529. 
For, since authors transcribe many things from one another, whatever is extant may be somewhere found, in any library that is but moderately furnished. Nor is diligence in collecting all things so necessary, as judgment to reject what is superfluous. Now if such a book were at hand, from thence any one might learn the whole mathematical history, and a good part of the science also."

While conditions have vastly changed since the time of Pell and Descartes, yet their views continue to be interesting and instructive. The great mathematical advances since these two authors flourished have tended to increase the difficulties of the student who desires to become acquainted with all the literature on some wide field. The important developments in mathematics could not now be embodied in one book. On the other hand, the large number of periodicals and books on periodicals and books has tended to make it much easier for the student to find out what has been done in various directions, and the broad fundamental theorems which have been established constitute a rich intellectual heritage, giving an inestimable advantage to the present students compared with those of earlier times.

12. Special historical periodicals. - While the periodicals on pure mathematics are very helpful and stimulating to the investigators and the teachers of this subject, the journals devoted to the history of mathematics became evidently still more essential to the workers along historical lines when the number of these workers became large. In fact, the former periodicals have tended to become more and more historical, but there is still a 
considerable difference between the periodicals which are explicitly devoting themselves to the history of mathematics and those whose explicit aims are different. This is probably largely due to the fact that the former devote much more space to ancient and medieval questions than the ratio of the mathematical developments of these periods to the entire mathematical developments would seem to justify, while the converse is true of some of the other periodicals.

According to G. Eneström the first periodical which should be regarded as a historical journal is the small Bulletin de bibliographie, d'histoire et de biographie mathématique, which was really a supplement of the Nouvelles Annales de Mathématiques, and was edited by O. Terquem from 1855 until his death in $1862 .^{*}$ The first large special journal devoted to the history of mathematics was started in Italy in 1868 by Prince Boncompagni, under the title Bullettino di bibliografie e di storia delle scienze matematiche e fisiche. Twenty large volumes of this journal appeared from I 868 to $\mathrm{I} 887$, when its publication ceased. A peculiarity of this periodical is that very extensive references are given even when they relate to matters where the literature is easily accessible, and it is probable that these extensive references have tended to decrease the use of this journal, since they are often so numerous as to burden the reader.

Among the later periodicals devoted to the history of mathematics the Bibliotheca Mathematica is most noteworthy. The first series of this periodical (I884-86) was devoted mainly to notices of new publications.

- G. Eneström, Bibliotheca Mathematica (3), Vol. I (1900), p. I. 
The second series (1887-99) was much more important; but the third series, beginning in 1900, showed another great advance both as regards importance and also as regards size. In fact, with the beginning of this series the journal became easily the leading historical journal of the world and it has been very helpful in stimulating the great historical activity at the beginning of our century.

In Italy a much smaller historical periodical was started by $\mathrm{G}$. Loria in 1898 under the title Bollettino di bibliografia e storia delle scienze matematiche, which is largely devoted to reviews and notices of new publications. A more important historical publication is the series of memoirs which have appeared since 1877 under the general title Abhandlungen zur Geschichte der mathematischen Wissenschaften. These memoirs appeared at first as supplements to the Zeitschrift für Mathematik und Physik, but since I90I they have appeared as separate publications. The series was founded by M. Cantor, and it includes a number of very important and extensive historical studies on various mathematical subjects.

Among the other periodicals which are sometimes, but not usually, classed with historical journals is the well-known Bulletin des sciences mathématiques, which was started in 1870 under. a slightly different name, and is mainly devoted to reviews of books and memoirs appearing in some of the leading periodicals. These reviews are very useful to those who desire to obtain a general idea of modern mathematical advances. Many of them are much more complete than those appearing in the Jahrbuch and relating to the same publications. 
The latter work reviews, however, very many more journal articles and it is much more conveniently arranged for the purpose of reference.

13. Encyclopedias and other works of reference. Various mathematical encyclopedias have been published, but in recent years there has been inaugurated a large work along this line, which so much surpasses all previous similar works that it practically stands alone. It was started in Germany and the first part of the German edition appeared in 1898 . Six years later the first part of the French edition appeared. The French edition, noted in $\S 6$, is not a mere translation of the German edition, but many parts of the work were so much enlarged and improved that they present practically a new treatment of the subjects concerned. In other parts the French edition exhibits but few changes from the earlier German edition.

In fact, the German edition was not the earlier in all cases. For instance, the part dealing with recent developments as regards functions of a real variable appeared first in the French edition. The vastness of this encyclopedia has made it necessary to secure the coöperation of a large number of mathematicians. In fact, more than three hundred names appeared in the published lists of collaborators. While Germans predominate among the collaborators of the German edition, and French predominate among the collaborators of the French edition, various other nations are represented in both of these sets of collaborators.

According to the Introduction to the German edition, the purpose of this encyclopedia is to give briefly, but as 
comprehensively as possible, a presentation of the fully established results in mathematics, in such a form that they can be quickly found. The historical developments of the mathematical methods since the beginning of the nineteenth century are to be exhibited by means of careful references to the literature. The encyclopedia is not to be restricted to so-called pure mathematics, but is to exhibit the applications of mathematics to mechanics, physics, astronomy, geodesy, and the various other branches, so as to represent fully the position which mathematics occupies in the civilization of to-day.

One of the great advantages of this large encyclopedia is that it tends to avoid duplication by establishing a higher minimum of general mathematical knowledge. Notwithstanding the scrupulous efforts to avoid duplication in the advanced mathematical periodicals yet such duplication has not always been avoided. The vastness of the new literature, combined with the fact that some of the new developments appeared first in somewhat obscure places, has often made it difficult for an author to determine whether his results were new. While some of this difficulty remains, yet the large encyclopedia, in which related important results are carefully associated, tends to reduce the difficulty materially. While an author might feel that the duplication of what appeared in a somewhat obscure place was pardonable, he would naturally feel that the duplication of what appeared in this large encyclopedia was not an excusable offense.

Among the smaller modern mathematical encyclopedias the Repertorio di matematiche superiori, per Ernesto Pascal, 1898 , is perhaps most favorably known, 
especially in its translated and enlarged forms. A second German edition of this work, in four parts, began to appear in I9Io. This is not a mere translation, but it is really a remodeled and greatly enlarged edition containing about twice as much as the original. The arrangement is not alphabetical but according to subjects, bringing closely related ones together and exhibiting their developments. The more important theorems are stated and their connections are exhibited, but proofs are seldom given. In these respects the present work is similar to the large encyclopedias mentioned above.

Various modern encyclopedias of elementary mathematics have appeared. Among these the Encyklopädie der Elementar-Mathematik, by $\mathrm{H}$. Weber and J. Wellstein is especially well known. Plans of an extensive Italian encyclopedia of elementary mathematics to be published under the auspices of the Italian mathematical society "Mathesis" were announced in L'Enseignement Mathématique, I9II, page I48. This important work is intended to supplement the large encyclopedias mentioned above, which do not exclude elementary mathematics, along important lines. Among the older mathematical encyclopedias, the Encyclopédie Méthodique. Mathematiques, in three volumes, by d'Alembert and others, I784-89, is well known. While the great recent advances are not found in such old encyclopedias, yet these works contain much that is still of value.

The most useful work of reference for the purpose of finding the periodical literature of the nineteenth century is the Subject Index of the Royal Society of London Catalogue of Scientific Papers, volume I, 1908. This 
Index aims to give a practically complete list of the mathematical articles which appeared during the nineteenth century, and, according to its Preface, it contains 38748 entries referring to articles which appeared in 700 serials. Since the beginning of the twentieth century this work is supplemented annually by volume A of the International Catalogue of Scientific Literature. The articles are classified according to subjects and arranged in a convenient form for reference.

There has not yet appeared an equally complete index of the literature which was published in the form of books. An effort to give a list of the most important books on pure mathematics which appeared during the nineteenth century resulted in the publication, in 1903 , of the Mathematischer Bücherschatz by E. Wölffing, but this work is quite incomplete, and it includes many entries of works which are not commonly called books. G. Valentin of Berlin, Germany, has collected a list of I50,000 titles of books and articles published before the beginning of the twentieth century, but this list has not yet been published. It is the most extensive list of mathematical publications that has been made to date.*

Various mathematical dictionaries have been published from time to time, but during the second half of the nineteenth century and the first decade of the twentieth there existed no such work that was up to date on the terms used in pure mathematics. The Mathematisches Vokabularium, by Felix Müller, published in r9o0, and giving the French and German equivalents of about

- A detailed account of this extensive mathematical bibliography was published by G. Eneström, Bibliotheca Malhematica, Vol. 1 I (I9rI), p. 153. 
ten thousand technical mathematical terms, supplied partly the need of such a work, and some of the larger general dictionaries have included more and more such terms; but the student has frequently been compelled to consult the various indices of treatises in order to find references to required definitions. The indices of the large encyclopedias are especially useful along this line, but they are clearly not so convenient as a good mathematical dictionary would be.

A very useful work to study the principal older as well as some more modern results is the Synopsis der höheren Mathematik by J. G. Hagen. This work, in three large volumes, is based mainly upon the larger treatises and it aims to be what its title implies, a guide to the chief results contained in these treatises. It does not, in general, give proofs, but it aims to state the main theorems and to give references to places where their proofs can be found. In many ways it is a masterpiece and the fact that it is the work of one man gives it a unity which could not have been secured otherwise. This fact should also serve as an inspiration to those who might be discouraged by the bigness of modern mathematical undertakings to enter alone upon an extensive task.

Among the numerous collections of useful formulas Carr's Synopsis of Elementary Results in Pure Mathematics occupies a prominent place. The formulas in this work are numbered from $I$ to $6{ }_{1} 65$ and relate to the following subjects, in order : algebra, theory of equations, plane and spherical trigonometry, elementary geometry and geometric conics, differential and integral calculus, calculus of variations, differential equations, calculus of 
finite differences, and plane and solid coördinate geometry. Many of the more important formulas are followed by suggestions in regard to their proofs and by brief explanatory notes. A much smaller collection of formulas is contained in Seaver's Mathematical Handbook, 1907, which aims to give the chief formulas of algebra, trigonometry, circular and hyperbolic functions, differential and integral calculus, and analytic geometry.

14. Mathematical Tables. - Tables play a prominent rôle in the development of mathematics. The ancient Egyptian mathematical work written by Ahmes about I 700 B.c. began with a table in which the proper fractions with 2 as a numerator and the various odd numbers from 5 to 99 as denominators were expressed as the sums of primary fractions; i.e., fractions with one as a common numerator. For instance, the following results are found in this table:

$$
\begin{aligned}
& \frac{2}{5}=\frac{1}{3}+\frac{1}{15}, \frac{2}{13}=\frac{1}{8}+\frac{1}{62}+\frac{1}{104}, \\
& \frac{2}{89}=\frac{1}{60}+\frac{1}{356}+\frac{1}{5} \frac{1}{4}+\frac{1}{890}, \frac{2}{99}=\frac{1}{66}+\frac{1}{198} .
\end{aligned}
$$

The extensive collections of ancient Babylonian clay tablets include also many tables, giving various multiples of numbers as well as powers of numbers. Weight and measure tables are also very ancient. In fact, the work of Ahmes contains examples of changing from one system of measure to another.

Some of the ancient Greek mathematicians constructed extensive tables. For instance, the noted astronomical work, known as the Almagest, by Ptolemy (about $5_{50}$ A.D.), contains a valuable table of the lengths of the chords for the various angles from 30 seconds 
to 30 seconds, which would be, if written in the decimal system, correct to five decimals. During the sixteenth and the seventeenth centuries very extensive trigonometric and logarithmic tables were computed in Europe. Among the tables giving the values of the natural trigonometric functions those computed under the direction of G. J. Rheticus ( $\mathrm{I}_{5} \mathrm{I}_{4}-76$ ) were especially valuable. Rheticus is said to have employed several computers at his own expense for a period of twelve years, and he is called " the greatest of table computers" in the extensive and valuable report of the Committee on Mathematical Tables of the British Association published in the Report of the British Association for the Advancement of Science, 1873 , pages I to I 75 .

Even in recent years extensive tables have been computed. In our own country D. N. Lehmer of the University of California completed, in I909, a "Factor Table for the first ten millions, containing the smallest factor of every number not divisible by $2,3,5$, or 7 , between the limits 0 and I0,017,000." In r9r4 the same author completed a "List of Prime Numbers from I to I0,006,72I." Both of these tables were published by the Carnegie Institution of Washington. In I9I I $\mathrm{H}$. Andoyer of the University of Paris published a table giving the logarithms of the trigonometric functions from $1 \mathrm{IO}^{\prime \prime}$ to $1 \mathrm{IO}^{\prime \prime}$ to fourteen decimal places, besides some still closer approximations for the logarithms of certain trigonometric functions. This table was published under the title Nouvelles Tables Trigonométriques Fondamentales, as it is expected to become fundamental for other tables. 
Tables are useful not only to those who desire to use mathematics as a tool but they frequently suggest new theorems, especially those relating to properties of integers, and hence they are often useful to the mathematical investigator. One of the best-known instances of the value of tables is afforded by the tables of logarithms of the natural numbers. This is especially true as regards the operation of extracting roots. In certain problems, like the solution of exponential equations, the logarithmic tables make it possible to solve problems readily whose solution without such tables would be very laborious. As a rule it may be said, however, that logarithms would be of little practical value if one were compelled to compute the logarithm whenever it is needed. The fact that these logarithms had to be computed only once for all time explains their great value to the intellectual world. It would be difficult to estimate the enormous amount of time saved by astronomers and others through the use of logarithmic tables alone.

The first mathematical table with which the ordinary student becomes familiar is a small multiplication table, or a table of Pythagoras.* This very brief table is met with so early in our intellectual development that it may be difficult for us to realize that only a few centuries ago such a table did not constitute a part of the intellectual equipment of the common people of the most civilized countries at that time. The popularity of special old devices taking the place of a multiplication table is evidence of the general lack of this mental

\footnotetext{
* The name table of Pythagoras for multiplication table seems to be due to a misunderstanding of ancient tables.
} 
equipment in early times. Among these special devices those commonly known as Napier's Bones, or Napier's Rods, are especially well known. They consisted of small prisms with square bases, containing on their faces, the various multiples from $\mathrm{I}$ to ro of the digits appearing at the head of the face.

Evidence of the lack of general familiarity with the multiplication table is also seen in the various rules, contained in the arithmetics of the Middle Ages, which were designed to enable people to multiply all numbers by committing the multiplication table only as far as 5 times 5. Such rules, found in an arithmetic of the twelfth century, may be expressed as follows:

$$
\begin{aligned}
& a b=\operatorname{10}[a-(\text { Io }-b)]+(\text { ro }-a)(\text { ro }-b) \text { when } a>5 \\
& \text { and } b>5 \\
& a b=\text { 10 } b-(\text { ro }-a) b \text { when } a>5 \text { and } b \leqq 5 .
\end{aligned}
$$

In these formulas $a$ and $b$ represent digits which can evidently be interchanged in the former formula. In words, the first formula may be expressed as follows: To multiply two digits each greater than 5 subtract each digit from Io, and multiply the remainders together, and add as many tens to their product as the $\left\{\begin{array}{l}\text { first } \\ \text { second }\end{array}\right\}$ digit exceeds the $\left\{\begin{array}{l}\text { second } \\ \text { first }\end{array}\right\}$ remainder.

Another rule of complementary multiplication is as follows: To multiply two numbers $a$ and $b$ find two other numbers $a^{\prime}$ and $b^{\prime}$ which have the same sum but whose product can be more easily obtained, and then multiply according to either one of the following two formulas : 


$$
\begin{aligned}
& a b=a^{\prime} b^{\prime}+\left(a-a^{\prime}\right)\left(b-a^{\prime}\right) \\
& a b=a^{\prime} b^{\prime}+\left(a-b^{\prime}\right)\left(b-b^{\prime}\right) .
\end{aligned}
$$

These formulas follow directly from the equation $a+b$ $=a^{\prime}+b^{\prime}$. To illustrate these formulas, let $a=7$, $b=9 ; a^{\prime}=10, b^{\prime}=6$. Hence

$$
\begin{aligned}
& 7 \cdot 9=10.6+(-3)(-\mathrm{I}) \\
& 7 \cdot 9=10.6+\mathrm{I} \cdot 3
\end{aligned}
$$

The given formulas are found in a French arithmetic of r823. A large number of other devices were used to reduce the essential part of the multiplication table to a minimum.

The literature of tables is very extensive and it relates to some of the most elementary parts, as well as to some of the most advanced parts, of our subject. Moreover, tables differ very widely in extent and in the amount of labor involved in their production. The production of some of the larger tables has involved a marvelous amount of perseverance and unselfish devotion. In some instances the modern calculating machines have simplified the construction of tables, and they have even affected the usefulness of certain types of tables. For about three hundred years it appeared as if the greater part of the labor put on natural trigonometric function tables during the sixteenth and the early part of the seventeenth century had been wasted, since these tables had been replaced by logarithmic tables. In recent years the latter have been partly replaced by calculating machines, which have brought the older natural function tables into more prominent use ; thus furnishing another instance of unforeseen usefulness of mathematical lore. 
The astronomers are the leading table computers of the present time, and the business of insurance is largely based on tables of various kinds; but the mathematicians have always taken a deep interest in tables, as may be inferred from the facts that one of the leading mathematical societies appointed in comparatively recent years a committee on tables, ${ }^{*}$ and that the large mathematical encyclopedias devote much space to tables and their history. Table computers have not always utilized the work of their predecessors and hence a vast amount of time has been wasted. On the other hand, many of the modern tables on the market seem to have been produced for commercial rather than for scholarly reasons, and these tables frequently involve no novelty of any importance. Efforts to increase the attractiveness of such tables have led to a great variety of form and even to the use of differently colored paper.

15. Collected Works. - According to Felix Müller's Führer durch die Mathematische Literatur, I909, page I2, the collected mathematical works of about 300 mathematicians have been published. These collected works differ very widely as regards size. At one extreme are the works of Galois, published in 1897 under the auspices of the French Mathematical Society, which cover only 6r pages. $\dagger$ At the other extreme there are the extensive works of Leonhard Euler whose publication was begun in IgII and which are expected to fill more than fortyfive large volumes. Among the other prolific writers

* Jahresbericht der Deutschen Mathematiker-Vereinigung, Vol. 7 (1899), p. 123. † In 1908 Jules Tannery published some additional fragments under the title "Manuscrits de Evariste Galois." 
whose collected works have been published, at least in part, are A. L. Cauchy and Arthur Cayley. The works of the latter appeared in I3 large volumes and include nearly a thousand different publications, while those of the former are expected to appear in 27 volumes, of which more than 20 volumes have already been published.

The great importance of a direct study of the master workers in mathematics has always been recognized. With the growing need of some mathematical knowledge on the part of those whose main interests lie along other lines, such as engineers, physicists, and chemists, there has come a praiseworthy effort to put the results obtained by others into a form in which they can be more readily comprehended. This transformation of results is frequently effected by those who have comparatively little mathematical insight, and hence the new forms in which these results appear frequently fail to suggest the helpful points of view found in the original. Hence it is of the utmost importance that those students who desire a deep mathematical insight should accustom themselves early to go directly to the original developments, at least in those cases where the original developments are direct, and are found in a language which does not impose too great difficulties.

The publication of the collected works of so many prominent mathematicians tends to show that it has been regarded as important to make the original works easily accessible. In recent years several very forceful expressions of faith in the importance of collected works have presented themselves in connection with the publication of Euler's works. Not only have various acade- 
mies and mathematical societies in different countries contributed liberally towards the expense of this publication, but, as was noted in $\S 6$, a new society was formed with the sole purpose of aiding this publication. This international society, known as the Leonhard EulerGesellschaft, is a unique organization in the history of mathematics, and it is a strong testimony of faith in the value of collected mathematical works.

The tendency during the last century has been towards mathematical coöperation in place of mathematical individualism. The periodicals and the numerous societies have exerted strong influences towards coöperation. With this coöperation there naturally goes a tendency on the part of the investigator towards assisting in a greater variety of developments at the expense of an exhaustive development of a particular field. The question therefore arises whether the collected works of particular mathematicians of the present and the future will be as desirable as such works were in the past. There will naturally be less and less continuity in such works in view of the greater coöperation. On the other hand, the developments in smaller regions should continue to be most complete and suggestive in the writings of the original discoverers, and hence it appears likely that such collections will always fill an important place in the mathematical literature.

Among the partial collections of works which appeared in a large number of different editions those of Euclid probably occupy the most prominent position. During the years $1887-93 \mathrm{P}$. Riccardi published lists noting 1500 such different publications, and he stated that, 
aside from the Bible, the Elements of Euclid had probably passed through the largest number of editions. The lists of Riccardi do not claim to be complete, but they exhibit clearly that the writings of Euclid have exerted a very strong influence on the intellectual life of the civilized world, and that they are a historic factor of great importance. The writings of Archimedes have appeared in a much smaller number of editions, but they have also exerted a great influence on the development of mathematics in view of the many elegant results which appear in them for the first time.

An important element in the publication of the collected works of those who have contributed largely to the advancement of knowledge is that such works constitute a kind of monument, which should serve as an inspiration to the future investigators. Reminders of the dignity and the importance of mathematical advances are so much more important because these advances are generally made by men working in comparative seclusion, by the men of thought, and not by the so-called men of action, who are in the public eye and receive inspiration from numerous public evidences of approval. A mathematical library without collected works would be like a cemetery without its monuments. This analogy has evidently limitations similar to the one which says that "when knowledge is dead we bury it in books," yet it may serve to emphasize the point at issue.

Editors of collected works generally aim to direct attention to errors which may have escaped the notice of the original writers, and hence these collected works serve not only to facilitate reference but also to avoid 
perplexities on the part of the student. Unfortunately some of the best-known collected works still involve a considerable number of errors which apparently were not noticed by the editors. As instances, we may cite the collected works of Cauchy and of Cayley. A large number of errors which appear in a particular part of the former were noted by Josephine E. Burns.*

To give a striking instance of an evident error in Cayley's writings which was not corrected by the editor of the part of his collected works in which this error is repeated, we may refer to volume Io, page 402 , of Cayley's Collected Mathematical Papers. It is here stated that there are three groups of order 6, and the supposed equations defining these groups are given. It is at once evident that Cayley defined here the cyclic group in two different ways. While such an error was surprising in I877, when Cayley published his paper, it is still more surprising that it was repeated almost twenty years later by the editor of his works. Collected works should tend to eliminate, not to perpetuate, errors.

* American Mathematical Monthly, Vol. 20 (1913), p. I47. 


\section{CHAPTER III}

General Historical Questions Relevant to MathEMATICS

16. Definitions of the term mathematics. - The term mathematics is of Greek origin and signifies learning or science. At the time of Plato all subjects of instruction were included under the term mathematics, but as learning advanced it was found convenient to restrict the scope of this term to special fields of learning, which are, however, not clearly defined. Various proposed definitions of mathematics were considered by Professor M. Bôcher in an address on the fundamental conceptions and methods of mathematics published in the Bulletin of the American Mathematical Society, volume in (1905), page II5. One of these definitions is that mathematics is the science which draws necessary conclusions. ${ }^{*}$ This definition is due to Benjamin Peirce and is valuable since it emphasizes a very important element in mathematical work, and tends to unify our conceptions of mathematics. One of its disadvantages is that it ignores the intuitional and non-rigorous methods which constitute a considerable part of what is usually called mathematics.

The more recent definition by Bertrand Russell, that

- Benjamin Peirce, American Journal of Mathematics, Vol. 4 (I88I), p. 97. 
mathematics is the subject in which we never know what we are talking about nor whether what we are saying is true, ${ }^{*}$ is also very instructive if it. is properly interpreted. As mathematics has advanced the symbols employed have, in general, been given broader and broader meanings. This naturally led to the employment of undefined symbols which are assumed to obey certain laws of combination. In using these symbols it is very true that we do not know "what we are talking about" because we desire to economize thought by restricting our symbols as little as possible. The conclusions reached in this manner clearly apply to all the things which obey the laws of combinations imposed on these symbols. $f$ The mathematician normally deals with symbols and terms such that each of these symbols and terms may represent successively an infinite number of single entities without vitiating the conclusions.

One reason why the mathematician does not know what he is talking about is that he has usually more important things to do than to inquire into the possible limitations of his symbols. It is sufficient for him to know that his results have very wide application. It does not mean that he ignores the actual world and is soaring in the skies. On the contrary, if all knowledge of mathematics could be suddenly taken away from us, there would be a state of chaos, and if all those things whose development depended upon mathematical prin-

* International Monthly, Vol. 4 (Igor), p. 84 .

† In algebra the term variable is also employed to represent merely a symbol of calculation with which one operates according to the rules of literal algebra. H. Weber, Kleines Lehrbuch der Algebra, 1912, p. 47. 
ciples could be removed, our lives and thoughts would be pauperized immeasurably. This removal would sweep away not only our modern houses and bridges, our commerce and landmarks, but also most of our concepts of the physical universe.

The fact that Bertrand Russell could say that the mathematician does not know whether what he is saying is true, is also very instructive when properly understood. As long as the term truth remains really undefined it is probably better for the mathematician to strive to be consistent and to leave for others to consider the question whether any mathematical proposition can be known to be true to a human being. The mathematician has other important things to do for the world. Even the critical mathematician has abandoned the search for truth.* Nevertheless, in the ordinarily accepted sense of truth, it should be said that the mathematician belongs very decidedly to the great army of seekers for truths.

While the given definition by Bertrand Russell thus appears very instructive it should be noted that it is entirely too general to serve to distinguish mathematics from other fields of human interests. Like such statements as "Mathematics is the science of saving thought," and "Mathematics is the art of giving the same name to different things," $\dagger$ it emphasizes important elements in mathematical work. Since it may be assumed that only a very small part of mathematics is known, and

* C. J. Keyser, Science, Vol. 35 (1912), p. 107.

$\dagger \mathrm{H}$. Poincare, Bulletin des Sciences Mathematiques, Vol. 32 (1908), p. 174; cf. Popular Science Monthly, Vol. 75 (1909), p. I17. 
since new discoveries have an influence on our conception of mathematics, it is clearly impossible to give a definition of this term which can be hoped to be permanently accepted. The proposed definitions are, however, of great value since they direct attention to some of the most prominent elements in mathematical work.

17. Grand divisions of mathematics. - Mathematics is commonly divided into two grand divisions, viz., pure mathematics and applied mathematics. There exists no clear line of division between these two parts. The ancient Greeks divided mathematics into arithmetic, geometry, music, and astronomy. ${ }^{*}$ These subjects were called the quadrivium by Boethius (about 500 A.D.) and others, and they constituted the mathematical subjects of learning during the Middle Ages. It may be observed that a part of astronomy is now classed under applied mathematics and that it still constitutes a very important mathematical subject. On the other hand, music is not now classed under mathematics, but the theory of sound, which constitutes the intellectual basis of music, is a special subject of the field of applied mathematics known as theoretical physics.

Pure mathematics is now commonly divided into three grand divisions ; $\dagger$ viz., algebra, analysis, and geometry. The first of these terms is of Arabian origin, and constitutes a permanent reminder of the contributions made to mathematics by the Arabs. For several cen-

* The following four additional divisions were also used : Logistics or art of calculation, geodesy or surveying, mechanics and optics.

$\uparrow$ These divisions relate to the subject matter of mathematics. In $\$ 3$ we noted three different grand divisions as regards the stages of development of mathematics. 
turies, beginning about 800 A.D., the Arabs made the most important mathematical contributions. This does not imply that their contributions were as significant as those made by the Greeks more than a thousand years earlier, but it presents to us a very interesting example of the influence of various outside factors on the development of mathematics.

In the early part of the seventh century of our era religious enthusiasm united the ignorant nomadic Arabian tribes into a forceful conquering nation. As a result of the vast conquests made by them enormous fortunes were accumulated and comforts of various kinds became more common. Among these were the fruits of the learning of other nations, especially as far as these related to the curing of bodily ills and the mathematical calculations which are so necessary in the transaction of business on a large scale. As evidence of the extensive business operations in those days, M. Cantor cites the report that a certain merchant, living in Al-Basra during the latter half of the eighth century, had an annual income of about seven million dollars, and that a certain Christian doctor of medicine was receiving an annual salary of about fifty thousand dollars.*

Fortunately the Arabs became deeply interested in foreign learning and translated into their own language a very large number of foreign works. Among these were the great Greek mathematical treasures now known as Euclid's Elements and Ptolemy's Almagest. The mathematical interest of the Arabs was, however, not

* M. Cantor, Vorlesungen über Geschichte der Mathematik, Vol. I, 1907, pp. $695-6$. 
restricted to translations, but it extended soon to the next higher step; viz., to the writing of treatises based on existing but scattered knowledge. One of these treatises is especially noteworthy in view of its remarkable influence. This is the work in whose title the term algebra appeared, for the first time as far as now known. Different writers have noted the title of this work in somewhat different ways. One of these is as follows: Algebr w'almukabala.*

The author of this book was Alkhwarismi, who wrote also a book on arithmetic during the first half of the ninth century. These works were modeled largely after Greek and Hindu works, but they were so well written that they remained standard works for centuries. This is especially true of the algebra. Both the algebra and the arithmetic were translated into Latin and were thus made more easily accessible to European scholars. It is interesting to note that the name of the author, Alkhwarismi, gave rise to our mathematical term algorithm, which is used, in general, to describe a formal method of procedure to solve mathematical questions. Hence the two common mathematical terms algebra and algorithm are of Arabian origin, and tend to remind us of the services to our science rendered by a nation whose prominence in mathematics lasted only a short time, but which was not entirely fruitless as regards original contributions.

The term analysis which is now commonly employed to represent a vast and rapidly growing field of mathe-

* This work together with an English translation was published by F. Rosen, London, 1831, under the title The Algebra of Mohammed ben Musa. 
[III.

matics was used by the Greeks with a different significance. In fact, most of the subjects which are now included under this term were unknown before the invention of the differential and the integral calculus. For some time the terms algebra and analysis were used interchangeably, as may be inferred from the statement in volume I, 1784, page I31, of the noted Encyclopédie Méthodique by d'Alembert and others. It is stated here that the first part of universal arithmetic is called algebra, while the second part is properly called analysis, but that each one of these two terms is often employed for the other.

Since the beginning of the nineteenth century the terms algebra and analysis have been more consistently used to denote the large fields of mathematics which they now represent. There is no clear line of division between these two fields, but the theory of algebraic equations may be regarded as a typical subject of algebra, while the theory of differential equations is a typical subject of analysis. In many cases subjects can be classed equally well under either of these two general headings, and there seems to be a tendency to classify special subjects with a view to a fair equality as regards the extent of the literature covered by these grand divisions. In fact, the main advantages of such general terms seems to be to secure a division as to quantity with some broad reference to quality.

The line of division between geometry and other subjects of pure mathematics is scarcely more definite than that between algebra and analysis. There are, of course, developments which may be regarded as typical 
geometric developments. The synthetic geometry of Jacob Steiner (I796-I863) may serve as an illustration of such a development. On the other hand, there are many developments in geometry where algebra or analysis play the fundamental rôle, and the modern tendency to make as little use as possible of intuition frequently leaves nothing of geometry except the language in dealing with some geometrical subjects. In fact, some special subjects can equally well be classed under any one of the three general headings algebra, analysis, and geometry.

It should be noted that the partitioning of pure mathematics into three grand divisions is not universally followed. In the International Catalogue of Scientific Literature (1902-), for instance, there appear four grand divisions of mathematics bearing the following headings : arithmetic and algebra, algebra and the theory of numbers, analysis, and geometry. In the first five volumes of this catalogue the first of these divisions was called " fundamental notions." In addition to these four grand divisions of mathematics this catalogue provides various headings for the general literature relating to pure mathematics and for the various instrumentalities which serve mathematical ends, such as textbooks, models, periodicals, etc.

It is of interest to note a certain law in the usage of terms for divisions of mathematics; viz., names for the basal subjects disappear in the case of the combination of subjects under one name. Thus when arithmetic and algebra are regarded as coming under one heading, the term algebra is used to embrace the two, since a knowledge of algebra implies a knowledge of arithmetic. 
Similarly when algebra and analysis are considered together as coming under the same heading, the term analysis is commonly used for this heading, since analysis is based on algebra and a thorough knowledge of analysis implies a knowledge of algebra. In many cases mathematics is divided into two grand divisions denoted respectively by the terms analysis and geometry. This is done, for instance, in Pascal's Repertorium der höheren Mathematik and also in the Index du Répertoire Bibliographique des Sciences Mathématiques.

Finally, if all the divisions of mathematics are to appear under a single heading, the term geometry is of ten used for this heading, since geometry is based on algebra and on analysis. This is done, for instance, in the French Academy of Sciences. The section of mathematics of this noted academy is known as the section of geometry. In France it is very common to speak of a mathematician as a geometer. In this extreme case the term geometry takes the place of the term mathematics itself, and it furnishes an interesting instance of the operation of the law noted in the preceding paragraph. It tends, however, to direct attention to the fact that mathematics is a unit and that all divisions are more or less arbitrary.

18. Subdivisions of mathematics. Two extensive bibliographies of mathematical literature were started in 1885 . One of these was planned by the French Mathematical Society; while the other was undertaken by a single man, viz., by the well-known Berlin librarian, G. Valentin. The former of these aimed to index all the mathematical literature, excluding books containing no scientific advances, from the beginning of the nineteenth 
century, and the historical literature from the beginning of the seventeenth century. The work of G. Valentin aimed to give a practically complete mathematical bibliography from the invention of printing to 1868 . That is, to the time when the Jahrbuch über die Fortschritte der Mathematik was founded. The latter date was afterwards changed to the end of the nineteenth century.

It is a singular fact that two such enormous undertakings should have been begun almost simultaneously in two different countries. On March 4, I885, the French Mathematical Society sent out a circular letter of three pages entitled "Projet de repertoire bibliographique " in which attention was directed to the great need of a good mathematical bibliography, and to some general features of a proposed extensive catalogue. This proposition received very favorable comments on the part of the mathematicians of various countries and finally led, in 1889 , to an international congress of mathematical bibliography, which was held at Paris under the presidency of $\mathbf{H}$. Poincaré.

At this congress the plan of classification which had been worked out since 1885 under the auspices of the French Mathematical Society was adopted, with numerous modifications as to details. A permanent commission of which $\mathrm{H}$. Poincaré was president was elected, and it was proposed that this commission should make such modification in this scheme of classification as appeared necessary from time to time. The general plan provided for twenty-three main divisions of mathematics, which were denoted by the capital letters of the 
Roman alphabet, excluding the letters $W, Y, Z$. Seventeen of these divisions were devoted to pure mathematics, and only six, viz., those denoted by the letters $R, S$, $T, U, V, X$, to applied mathematics, including under applied mathematics philosophy, history, and biography, which were classed under $V$.

An indefinite extension of the number of the principal divisions of mathematics is provided for by affecting the capital letters with positive integral exponents. In this manner the number of these main divisions has been greatly increased since the first plan was adopted. The subject matter coming under a capital letter, with or without an exponent, is subdivided, and these subdivisions are denoted by the successive natural numbers. The subject matter under each of these natural numbers is again subdivided, and these subdivisions are denoted by the small letters of the Roman alphabet.

Finally, the subject matter coming under each of these small Roman letters is subdivided, and these smallest divisions are denoted by the letters of the Greek alphabet. For instance, the notation

$$
J 4 \text { a } a
$$

indicates that the work in question comes under the large division $J$; which includes combinatory analysis, calculus of probabilities, calculus of variations, general theory of groups of transformation, and the theory of aggregates. The number 4 indicates that it comes under the subdivision headed general theory of group of transformation. The letter $a$ denotes that it comes under the further subdivision with the heading generalities on 
substitutions and groups. Finally, the letter $a$ indicates that it relates to the special subject of transitivity of substitution groups.

It is evident that this method of classification provides for an indefinite increase in the number of divisions and subdivisions. According to G. Eneström the number of divisions and subdivisions in the original classification adopted in 1889 was about $2000 .{ }^{*}$ This number has been considerably increased since that time by additions introduced in the revised methods of classification adopted at meetings of the permanent commission.

This method of classification is explained in detail in a book entitled Index du Répertoire Bibliographique des Sciences Mathématiques, published by Gauthier-Villars et Fils, Paris. The method has been widely used, especially in France. Unfortunately the proposed card index which led to its adoption has progressed very slowly. Although more than twenty years have passed since the first part was published, in 1894, only about half of the entire catalogue has been completed. $\dagger$ The given classification is used in the Revue Semestrielle des Publications Mathématiques. This use has probably contributed more towards making it commonly known than the said card catalogue for which it was devised.

Another extensive classification which has been widely

* G. Eneström, Bibliotheca Mathematica, series 2, vol. Ir, I897, p. 67 .

$\dagger$ An analysis of the first 2000 cards was presented before the Fifth International Mathematical Congress, held at Cambridge, England, in 1912. According to this analysis by A. Gérardin, 18,523 articles were indexed on these cards. This is a little less than one half of the entries in the Royal Society of London Index Volume on the mathematical articles which appeared during the nineteenth century. 
used is the "Schedule of Classification (A)," prepared for the classification of pure mathematics in the International Catalogue of Scientific Literature. This schedule was adopted after three international conferences held at London, England. These conferences were held in the years 1896,1898 and 1900 . The first of these conferences was attended by delegates from Canada, Cape Colony, Denmark, France, Germany, Greece, Hungary, India, Italy, Japan, Mexico, Natal, the Netherlands, New South Wales, New Zealand, Norway, Queensland, Sweden, Switzerland, the United Kingdom, and the United States. The international coöperation in devising this schedule of classification was so much the more important in view of the fact that seventeen different sciences were to be classified in a similar manner. These separate sciences were denoted by the capital letters of the Roman alphabet as follows:
A - Mathematics.
B - Mechanics.
C - Physics.
D - Chemistry.
$\mathrm{E}$ - Astronomy.
F - Meteorology (including Terrestrial Magnetism).
G - Mineralogy (including Petrology and Crystal- lography).
$\mathrm{H}$ - Geology.
J - Geography (Mathematical and Physical).
$\mathrm{K}$ - Paleontology.
L - General Biology.
M - Botany.
$\mathrm{N}$ - Zoölogy. 
O - Human Anatomy.

P - Physical Anthropology.

Q - Physiology (including experimental Psychology, Pharmacology, and experimental Pathology).

$\mathrm{R}$ - Bacteriology.

According to the Preface of the first annual issue of the volume relating to mathematics the supreme control of the catalogue was vested in International Conventions to be held in London in 1905, r9ro, and every tenth year thereafter.

The classification which was finally adopted is a decimal system, but it differs widely from the "Dewey System." Four figures are used. Thus the general subject denoted by arithmetic and algebra begins with 0400, the preceding numbers having been reserved for such subjects as philosophy, history, pedagogy, etc. Analysis begins with 3200 , while Geometry begins with 6400. If all the numbers were used the mathematical literature would be divided into ro, 000 parts, and an indefinite extension could be readily obtained by increasing the number of figures.

The importance of a knowledge of this system of classification has been greatly increased by the publication in I908 of a Subject Index covering the periodical mathematical literature of the entire nineteenth century, and following this system of classification. According to the Preface of this invaluable Index, which covers the greater part of the field to which the great bibliographical undertakings of the French Mathematical Society and of G. Valentin relate, there are in the Index 38,748 entries referring to 700 serials. An important advantage of this 
classification is that it is similar to those used in the International Catalogue for indexing the other pure sciences. The services of the Royal Society of London in furthering these great bibliographical undertakings are of the highest importance for the advancement of science.

By means of the given Subject Index it is easy to get an approximate notion in regard to the relative research activities in various fields of mathematics during the nineteenth century. For instance, the listing of the papers on arithmetic, algebra, and the theory of numbers required about 190 pages of this Index. The listed papers on analysis cover about I80 pages, while those on geometry cover about 240 pages. It thus appears that the publications during the nineteenth century were fairly evenly divided between the three large fields commonly known as algebra, analysis, and geometry. As the developments in these three large fields are mutually helpful, it is to be hoped that each of them will receive in the future its due share of attention.

As mathematics grows there is a tendency to divide into more and more subjects, but it is interesting to observe that there is also a tendency, though less strong, towards absorption. Thus the subject of algebraic analysis did not really exist as a distinct subject after the works of Weierstrass and Méray became known, since it was included in the theory of elementary analytic functions. In our own day the theory of aggregates tends more and more to cease as a distinct subject. On the other hand, it is becoming a funda- 
mental part of various other subjects which it clarifies and vivifies.*

19. Some dominant concepts of mathematics. Before the classic Greek period of mathematical development, applications to astronomy and surveying seem to have furnished the main incentives for the study of mathematics. In a broad way it has been said that the ancient Babylonians were led to mathematical study through their interest in the stars, while the ancient Egyptians were led to this study through their interest in measurement of land. The former received their inspiration from above; the latter, from below. The term geometry points towards the influence of measurement of land in the early development of one of the extensive fields of pure mathematics.

The classic Greek period, which may be represented by the works of Euclid, Archimedes, and Apollonius, exhibits a new dominating concept; viz., the concept of irrational quantities, giving rise to the mathematics of a thought-world, and exhibiting many facts which are too refined to receive visible expression in the outside world. While the ancient Babylonians received their mathematical inspiration from the stars, and the ancient Egyptians received similar inspiration from the earth, the ancient Greeks were inspired to study mathematics by the thought-world. The concept of irrational quantities may perhaps be said to have been the dominating mathematical concept leading to the great advances of the ancient Greeks.

The earliest dominating mathematical concept during

- Cf. Encyclopedie des Sciences Mathématiques, tome I, volume r, p. 530. 
the revival of learning in the latter part of the Middle Ages seems to have been the solution of equations in one unknown. The intellectual triumphs of the Italian mathematicians, who found during the sixteenth century general algebraic solutions for the cubic and the biquadratic, naturally inspired great hopes of further progress along this line. More than two centuries later Lagrange gave a masterly review, in his famous memoir entitled Réflexions sur la résolution algébrique des équations, of the efforts to which these hopes gave rise, and, in turn, he started efforts in a new direction, which culminated in the works of Abel and Galois, and have since been perfected along various lines.

In the given memoir Lagrange said "the theory of equations is of all parts of analysis the one, we would think, which ought to have acquired the greatest degree of perfection, by reason both of its importance and of the rapidity of the progress that its first inventors made; but although the mathematicians of later days have not ceased to apply themselves, there remains much in order that their efforts may meet with the success that one could desire. In regard to the solution of literal equations one has hardly advanced farther than one was in Cardan's time, who was the first to publish the solution of equations of the third and fourth degrees. The first successes of the Italian analysts in this branch seem to have marked the limit of possible discoveries; at any rate it is certain that all attempts that have been made up to the present time to push back the limits of this branch of algebra have hardly served for other purposes than to find new methods to solve the equations of the 
third and fourth degrees, none of which seem applicable to equations of higher degrees."

Two fundamental questions relating to the theory of equations in one unknown are : Does a root always exist? and by what methods can the roots be found? The former of these was answered once for all in the dissertation of Gauss, but the latter has been much more fruitful as it has led to vast new theories. On account of the developments relating to the latter question the equation has occupied such a central position in mathematics. In modern times interest in the theory of algebraic equations has been somewhat increased on account of its fundamental relation to the theory of differential equations, which occupies a central place in the applications of mathematics.

The fundamental place of the equation in elementary mathematics is forcibly expressed by Sir Oliver Lodge in the following words, "An equation is the most serious and important thing in mathematics."*. The dominating rôle of the algebraic equation in mathematical investigations was gradually lost by the rapid developments based upon concepts which were clearly formulated during the seventeenth century. Among these the concept of function is especially noteworthy. According to Sophus Lie, the curve as a representation of a function of a single variable presented the most important object of mathematical investigation during a period of nearly two hundred years beginning with Descartes. $\dagger$ Until towards the end of the seventeenth century the concept of func-

* Sir Oliver Lodge, Easy Mathematics, 1906, p. 127.

† S. Lie, Leipziger Berichte Mathematisch-Physische Classe, r895, p. 267. 
[III.

tion had not been sufficiently clearly developed to need a special name. It sufficed to speak of this concept in a purely geometric language as the ordinate of a curve for a given abscissa. While various approaches to our present definition of function were made earlier, a modern definition seems to have been first given by John Bernoulli in a letter addressed to G. W. Leibniz, dated July 5, I698. John Bernoulli seems also to have been the first to use the word function with its precise actual meaning. According to Felix Müller (Bibliotheca Mathematica, volume 2, I901, page 285) the term function is due to Leibniz.

The statement that the term function was first used to denote a power of a single variable has been frequently made in books dealing with function theory, but there appears to be no historic basis for this statement. On the other hand, it seems to be based upon a misinterpretation of a statement made by J. d'Alembert in the Encyclopédie ou Dictionnaire raisonné, volume 7 , I757, page 50, and to have been transmitted through the carelessness of writers who accepted historic statements without going to the trouble to verify them.*

While the concept of function has maintained a prominent place in mathematics, various other concepts began to assume more and more prominent places in the mathematical literature of the latter part of the nineteenth century. Writing in $1895, \mathrm{~S}$. Lie observes that in the nineteenth century " the concepts of substitution and substitution groups, transformation and transformation groups, invariants, differential invariants and dif-

* Cf. Encyclopedie des Sciences Mathematiques, tome II, Vol. I, p. 3. 
ferential parameters present themselves more and more clearly as the most important concepts of mathematics." A considerable number of other very important mathematical concepts, among which are the concepts of matrices and domain of rationality, presented themselves more and more clearly during the nineteenth century, and it would appear bold to predict the relative importance of these various concepts in the future development of our subject. There is, however, a hierarchy among mathematical concepts, and the individuals composing this hierarchy vary from time to time.

For the purpose of illustrating the development of an important modern mathematical concept we proceed to give some details in regard to the history of the concept of group. In its most elementary form this concept presented itself very early in the development of mathematics.* It was, however, not at first explicitly formulated because of its simplicity. According to $\mathrm{H}$. Poincaré the principal foundation of Euclid's demonstrations is really the group and its properties. $\dagger$ The assumption that the displacements form a group is involved in the proof by superposition. Even the fundamental notion of length implies that not all figures

* In the fifth edition, I91 2, of Ball's History of Mathematics, p. 475, it is stated that "a new development of algebra - the theory of groups of substitutions was suggested by Evariste Galois." As a matter of fact the elements of this theory were studied before the days of Galois. On the same page is found the statement, "the theory of groups, and of subgroups or invariants, has profoundly modified the treatment of the theory of equations." This statement seems to imply that subgroups and invariants are the same kind of concepts. As a matter of fact they are entirely distinct concepts.

$†$ H. Poincaré, "On the Foundations of Geometry," The Monist, Vol. 9 (1898), p. 34 . 
formed by two points are superposable, and this is related to the notion of group as it involves the notion of displacement.

While the concept of group is involved in the fundamental notions of elementary geometry and constitutes the main basis of the dynamic elements in these notions, its early development is due to a study of the number of formal values which rational integral functions of several variables assume when these variables are permuted in every possible manner. In about 1770 this question was moved into the foreground of mathematical investigation by two memoirs on the solution of algebraic equations written respectively by J. L. Lagrange and A. T. Vandermonde. The former of these seems to have been especially influential. It was entitled Réflexions sur la résolution algébrique des équations, and appeared in the Nouveaux Mémoires de l'Académie de Berlin, I772. In this memoir there appears, in an imperfect form, the most important theorem of group theory; viz., the theorem that the order of a group is divisible by the order of each one of its subgroups. This elementary theorem is often called Lagrange's theorem, although Lagrange did not develop it in its general abstract form.

Lagrange's study of the possible values of rational functions of several variables revealed the beautiful theorem that a necessary and sufficient condition that two such functions can be expressed rationally in terms of each other is that they belong to the same substitution group. Lagrange called the functions which belong to the same group similar functions. The given theorem was sufficiently general and far-reaching to direct atten- 
tion to the importance of a study of substitution groups. On the other hand, this study soon revealed many interesting and far-reaching theorems relating to the subject itself, so that the theory of substitutions gradually became an independent subject. In about 1845, A. L. Cauchy published a number of articles on this theory, in which he developed a large number of new and important properties of substitution groups. In view of the extent and importance of this work, Cauchy is commonly regarded as the founder of the theory of substitution groups.

Not only did Cauchy tend to the study of substitution groups independently of their direct application, but he even tended to lay more and more stress on the abstract properties of groups. One of the most fundamental theorems established by him is the fact that every substitution group whose order is divisible by a prime number must contain a subgroup whose order is equal to this prime number. This theorem had been stated without proof by E. Galois * (I8II-32). It was extended about thirty years later by L. Sylow, and, in this extended form, it is known as Sylow's Theorem. It plays a very fundamental rôle in the abstract theory of groups. While there was an early tendency towards more and more abstraction in the development of the theory of substitution groups, the beginning of the theory of abstract groups is commonly ascribed to an article by A. Cayley, published in 1854 under the title, On the theory of groups as depending on the symbolic equation $\theta^{n}=\mathrm{I}$.

Thus far we have sketched the development of group

- Manuscrits de Evariste Galois, publiés par J. Tannery, Paris,.'1908, p. 39. 
theory in connection with algebra, and especially as an outgrowth from the theory of equations. About 1870 the usefulness of the concept of groups in other domains of mathematics became evident, especially through the works of C. Jordan, S. Lie, and F. Klein. Klein's noted Program on entering the Philosophical Faculty and the Senate of the University of Erlangen in $1872 *$ regarded all geometry as a group-theoretic problem, and the extensive investigations which were inspired by it have exhibited the fruitfulness of this concept as a guiding and unifying principle in the development of geometry. This is not confined to the more advanced part of geometry but extends to the very foundations of the subject.

The theory of continuous transformation groups which was founded by S. Lie in about 1870 was developed vigorously during the last quarter of the nineteenth century, and exhibited the importance of the group concepts in various fields of mathematics. In particular, Lie laid stress on the application of this concept to the solution of differential equations, and several textbooks on differential equations have been written from this point of view. The mathematical literature of the last quarter of the nineteenth century gave more and more evidence of the dominance of the group concepts so that J. Pierpont could truthfully say in reviewing the mathematical developments of the century "In résumé, we may thus say that the group concept, hardly noticeable at the beginning of the century, has at its close become one of

- An English translation of this program appeared in the Bulletin of the New York Mathematical Society, Vol. 2 (1893), p. 2 I5. 
the fundamental and most fruitful notions in the whole range of our science." *

The dominance of the group concept in the literature of the latter part of the nineteenth century should not be construed to mean that a very large portion of the literature of this period was devoted to the development of the theory of groups. On the contrary, this dominance merely implies that the concept of group was used as a guiding principle which unified and clarified large portions of the mathematical developments. A considerable literature in which the groups themselves formed the main objects of study was also developed during this period, but this forms a very minor part of the entire mathematical developments of this period. The value of the group concept in a special form as a guiding principle is set forth clearly in the following words by one of the foremost investigators of this period: "There is a theory which has been equally useful to me in all my researches, namely, that of groups formed by linear substitutions. In fact, these substitutions play a preponderant rôle in the study of linear equations and that of arithmetic forms. It is to this circumstance that one ought to attribute the interrelations, of ten unexpected, which I shall note later between the theory of numbers and the theory of Fuchsian functions, - theories which, moreover, do not at first appear to have any point of contact." $\dagger$

A fundamental element in the concept of group is that

* J. Pierpont, Bulletin of the American Mathematical Sociely, Vol. II (1904), p. 144 .

† H. Poincaré, Notice sur les travaux scientifiques, I884, p. 7. 
[III.

objects of thought may be regarded both as operators and as operands, and constitute a complete set when the units are combined according to fixed laws. In the most general sense, a set of objects is said to form a group when a rule is given according to which one can deduce from any two, $A$ and $B$, of the objects of the set a third object, $C$, of the same set.* The term group is, however, commonly used with a much more restricted meaning. It is interesting to note that in a considerable part of the early literature on groups no special term was used to denote the fundamental concept involved. This is true, for instance, of the work of C. F. Gauss ( $1777^{-}$ r855) who employed the concept of groups in some of his developments in the theory of numbers, and was influential in introducing this concept. In fact, on entering the Berlin Academy of Sciences, Frobenius said that the group concept was introduced into mathematics by Gauss and Galois. $\dagger$ Even Klein and Lie used the term "closed system" instead of the term group in their earliest work involving the group concept, published jointly in volume 4 of the Mathematische Annalen. The technical term group was introduced by Galois, but many later writers used other terms for this concept. Cauchy, for instance, generally used the term "system of conjugate substitutions" instead of substitution group.

20. Mathematical.notation and terminology. - In the Introduction to his Vorlesungen über Geschichte der Mathematik, Moritz Cantor asked the following question :

* Encyclopédie des Sciences Mathematiques, tome I, Vol. 2, p. 243. $\uparrow$ G. Frobenius, Berliner Sitzungsberichte, 1893, p. 627 . 
Why has mathematics from the earliest times found support, simplification, and advancement by the introduction of special number or other mathematical symbols? He does not undertake to answer this question, but directs attention to the fact that number symbols appear among the historical inscriptions of the oldest civilizations. In much more recent times, other sciences have developed a symbolic language, for instance, the science of chemistry, but mathematics continues to be the science par excellence with a special symbolic language.

There is, however, a very wide difference between the number of special symbols employed by various mathematical writers. On the one hand, we have such works as the Formulario Mathematico of G. Peano and the Principia Mathematica by Whitehead and Russell, where the uninitiated finds little that looks familiar even in the language. On the other hand, there are considerable parts of the large mathematical encyclopedia which are free from any special mathematical symbols. Although a special mathematical symbolism offers the objection that one has to learn a new language, yet it secures such a great gain in space, and hence in the time required to grasp the questions involved, that it often affords a great mental gain. To appreciate the value of special notation one has only to write out, in ordinary language, a set of algebraic equations.

Not only are special number symbols very old, but even symbols for operations appeared in the earliest extensive mathematical work which has been deciphered. In the well-known work of the Egyptian scribe Ahmes 
there appear special symbols for addition, subtraction, and equality. The symbols employed for these and other operations and relations have varied greatly from time to time, and there are many points in the history of our modern symbols which are still disputed. If we come to the history of the symbols for the more modern concepts there is evidently less room for uncertainty. In a historical note on the symbols which have been employed to denote a function of one or more variables G. Eneström directed attention to various symbols used and proposed, before our present notation, due to Clairaut and Euler, was commonly adopted.* For instance, Leibniz proposed the symbols $\bar{x}|\underline{1}, \bar{x}| 2\rfloor$, etc., and $\overline{x ; y} \mathbf{I}, \overline{x ; y} 2$ ], etc., for different functions of one and two variables respectively, but this suggestion was not favorably received.

In I909 D. André published a volume of 500 pages entitled Des Notations Mathématiques, énumération, choix et usage. This book seems to be the first to give a general treatment of the problem of mathematical notation. It discusses in detail the guiding principles in the choice of a notation, and it formulates several fundamental rules. The first two of these are stated on pages 166 and I70, as follows: A sign should always represent the same object, and the same object should always be represented by the same sign. This implies a $(\mathrm{I}, \mathrm{I})$ correspondence between the signs and the objects. The single object for which a sign or symbol stands is, however, not always fixed, nor is it always defined. Cf. $\S \mathrm{I6}$.

* G. Eneström, Bibliotheca Mathematica, 189r, p. 89. 
The objects considered here may be complex and decomposable into an infinite number of other objects, as is the case, for instance, when we use a single symbol for a large class of functions of $x$. Such simple rules may appear to the reader as platitudes, yet their formulation is not without interest in view of the fundamental importance of a good notation. Mathematical progress along many lines has been fundamentally. influenced by a good notation, and it has been stated that modern mathematics would not exist if we did not possess a special mathematical notation.*

The great advantages of a good notation for the system of natural numbers have been frequently pointed out. In particular the discovery of $\circ$ has been regarded as one of the capital discoveries in view of its usefulness in the elementary operations of arithmetic. As a more modern instance, the advantages of our notations for determinants and matrices in securing a deep insight into the meaning of a system of linear equations may be cited. A good notation is not only a useful aid in mathematical developments but it is also frequently suggestive of new results, and hence it constitutes a useful aid to the investigator as well as to the student.

In addition to the public notations employed in the mathematical literature probably most of the successful investigators have a private notation which represents the fruit of their own thought and enables them to attain to certain heights which were not reached by their predecessors. In many cases, this private notation is never fully committed to paper, but it represents a distinct

- Bulletin des Sciences Mathematiques, Vol. 33 (1909), p. 228. 
mental equipment and is a natural outcome of serious independent thought.

Mathematical terminology serves the same general purposes as mathematical notation, since it tends to make our expressions more compact, and hence it tends towards an economy of thought. What the mind would otherwise have to gather together at various times, it gathers together once for all and the single term or the simple notation recalls this accumulation of facts. The special terms thus simplify matters for those who comprehend clearly the elements involved in these terms. On the other hand these terms confuse those who do not bear in mind the full significance of these elements. Hence the use of new terms involves questions of a somewhat serious nature, and great differences exist among mathematical writers in regard to the introduction of new terms for important concepts.

Among the modern writers J. J. Sylvester has perhaps introduced the largest number of new terms. He seems to have taken a certain pride in the fact that so many of his terms were generally adopted by other writers, as may be inferred from the following quotation: "Perhaps I may without immodesty lay claim to the appellation of Mathematical Adam, as I believe that I have given more names (passed into general circulation) of the creatures of the mathematical reason than all the other mathematicians of the age combined." *

The extent to which new mathematical terms have been introduced has been viewed by some with considerable misgivings. Already in $1869 \mathrm{H}$. Hankel was led

- J. J. Sylvester, Nature, Vol. 37 (1888), p. 152. 
to compare mathematics with the Tower of Babel in view of the fact that mathematicians are speaking such different languages.* One of the greatest sources for new terms in America is the habit of using terms of various languages (for instance, menge, ensemble, and aggregate) for the same concept. In view of the fact that mathematics is cosmopolitan it would appear much wiser to use the same term in all the languages. Even when this is done the number of technical mathematical terms is very large as may be inferred from the fact that more than ten thousand such terms appear in Felix Müller's Mathematisches Vokabularium, r9o0. According to the Preface of this work the Germans are more inclined than the French to use translations of foreign terms instead of adopting these foreign terms.

Many mathematical terms are composite. The adjectives which appear most frequently in the given Vokabularium are, in the order of frequency, as follows: harmonic, conjugate, spheric, elliptic, geometric, polar, reciprocal, imaginary, linear, double, logarithmic, quadratic, absolute, parabolic, cubic, elementary, normal, hyperbolic, orthogonal, plane, projective, oblique, rational, fundamental, regular, asymptotic, geodetic, composite, general, conical, simple, analytic, central, simultaneous, adjoint, algebraic, cyclic, cylindrical, focal, symmetric, mechanical, relative, trigonometric, straight line, inverse, mathematical, graphic, real, complex, equivalent, perspective, characteristic, numerical, involutory, irrational, transcendental, metric, parallel, continuous, col-

* H. Hankel, Die Entwickelung der Mathematik in den letzten Jahrhunderten, 1869, p. 34 . 
linear, partial, primitive, periodic, singular, rectangular, tetrahedral, binary, unideterminate, infinite, and stationary. Among the 56 principal words with which the adjective harmonic appears in this Vokabularium are the following: harmonic axis, harmonic analysis, harmonic movement, harmonic pencil, harmonic center, harmonic function, etc.*

It is of interest to note the languages from which our mathematical terms came, as these languages throw some light on the time when these terms came into general use. The word pyramid is said to have come from the Egyptian word Piremus, while the terms algebra, algorithm, cipher, and zenith are Arabic. A large number of our terms are Greek, as may be seen from the following list: mathematics, arithmetic, geometry, geodesy, mechanics, astronomy, stereometry, trigonometry, physics, statics, dynamics, method, analysis, theorem, system, axiom, ellipse, hyperbola, parabola, polygon, polynomial, polyhedron, diameter, parameter, asymptote, homogeneous, parallel, sphere, harmonic, homologous, symmetric, etc.

Among the Latin mathematical terms in common use we may cite the following: addition, subtraction, multiplication, division, sum, product, quotient, definition, determination, permutation, combination, variation, rectification, line, point, rule, aggregate, argument, radius, factor, abscissa, ordinate, coefficient, determinant, proportion, progression, minute, second, function, mantissa, positive, negative, decimal, commensurable, rational, concave, congruent, etc. Some terms are formed

* Felix Müller, Bibliotheca Mathematica, Vol. 2 (I901), p. 317. 
by combinations of words from several languages. A noted example is the term almagest, which is a combination of a Greek word and the Arabic al. Binomial, biharmonic, betafunction, gammafunction and others are partly Greek and partly Latin.*

In the newer subjects the tendency is especially strong to use different terms for the same concept. For instance, in the theory of groups the following seven terms have been used by various writers to denote a single concept: invariant subgroup, self-conjugate subgroup, normal divisor, monotypic subgroup, proper divisor, distinguished subgroup, autojug. What is still more confusing is the use of the same term with different meanings. For instance, in volume 1 , page 238 , of the Igro edition of Pascal's Repertorium, the symmetric group of order 6 is called the anharmonic group, while Capelli uses the same name for an entirely different group in the 1909 edition, page II I, of his noted algebra, entitled Istituzioni di analisi algebrica. In his review of the third edition of volume 2 of Jordan's Cours d'Analyse de l' Ecole Polytechnique, $\mathrm{H}$. Lebesgue says that it is perhaps regrettable that the term perfect ensemble is used in this work for what is now commonly called a closed ensemble, perfect ensemble having generally a different meaning. $\dagger$

Questions of notation and terminology have been subjects of discussion at many conferences. The topic "mathematical nomenclature" appeared on the programs of the first two international congresses of mathematicians held respectively at Zürich, Switzerland, in 1897 ,

- Loc. cit., p. 314 .

† H. Lebesgue, Bulletin des Sciences Mathematiques, Vol. 39 (I915), p. I8. 
and at Paris, France, in rgoo. While such conferences accomplish much towards improving notation and nomenclature, it is also true that the worst offenders seldom attend such conferences. Some of the most important mathematical work is done by men who are so busy with their own investigations that they seldom take the time to go to meetings, or even to read the current literature with care. While deficiencies as regards references and terminology frequently mar the work of such men, it must be observed that such deficiencies are not matters of first importance.

21. Errors in the mathematical literature. - It would be difficult to overestimate the influence which errors have had in the development of mathematics. The confidence and independence of thought which is cultivated by being able to prove completely that some of the best-known investigators overlooked important factors in their work is of great value provided it does not lead one to overlook the good in seeking the faulty. In $1826, \mathrm{~N}$. H. Abel wrote to his friend Holmboe that most of the papers dealing with infinite series were inexact,* and this observation doubtless had a great influence on his mind. Many prominent mathematicians have been somewhat careless as regards details while tracing with the keenest interest the main points involved, but there are also cases where the main points in question were missed by mathematicians of high standing.

In 1904 E. Maillet proposed, as question number 2855 of L'Intermédiaire des Mathématiciens, the making

* Niels Henrik Abel Memorial, Correspondance, 1902, p. I6. 
of a list of errors committed by prominent deceased mathematicians. Maillet began this list by referring to errors committed by Ampère, Abel, Chasles, Legendre, Bertrand, Laplace, and others. Many others have contributed towards extending this list of references, but it is still very incomplete. It is, however, sufficiently extensive to exhibit many interesting questions which have been imperfectly understood by eminent authorities, and hence such a list has distinct pedagogic value. A fortunate element about most of the mathematical errors is that their correction can be readily understood and hence there is little room for controversy.

Reviews probably constitute the most important single instrument to combat modern mathematical errors. Unfortunately reviewers do not always use this instrument wisely. In many cases this may be due to a lack of self-confidence on the part of the reviewer. In other cases it is doubtless due to an inclination to write reviews which will please the authors of the works under review. A conscientious reviewer cannot escape a sense of duty to the public and to the truth.

Although errors have been very influential in inspiring young investigators, and have thus been an important factor in the development of mathematics, it must also be noted that they have done much harm. The beauty and insight furnished by correct and fundamental results are even more inspiring than the sense of power secured through the discovery of errors in the works of eminent men. The former have the additional advantage that they have no evil tendencies.

Some of the best-known errors in the mathematical 
literature are found in the supposed proofs of the parallel axiom, starting with those of Ptolemy and Proclus and extending into the recent literature. Even such good and popular elementary textbooks on geometry as those of Legendre ( $175^{2-1833)}$ gave incorrect proofs of this kind. The bad effect, on the brightest young minds, produced by being obliged to reproduce such false arguments and to pretend to understand them is the most serious consideration. Fortunately our modern geometries are very much more free from false arguments than those of earlier times, but we still sometimes expect young students to understand what the best mathematicians say they cannot understand.

The errors which the mathematical student generally meets first appear in the answers to problems in the textbooks. Comparatively few textbooks are entirely free from errors, and, in case of short problems where the answer can be readily verified, such errors often tend to lead the student to consider the problem more carefully. A verified result is always preferable to one which has only been compared with the answer in the book. It would, however, appear more desirable to omit the answers in those cases where the student may be reasonably expected to verify his results, and to give only correct answers to the other problems. The study of mathematics naturally tends toward an abhorrence of concealed errors, and this important tendency should not be diminished by a faulty textbook. It should, however, always be remembered that a textbook ought to be regarded as a guide to the truths, rather.than as an entirely reliable bearer of the truths. 
The errors which have been noted thus far are those which should be eliminated as far as possible. There is a very large class of necessary errors in mathematics, since mathematics is a science of approximations as well as an exact science. For instance, practically all the logarithms found in any logarithmic table are only approximately correct. Similarly, only a very few of the numerical values found in the tables of natural trigonometric functions are accurate. One of the earliest approximate vaiues to be used extensively in mathematics is a numerical approximation for $\pi$, the ratio between the circumference and the diameter of a circle. When the ancient Babylonians substituted 3, and the ancient Egyptians substituted 256/81, for this ratio, they introduced, intentionally or unintentionally, an erroneous value for this ratio.

Another type of errors is due to the fact that the mathematician has frequently to deal with data which are not only inaccurate but also conflicting. Since purely physical measurement may be assumed to be inaccurate, and in the application of mathematics it is often necessary to deal with such measurement, it is clear that there is a need in mathematics of a method of dealing with inaccurate and conflicting data. This has given rise to a special subject of pure mathematics, commonly known as the Theory of Errors. It may be observed that while the Theory of Errors, founded by C. F. Gauss near the beginning of the nineteenth century, was at first a subject of applied mathematics, it has been gradually absorbed by pure mathematics. In fact, the whole tendency of scientific learning is towards pure mathe- 
matics through the intermediary of applied mathematics. Pure mathematics is the great all absorbing whirlpool in a large domain of scientific knowledge. By way of illustration we may cite the fact that " there is a constant tendency for mathematical physics to be absorbed in pure mathematics." *

A queer historical error occurs under the word " group" in the eleventh edition of the Encyclopedia Britannica. It is stated here that the mathematical technical sense of the word group is not older than 1870 . If it is recalled that the renowned British mathematician A. Cayley (r821-I895) used the term group with its technical meaning in the heading of a number of his articles, beginning as early as $\mathrm{I} 854$, in the Philosophical Magazine, and that two of his countrymen, T. P. Kirkman and J. J. Sylvester, used this term frequently a few years later, it appears very strange that an English scholar made the above statement in such an eminently useful work of reference. Errors as regards historical statements occur very frequently even in many of our best works of reference. It is to be hoped that the rapid spread of historical knowledge will tend towards a rapid diminution in this type of errors.

In recent years there has been developed a very extensive erroneous mathematical literature by people who were anxious to secure the large Fermat Prize, which will be more fully explained in $\S 3 \mathrm{I}$. It may be noted here that this prize has been the cause of such a vast amount of literature as to lead to a special name; viz., the litera-

* A. E. H. Love, Proceedings of the London Mathematical Sociely, Vol. 14 (1915), p. I83. 
ture of the Fermatists, most of which is as curious and as senseless as the noted literature of the circle-squarers. Fermat announced his theorem in Latin as follows: " Cubum autem in duos cubos, aut quadrato-quadratum in duos quadratos, et generaliter nullam in infinitam ultra quadratum potestam in duas ejusdem nominis fas est dividere, cujus rei demonstrationem mirabilem sane detexi. Hanc marginis exiguitas non caperet."

Unless a solution of this problem will be found before the expiration of the century during which this prize may remain open, it is difficult to estimate the enormous extent of erroneous literature which it may call into being. More than a thousand false proofs were published during the first two or three years after the prize was announced.* The apparently elementary nature of the problem may perhaps explain the fact that so many people without any mathematical insight or training have undertaken to find its solution. The failure on the part of so many great mathematicians to obtain a solution does not seem to impress some of those who approach the problem with the most meager mathematical equipment. Possibly their failures may awaken a sense of modesty as regards their own abilities, even if they do not inspire more respect for those who are mathematically equipped.

Whether Fermat actually had a proof of this theorem or was led to think that he had a proof by an error in his work cannot now be determined. He was a good mathematician and found a number of very interesting and fundamental theorems in Number Theory, which were also

* W. Lietzmann, Der Pythagoreische Lehrsatz, 1912, p. 63. 
stated, without proof, on the margin of the same book and have since been proved. Hence the theorem in question has been attacked by a number of prominent mathematicians. Some of these were thus led to important developments without however being able either to prove or to disprove this particular theorem. For instance, Kummer's beautiful theory of ideal numbers grew entirely out of the efforts made by E. E. Kummer (1810-1893) to prove this theorem,* and this theory is probably more important than a proof of Fermat's theorem would be if it were based only upon methods known in Fermat's day.

The indirect value of a proof of Fermat's greater theorem may thus be expected to be most important, as it is to be hoped that efforts to prove it may lead to other important new mathematical methods, and thus give rise to strong instruments for attacking other mathematical difficulties. Such difficulties abound in many domains of mathematics and will probably grow in number with every mathematical advance.

In view of the fact that the prize offered for the solution of Fermat's greater theorem is nearly $\$ 25,000$ and that lack of marginal space in his copy of Diophantus was the reason given by Fermat for not communicating his proof, one might be tempted to wish that one could send credit for a dime back through the ages to Fermat and thus secure this coveted proof if it actually existed. This might, however, result more seriously than one would at first suppose; for if Fermat had bought on

- K. Hensel, Festschrift zur Feier des 100. Geburtstages Edward Kummers, 1910, p. 19. 
credit a dime's worth of paper even during the year of his death ( $166_{5}$ ) and if this bill had been drawing compound interest at the rate of six per cent since that time, the bill would now amount to more than seven times as much as the prize in question.

In view of the large number of errors in the mathematical literature, the young mathematician will naturally ask himself the question what attitude he ought to take in regard to these errors. He can, for instance, devote all his time to the exposure of real errors, or he can pass them by entirely and devote himself to the discovery of new results which are not directly involved in the erroneous literature.

The caliber of a mathematician can probably be judged just as accurately from the errors to which he pays attention as from the new results he announces. In both cases a man can devote himself to trivialities or to big things. Some of the greatest investigators started their careers by pointing out great errors. C. F. Gauss, for instance, pointed out in his doctor's dissertation errors by some of the leading earlier investigators in regard to a proof of the fundamental theorem of algebra, and succeeded in giving a first rigorous proof of this theorem. On the other hand, P. Bachmann states in the Preface of volume I of his Zahlentheorie, 1892, that Gauss's Disquisitiones Arithmeticae, r8or, was scarcely readable on account of the large number of annoying typographical errors. The correction of the latter type of errors is comparatively insignificant, but that of the former type is of the greatest importance, and there are many intermediate grades, where the importance or 
unimportance of corrections cannot be so readily determined.

As further evidence of the occurrence of errors even in the best mathematical literature it may be observed that both the German and the French editions of the large encyclopedia made special provisions for correction and additions. Those relating to the German edition were at first published in the Archio der Mathematik und Physik, but since 1907 they have appeared from time to time in the Jahresbericht der Deutschen MathematikerVereinigung. The French edition published special pages entitled Tribune publique for the purpose of noting the corrections and desirable additions observed by the readers.

22. Living mathematicians. - The interest of the mathematical student in the living mathematicians should not be mainly due to curiosity, but it should be largely due to the fact that living mathematicians are the sources of present mathematical activities. Moreover, the farther the student pursues his work, the more will he be assisted by the advice of men who are authorities in special fields of mathematics. This is especially true in case a student expects to enter upon research work with a view to becoming one of those who are able to contribute towards the advancement of mathematical knowledge along important lines.

Judging from the biographies of the prominent mathematicians of the past, it is not essential to study directly under a great mathematician in order to achieve greatness along mathematical lines; nor is it true that the greater part of those whose student work was guided by the greatest mathematicians have themselves attained emi- 
nent standing in the mathematical world. On the other hand, it is doubtless true that the unusually successful investigators are in the best position to direct the work of their students towards a successful career. In fact, it seems very unlikely that those who have failed to discover important new results will be of much help to others who are seeking to make a start in such discoveries.

With the rapid extensions of mathematical activities there has come a greater variety of leadership in the mathematical world, and hence it results that mathematical prominence is due to an increasingly large number of different factors. It therefore becomes more and more difficult to judge the relative standing of eminent living mathematicians. Sometimes there arises a man whom nearly all agree to proclaim to be the foremost among living mathematicians. This was the case, for instance, a few years ago as regards $\mathrm{H}$. Poincaré. As an earlier instance of this kind we may refer to the letter of Frederick the Great to Lagrange, in which he expressed the wish that the greatest king of Europe might have the greatest mathematician of Europe resident at his court.

The student who desires to form a somewhat independent judgment as regards the relative eminence of various living mathematicians has a difficult problem before him. As a first approximation he might consult the reviews of the writings of the various men under consideration, and the way these writings enter into the discussions of recent advances relating to the fields concerned. In this respect, the large mathematical encyclopedias should be especially useful in case the main publications of the men under consideration are not too 
[III.

recent. Various other works of reference in which recent advances are considered should be consulted. Among these may be mentioned Pascal's Repertorium der höheren Mathematik and the Jahrbuch über die Fortschritte der Mathematik.

Election to membership in bodies where the membership is kept very small furnishes another easily accessible indirect mode of judging the standing of eminent mathematicians. Some of the leading mathematical societies elect "Honorary Members," and these are usually chosen with great care. The London Mathematical Society, for example, had nineteen such members in I9I4. The Circolo Matematico di Palermo, which has a large international membership, elects some of its most noted members as non-resident members of its editorial committee, and thus secures a list of very distinguished mathematicians. Some of the leading academies choose their members with great care, and hence these elections imply relatively high standing at the time the elections were held. In America the National Academy of Sciences is well known as an institution of this type.

Among the numerous other elements which may be used to form an independent judgment of the relative standing of living mathematicians are the international medals and prizes. The well-known Nobel prizes, first awarded in I90I, are not given for mathematical work, being restricted to the encouragement of advances along the following five lines: physical science, chemistry, physiology or medicine, literary work of an idealistic nature, and peace movements. On the other hand, there are various other prizes, whose monetary value is usually 
less than a thousand dollars, which are awarded for important advances along certain lines specified in the announcements of these prizes. Among these prizes those offered by the Paris Academy of Sciences are perhaps best known, but a number of other prizes are offered annually. Details in regard to them are readily available in the notes of the various mathematical periodicals.

Professor E. C. Pickering of Harvard University published two brief articles in volumes 73 and 74 of the Popular Science Monthly, I908-09, under the title " Foreign Associates of National Academies," in which he considered the value of various scientific honors for the determination of relative scientific standing. He pointed out that election as foreign associate in an eminent scientific body was one of the surest signs of high scientific achievements, and he considered in some details the activities along this line, especially as far as they relate to American scientists, of the following seven very prominent national academies : *

\begin{tabular}{|c|c|c|}
\hline Country & NAME OF THE ACADEMY & $\begin{array}{l}\text { WHEN } \\
\text { FOUNDED }\end{array}$ \\
\hline 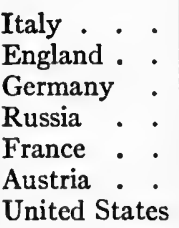 & $\begin{array}{l}\text { Royal Academy of the Lincei } \\
\text { Royal Society of London } \\
\text { Royal Prussian Academy of Sciences } \\
\text { Imperial Academy of Petrograd } \\
\text { Institute of France } \\
\text { Royal Academy of Sciences } \\
\text { National Academy of Sciences }\end{array}$ & $\begin{array}{l}\text { I603 } \\
\text { I645 } \\
\text { I } 700 \\
\text { I } 725 \\
1795 \\
1847 \\
\text { I } 863\end{array}$ \\
\hline
\end{tabular}

* With regard to American mathematicians in particular the reader may consult the article entitled "American Mathematics," Popular Science Monlhly, Vol. 79 (I9II), p. 459. 
The lists of members of these academies and other similar bodies can be readily consulted, and hence it is an easy matter to obtain some ideas in reference to the standing of some of the leading mathematicians of the world. It is, however, very important to distinguish between such bodies and those which elect almost every one who is supposed to be willing to accept a membership. Moreover, the number of members of the most eminent societies is so limited that the lists of their members can be used only to determine the standing of a very few men. Elections to prominent official positions in the mathematical societies are also helpful along this line.

While the question of the relative mathematical standing of various men is exceedingly difficult, it is nevertheless desirable that efforts should be made towards securing as close an approximation as possible to a correct solution. If this is not done, many of those who are intrusted with the filling of numerous important positions, or with conferring high honors, will have to act with insufficient light. The harm which naturally results from serious errors along this line is very far-reaching, as it tends to perpetuate itself. Too many of our good mathematical positions have been filled by men who were not so well qualified as other men who were available at the time these positions were filled. ${ }^{*}$ Hence the independent study of the work of various living mathematicians tends to enable a man to become a more useful citizen and it also enables him to determine the type of work which is most likely to lead to success.

* Cf. E. J. Wilczynski, Bulletin of the American Mathematical Society, Vol. 15 (1909), p. 492. 
In recent years there have appeared in various countries a large number of books under the general title Who is Who, which aim to give short biographical sketches of those in whom the public is mostly interested. While unusually high scientific attainments attract public attention, yet these are not apt to appeal so strongly to the public as some other attainments, such as prominent positions or popular publications. Hence the books of the Who is Who type are of little value in determining mathematical standing.

A much more useful type of work along this line is represented by the publication entitled American Men of Science, which was prepared with unusual care, and aimed to distinguish by means of asterisks those who belonged at the time when the information was collected to the first thousand American scientists.

Mathematicians differ very widely as regards methods of work. A statistical study of these methods based upon a questionnaire was published by $\mathrm{H}$. Fehr under the title Enquête sur la méthode de travail des mathématiciens, Paris, r9r2. Unfortunately comparatively few of the leading mathematicians sent in answers to this questionnaire, but, notwithstanding this limitation, the answers received are of considerable interest, and they exhibit very clearly the fact that unusual mathematical ability may be attended by a great variety of other gifts, and may exhibit itself for the first time at various ages. There have been comparatively few really great mathematicians of whom it could be truthfully said that they were only mathematicians. On the contrary, they were generally great men first, and their mathematical great- 
ness was merely a particular form of expression of this fact.

The main reason for a study of the living mathematicians is, however, not to be found in a desire to talk about them, but it is to become more thoroughly acquainted with the best methods of work and with the most recent important advances. The biographies of successful men in our own line of work are always interesting and useful, but the study of such biographies should begin with the present or the recent past. A study of the life and work of Poincare is more valuable to the modern student of mathematics than a study of the disputed points about the life and work of Pythagoras, even if the details of the work of the former might have to be omitted on account of their difficulties.

The investigators in pure mathematics constitute now a small army of several thousand men and a few women.* The question naturally arises, What is this little army trying to accomplish? A direct answer is that it is trying to find and to construct paths and roads of thought which connect with or belong to a network of thought roads commonly known as mathematics. Some are engaged in constructing trails through what appears to be an almost impassable region, while others are widening and smoothing roads which have been traveled for cen-

* Between 5 and ro per cent of the members of the American Mathematical Society are women, but the per cent of women in the leading foreign mathematical societies is much smaller. Less than 2 per cent of the national mathematical societies of France, Germany, Italy, and Spain are women, according to recent lists of members. The per cent of important mathematical contributions by women does not appear to be larger, as a rule, than that of their representation in the leading societies. 
turies. There are others who are engaged in driving piles in the hope of securing a solid foundation for roads through regions where quicksand and mire have combined to obstruct progress. This army has no generals and no minor officers, but hearty coöperation prevails, and the frequent conquests constitute the inspiration for continuous arduous efforts.

23. Mathematics as an educational subject. - Probably no people ever exhibited a greater faith in the educational value of mathematics than that exhibited by the ancient Greeks. Among the evidences of this faith are the number mysticisms of the Pythagorean School, and the fact that many of the ancient Greeks considered a mathematical training as an essential prerequisite to enter upon the study of philosophy. In fact, Plato, who started a noted school of philosophy, announced this view in the following forceful words: "Let no one ignorant of geometry come under my roof."

In recent times there has developed a rapidly growing interest in the natural sciences. The old method of the Greeks to look inward for knowledge has been largely replaced by the method of looking outward and depending upon patient experimentation for the foundation of knowledge. At the same time mathematics has been largely transformed from a non-empirical science to a semi-experimental science. The works of Lobačevsk $\ddot{y}$, Weierstrass, Cantor, and others have cast doubt on the older intuitional methods and have tended towards the modern postulational methods.*

* Cf. K. Ott, Abhandlungen über den mathematischen Unterricht in Deutschland, Vol. 4, Part 2, p. 1. 
Mathematics has thus kept in touch with the great scientific activity of the age. Just as it rendered most useful service to the ancient Greeks in their philosophical speculations by exhibiting such fundamental non-empirical facts as the existence of irrational numbers, so it now stands at the side of the natural scientist, having proved itself so useful that there is a tendency in some of these sciences to meet the student with the ancient Platonic advice: Let no one ignorant of mathematics come under my roof. These instances of the adaptability of mathematics for purposes of rendering most fundamental services in the study of other subjects tend to explain the persistence of mathematics in the educational systems of the leading countries.

Two fundamental reasons for the continuance of mathematics in the educational systems of the world are furnished by the great simplicity and the great usefulness of this subject. The simplicity of the elements of mathematics may explain the fact that, according to many ancient Babylonian tablets, a somewhat extensive knowledge of properties of numbers was acquired by the pupils in the Babylonian schools several thousand years before our era. On the other hand, the great usefulness of mathematics serves to explain the persistence of this subject in the modern educational systems. Mathematics provides a kind of intellectual shorthand, and hence becomes more and more necessary as the number of facts to be dealt with increases.

The scientific world has devoted much attention to the collection and the classification of facts relative to material things and has thereby secured already an immensely 
valuable store of knowledge. As the number of these facts increases, stronger and stronger means of intellectual penetration are needed. In many cases mathematics has already provided such means to a large extent; and, judging from the past, one may reasonably expect that the demand for such means will continue to increase as long as scientific knowledge continues to grow. Hence there seems to be no good reason to suppose that the usefulness of mathematics to the natural sciences will ever wane. On the contrary, this usefulness may reasonably be expected to increase with the growth of knowledge.

The preceding remarks aim mainly to explain the persistence of mathematics in the systems of elementary and secondary education. There is perhaps a stronger reason than any of those mentioned why mathematics may be expected to remain in the systems of higher education, viz., the intrinsic beauty of its results. This beauty cannot be understood until the student has made some progress in this field. On some students it dawns earlier than on others; but it is certain that it will present itself to all who enter sufficiently into this field, and, after it has once dawned on one, it will continue to grow with the increase of mathematical knowledge.

Investigation in mathematics becomes enchanting in view of the fact that a discovery usually throws new light on a multitude of other facts and hence it means not one discovery but a hundred discoveries. In view of the close relations between the various mathematical developments and the mutual dependence of various theorems, the student of advanced mathematics usually finds this field sufficiently attractive in itself, without re- 
gard to applications. Moreover, as the explored regions of mathematics increase the frontier between the known and the unknown increases and offers more abundant room for investigations. Hence the future of mathematics in systems of higher education seems also assured.

It should not be inferred that mathematics has always held its proper position in systems of education. Even in the early days of our oldest American university mathematics was regarded as a finishing subject instead of a fundamental subject to be used in other fields. In fact, according to Quincy's History of Harvard University,* the study of mathematics was begun at Harvard College in the senior year even as late as 1726 , ninety years after the founding of this institution. At this time the students of Harvard College began arithmetic and geometry during their final year, after they had completed their study of natural philosophy and physics. (Cf. § I.)

In the early European universities the study of mathematics was frequently entirely neglected, but it must be remembered that conditions were very different then. When one reads that as late as 1366 the students of Paris University were expressly forbidden by a statute of Pope Urban V to use benches or seats in the lecture rooms, but were expected to sit or to lie on straw scattered on the floor, one may get some idea of how primitive the conditions were during the early period of European universities. $\dagger$ If university students were not allowed the luxury of benches to sit on while listening to the lectures, one cannot believe that they had much in the way of other facilities.

* Vol. I, p. 441 .

$\dagger$ Cf. Ball, $\boldsymbol{A}$ History of the Study of Mathematics at Cambridge, 1889, p. 143. 


\section{CHAPTER IV}

Fundamental Developments in Arithmetic

24. Existence of an infinite number of prime numbers. - If all mathematicians were asked to vote on the most influential mathematical treatise that has ever been written it is likely that Euclid's Elements, written about 300 B.c., would receive the largest number of the votes.* Three of the thirteen books included in these Elements are devoted to the theory of numbers. In particular, these books contain a proof of the theorem that the number of prime numbers is infinite. This proof is so elementary that it can be given in a few lines, as follows :

If the number of prime numbers were finite there would be some largest prime number $p$. The product $P$ obtained by multiplying this prime by all the smaller primes may be expressed as follows :

$$
2 \cdot 3 \cdot 5 \cdot 7 \cdot \text { II } \cdot \ldots \cdot p=P,
$$

where the lower dots stand for the omitted prime numbers. Since $P+\mathrm{I}$ is not divisible by any one of these prime numbers (giving the remainder I when divided by each of them) it results that $P+I$ is either a prime number or it is divisible by a prime number which exceeds $p$. In either case there must be a prime number

* English translation with notes by T. L. Heath, 3 vols., Cambridge, 1908 . 
which exceeds $p$, and hence the number of prime numbers is infinile.

This theorem, proved by Euclid in the given manner, was proved differently about 2000 years later by Euler, who based his proof on the divergence of a harmonic series. It has been extended along various lines. One of the most important extensions is due to the German mathematician P. G. L. Dirichlet (I805-59), who proved that every arithmetic progression in which the first term and the common difference are relatively prime natural numbers includes an infinite number of prime numbers. That is, if $a$ and $d$ represent any two relatively prime natural numbers, then the form

$$
a+n d
$$

represents an infinite number of prime numbers if $n$ represents successively the separate natural numbers. The truth of this theorem had been suspected by earlier mathematicians, and at least one of them, A. M. Legendre (I752-I833), published a supposed proof of it, but this proof was later found to be incomplete.

It is of interest to note that no solution has yet been found for many standing problems relating to prime numbers. Among these standing problems the following two are of considerable historic interest.* Every even composite number is the sum of two prime numbers, and there is an infinite number of prime numbers which have the property that each of them differs from some

* A considerable number of such problems were treated in an admirable manner by Professor E. Landua: Proceedings of the Fifth International Congress of Mathematicians. Vol. I (I912), p. 93. 
other prime number by only two units. The former of these two theorems is commonly known as Goldbach's theorem, as it is found in a letter dated June 7, I742, written by C. Goldbach to the great Swiss mathematician L. Euler. If the number one is to be regarded as a prime number, as is sometimes done, the adjective composite should be omitted in the given statement of this theorem. The statements of many other theorems relating to the theory of numbers are very easily understood but are very difficult either to prove or to disprove, and this feature constitutes one of the charms of this subject.

25. Sieve of Eratosthenes. - The given proof by Euclid of the fact that there is an infinite number of prime numbers dispelled forever the prospect of being able to find all the prime numbers. On the other hand, it tended to give more dignity to investigations relating to the determination of the number of primes in given intervals. Investigations along this line were started shortly after the appearance of Euclid's Elements by a Greek mathematician, whose name is associated with a very elementary method for finding all the prime numbers which are less than a given number $n$. This method is commonly known as the Sieve of Eratosthenes, and is embodied in the following rule:

Write down in order the natural odd numbers beginning with 3 , as follows :

$$
3,5,7,9, \text { II, I3 } 15, \text { I } 7, \text { I9, } 2 \text { I, } \cdots .
$$

Cancel every third number after 3 , then cancel every fifth number after 5 , etc. In general, starting successively with the smallest uncancelled number $p$ which 
has not been used in this way, cancel every $p$ th number after the number $p$. The uncancelled numbers, at least up to $(p+2)^{2}$, in the given series will be prime numbers, and by adding the number 2 to this set of uncancelled numbers we obtain all the prime numbers which are less than $(p+2)^{2}$.

The latter part of this rule is based upon the evident fact that in order to determine whether the number $n$ is a prime or not, it is only necessary to determine whether $n$ is divisible by a prime number which does not exceed $\sqrt{n}$. This fact was not stated by Eratosthenes (276-I94 B.C.); it was, however, explicitly stated in the noted Liber Abaci (1228) by Leonardo of Pisa, which we meet frequently in a study of the history of medieval mathematics. In fact, this work is one of the most prominent books in the history of mathematics.

It might be observed that the process of finding prime numbers by the method called Sieve of Eratosthenes is too elementary to deserve special attention. Doubtless this method has been re-discovered by many schoolboys since the epoch of the noted "First Alexandrian School" to which Eratosthenes belonged. The importance of mathematical discoveries depends mainly upon the usefulness of these discoveries in the further development of mathematics, and very elementary matters of great utility in this development or of permanent popular interest have an unusual charm for the historian. From this standpoint the Sieve of Eratosthenes is a significant fact in the history of mathematics.

Among the many important results relating to the number of primes in a given interval we shall note here a 
comparatively recent one, which can be stated in a very simple form. This result was discovered more than two thousand years after Eratosthenes had developed his sieve process, and is due to a Russian mathematician, P. L. Cebysëv (182I-94). It may be stated as follows : If $n$ is any natural number greater than 3 there is always at least one prime number between $n$ (exclusive) and $2 n-2$ (inclusive). This useful theorem is known as Bertrand's postulate, since the noted French mathematician J.' L. F. Bertrand (1822-I900) had previously assumed it for the purpose of proving a theorem relating to the theory of substitution groups. The work of Čebyšëv deserves mention also because it may be said to constitute the beginning of a new period of activity in investigations relating to the number of primes in a given interval, even if his methods seem to represent the end of a period. He was the first to find definite results in the general theory of prime numbers.

26. Irrational quantities and irrational numbers. $-\mathbf{A}$ number which can be represented in the form $m / n$, where $m$ and $n$ are integers, is said to be a rational number, or a commensurable number. All real numbers which cannot be represented in this form are said to be irrational numbers, or incommensurable numbers. Hence the irrational numbers are defined negatively as real numbers which are not rational. The rational numbers are composed of the positive and negative integers and quotients of such integers. In fact, the latter include the former. Positive integers and positive fractions are found among some very ancient mathematical records, and it seems reasonable to assume that they are of prehistoric origin. 
On the other hand, the negative and the irrational numbers seem to have come into use after there existed a considerable mathematical literature. The ancient Greeks were very much interested in irrational quantities,* and several types of irrational quantities, which can be obtained by certain geometric constructions, were studied in the tenth book of Euclid's Elements. This book contains also a very simple proof of the fact that the square root of 2 cannot be a rational number, the proof being practically as follows: If $\sqrt{2}=\alpha / \beta$, where $\alpha$ and $\beta$ are positive integers, then $\alpha^{2}=2 \beta^{2}$, and hence $\alpha^{2}$ and $\alpha$ must be even numbers. Since it may be assumed that $\alpha$ and $\beta$ are relatively prime, it results that $\beta$ is odd. Let $\alpha=2 \gamma$ and hence $\alpha^{2}=4 \gamma^{2}$. The equation $\alpha^{2}={ }_{2} \beta^{2}$ implies the equation $4 \gamma^{2}=2 \beta^{2}$, or $2 \gamma^{2}=\beta^{2}$. Hence $\beta$ must be even, which is contrary to the hypothesis. We were therefore led to a contradiction by assuming that $\sqrt{2}$ is a rational number. That is, if this square root is a number, it must be an irrational number.

This proof is of considerable historic interest since it seems to explain a statement by Aristotle ( $384-322$ B.c.) who often referred to the irrationality of the diagonal of a square whose side is unity, and stated in one place that the reason for this irrationality was that otherwise an even and an odd would have to be equal to each other. As the length of this diagonal is equal to $\sqrt{2}$, the above proof by Euclid, which was also based upon the ratio

* It is often stated that the conception of irrationals is native to India, but this is not generally regarded as proven. Cf. G. Eneström, Bibliotheca Mathematica, Vol. 12 (1912), p. 184 . 
between the diagonal and the side of a unit square, seems to explain the given statement by Aristotle.

The fact that the irrationality of the $\sqrt{2}$ was known long before Euclid's Elements were written seems also to be implied in a statement by Plato $(429-348$ B.C.) to the effect that his teacher in mathematics, the Pythagorean Theodorus of Cyrene, had proved the irrationality of the square root of 3,5 , and of other numbers up to 17. As no reference is made here to the irrationality of the square root of 2 , it is natural to infer that its irrationality had been established previously and was well known at the time of Theodorus of Cyrene.

It should be noted that Euclid employed the terms

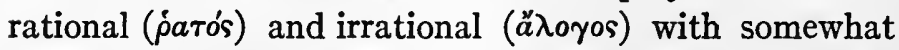
different meanings from those now assigned to them as defined at the beginning of this section. To explain the meaning assigned to these terms by Euclid, let $a$ and $b$ be rational numbers in the modern sense, and suppose that $b$ is not a perfect square. According to Euclid's definition the $\sqrt{b}$ is rational but $a+\sqrt{b}$ is irrational. That is, while the side of a square whose area is commensurable is incommensurable in length, Euclid says that this side is commensurable in power and considers it as rational. We shall however continue to use the terms rational and irrational with their modern meaning even when we speak about the work of Euclid.

Special emphasis should be placed on the fact that the ancient Greek writers made a sharp distinction between what we now call irrational numbers and irrational quantities. Although they were so deeply interested in the irrational quantities they did not employ irrational 
numbers, and thus they made a sharp distinction between the study of numbers and that of quantities or magnitudes. In their theory of proportion between quantities (commensurable and incommensurable) as developed in the fifth book of Euclid's Elements, they laid a rigorous foundation for a theory of irrational numbers, but they did not deduce such a theory, and do not seem to have regarded it as desirable. In fact, they seem to have regarded it undesirable to secure for arithmetic that universal character which they developed in their study of geometric magnitudes. This ancient Greek view impeded mathematical progress during two thousand years until Descartes exhibited the deep unity of these two fields.

In the tenth book of Euclid's Elements it is stated explicitly that incommensurable magnitudes do not have the same relation to each other as numbers. Just when it was first proved that incommensurable magnitudes exist is not known. The ancients attributed the discovery of these magnitudes to Pythagoras (580-50I B.c.) and many modern historians have supported this view.

On the other hand, H. Wieleitner says that it appears now quite probable that this discovery was not made until towards the end of the fifth century before Christ.* The fact of greatest interest in this connection is that the ancient Greeks fully realized the great importance of this discovery, and that it served to emphasize the great importance of mathematical studies in the development

* H. Wieleitner, Der Begriff der Zahl in seiner logischen und historischen Entwicklung, 1911, p. 44 . 
of accurate thinking. The introduction of what is commonly called the irrational quantities was a great step towards introducing more rationality into mathematical work.

27. Significance of irrational numbers and their general introduction. - In order to understand the history of the introduction of irrational numbers it is desirable to have a clear view as regards their nature and significance. Assuming that all real numbers can be represented by points on a straight line in the usual way, the integers being represented as follows,

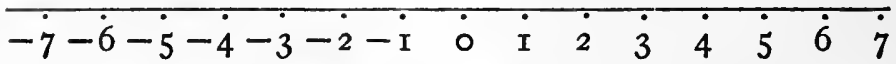

it is clear that between any two different rational numbers there must lie another, and therefore an infinite number of other rational numbers. In other words, no matter how short we make any real segment of this line, its points will always represent an infinite number of rational numbers. The existence of points on this line which do not correspond to rational numbers is therefore not directly evident. This existence becomes evident, however, if we lay off a line segment equal to the diaggonal of a square whose side is unity, starting from the origin.

The existence of irrational numbers can also be readily proved in another way. If we reduce any fraction whose denominator is not of the form $2^{\alpha} \cdot 5^{\beta}$ to a decimal fraction it is well known, and easily proved, that the decimal will not terminate. For instance,

$$
\frac{3}{7}=.42857 \text { 1 } 4285714285 \cdots \text {. }
$$


It should be observed that this decimal is periodic; that is, there is a set of numbers which are repeated in the same order. If we had started with any other rational fraction whose denominator is not of the form $2^{a} \cdot 5^{\beta}$ we should also have arrived at a periodic decimal. This results directly from the fact that in reducing such a fraction to a decimal the remainders are always less than the denominator, and, as no such remainder can be zero, the number of distinct remainders cannot exceed this denominator diminished by unity. Hence it results that the number of figures in the period of a decimal fraction which is equal to a rational number of the form $m / n$ cannot exceed $n-\mathrm{I}$.

For our present purpose it is not necessary to enter upon any of the many interesting considerations in regard to the periods in the decimal fractions which are equal to an ordinary rational fraction. It is, however, important to observe that every decimal fraction which is periodic is equal to an ordinary rational fraction, so that the periodicity of a non-terminating decimal fraction is a necessary and sufficient condition that the decimal fraction is equal to an ordinary rational fraction. This follows directly from the theory of infinite geometric series.

To prove the existence of irrational numbers it remains therefore only to show that it is possible to write nonterminating decimals which are not periodic and that these are actually numbers. The former of these two steps is easily accomphshed. For instance, we may write a decimal involving the symbols $I$ and 2 such 
that after each successive 2 the $I$ is repeated once oftener than before, as follows:

It is evident that such a decimal fraction is not periodic. Moreover, it may be supposed to represent a number since such decimals clearly obey the ordinary laws of arithmetic when they are combined according to the fundamental operations, and they represent real values between rational numbers.

The given illustration may also serve to clarify the statement that when one extracts the square root of 2 , for instance, to a large number of decimals, one never arrives at a point from which the figures repeat themselves in a regular order. Hence it is not possible to find an arbitrary number of additional figures directly by repeating those which have already been found. In the given illustration a definite law was assumed for the sake of establishing clearly that such a decimal need not be periodic, but this non-periodicity is clearly not dependent upon the existence of such a law. In fact, any possible lawlessness in the succession of these figures would also establish non-periodicity.

The complete introduction of irrational numbers was a very slow process. The assumption of a $(\mathrm{r}, \mathrm{I})$ correspondence between the points of a line and the real numbers, which seems to us so natural but is contrary to the Greek view, combined with the proof that incommensurable line segments exist, made it essential to use irrational numbers. Hence the development of analytic geometry naturally led to a general use of irrational 
[Iv.

numbers, and this development removed forever the distinction between the continuity of real numbers and that of a geometric line, which the Greek influence had so long and so harmfully maintained. The general concept of the irrational numbers did not become popular among mathematicians before the nineteenth century, and a rigorous presentation of the theory of irrational numbers appeared for the first time in about 1870 in the works of C. Méray, K. Weierstrass, G. Cantor, R. Dedekind, and others. The slowness with which a rigorous treatment of irrational numbers came into general use is an interesting fact in the history of mathematics, and it throws light on the question when the young student may reasonably be expected to use such numbers intelligently.

Irrational numbers are divided into two large classes, viz., the algebraic irrational numbers and the transcendental numbers. We have observed that the early Greeks knew that the arithmetic root of the equation $x^{2}-2=0$ cannot be a rational number. This root is said to be an algebraic irrational number since it satisfies an algebraic equation with rational coefficients. The question arises whether every irrational number is necessarily a root of some algebraic equation with rational coefficients.

This question is one of those which relate to very elementary concepts in mathematics but which are difficult to answer. In fact, no satisfactory answer to the given question was found until about the middle of the nineteenth century. In $\mathrm{r} 844 \mathrm{~J}$. Liouville communicated to the Paris Academy of Sciences a paper in which 
he proved the existence of transcendental numbers, and thus he broadened in a remarkable manner the human concept of the nature of real numbers. The three types of real numbers - rational, algebraic irrational, and transcendental - include all the real numbers.

The fundamental place of the number concept in mathematics makes it necessary to understand the difference between these three types of numbers in order to comprehend some of the fundamental elements in the history of mathematics. As an instance of an equation which has a transcendental number for a root the following may be given:

$$
x^{i \pi}+\mathrm{I}=0
$$

where $i=\sqrt{-\mathrm{I}}$ and $\pi$ represents the ratio between the circumference and the diameter of a circle. L. Euler proved that this very interesting equation has the transcendental number $e$ for one of its roots. F. Klein states that the formula $e^{i \pi}+\mathrm{r}=0$ " is certainly one of the most remarkable in all mathematics," - Famous Problems in Elementary Geometry, translated by Beman and Smith, I897, p. 59 .

28. Extraction of the square root. - The first four fundamental operations of arithmetic - addition, subtraction, multiplication, and division - are so elementary that it is natural to assume that they are of prehistoric origin. Even the fifth fundamental operation - raising to powers - may reasonably be classed with the prehistoric operations. In fact, the two well-known Babylonian Tablets of Senkereh, which were found in 1854 near Senkereh on the Euphrates and which are supposed to 
have been written about 2000 B.c., contain tables of squares and cubes. This table of squares gives the squares of the successive natural numbers from I to 60 , while the table of cubes is complete for the successive natural numbers from $\mathrm{x}$ to 32 . The tablet containing the latter table is incomplete, and it is generally assumed that the table of cubes was also complete to the number 60 .

Closely related to tables of powers are tables of roots. In fact, the same table may serve both purposes, and it is not known whether the tables of the noted Babylonian Tablets were intended to serve as square and cube root tables, or as power tables. The difference between raising a number to its $n$th power, $n$ being a positive integer, and extracting the $n$th root of a number which is an exact $n$th power, is not very wide. On the other hand, the general question of root extraction as a sixth operation in arithmetic is a very important step beyond the other five fundamental arithmetical operations.

In fact, the first five operations are known as the fundamental rational operations of arithmetic, since they lead only to rational numbers in case we start with rational numbers, and exclude the meaningless operation of dividing by zero. On the other hand, root extraction is an irrational operation, since it generally leads to irrational numbers when performed on rational numbers. It was observed in the two preceding sections that the introduction of the irrational numbers was a very slow process which was completed only in modern times. This should, however, not be regarded as evidence tending to show that approximate root extraction was 
begun only recently. In fact, this is not the case, as we proceed to show.

We have already referred to the fact that some mathematical developments are essential for materialistic reasons even in early stages of civilization. It should, however, be strongly emphasized that the development of mathematics is not entirely due to materialistic incentives. As an instance of other strong incentives we may refer to the religious practices of the ancient Hindus. It was assumed by these people that their sacred offering would not be accepted by their gods unless the altars were in exactly the correct form and were placed in exact positions as regards the true east and west line. Hence their books dealing with religious rites were accompanied by short mathematical treatises.

The dates of these treatises have not been fully established but it is supposed that they comprise rules which were practiced at least as early as 800 B.c. Among these rules we find the following approximate value for the square root of 2 :

$$
\sqrt{2}=I+\frac{I}{3}+\frac{I}{3 \cdot 4}-\frac{I}{3 \cdot 4 \cdot 34} .
$$

If this value is expressed in the decimal form, it is equal to $1.414215+$, while the exact value of the $\sqrt{2}$ is $\mathrm{I} 4 \mathrm{II}_{4} \mathrm{II} 3+$. Hence the Hindu approximation is very close to the truth, and it stands in great contrast with some of the very inaccurate approximations used by some other ancients. As an instance of such inaccuracy we need only refer to the fact that the ancient Jews, as well as some other nations, assumed that the value of $\pi$ is 3 . 
Many instances of square root extraction appear also on ancient Egyptian papyri, even if the noted ancient Egyptian mathematical work entitled Prescript to arrive at a knowledge of all dark things, and written by an Egyptian scribe Ahmes before I700 B.C., does not contain any problems which were solved by means of extracting the square root. Among the papyri in the Berlin Museum there is, for instance, one which contains a problem equivalent to the following two simultaneous equations :

$$
x^{2}+y^{2}=100, y=\frac{3}{4} x
$$

In the solution of this problem there occur the following two equations :

$$
\sqrt{\frac{25}{16}}=\frac{5}{4}, \sqrt{100}=10 \text {. }
$$

29. Fundamental operations of arithmetic. - Various operations have been included under the term fundamental operations of arithmetic. The Hindus had six fundamental operations, viz., addition, subtraction, multiplication, division, raising to powers, and extracting roots. This classification has been widely adopted. On the other hand, some writers have included numeration under the term fundamental operations, and some of the older writers regarded doubling and halving as special operations instead of including these operations under the general terms multiplication and division respectively.

Since the operations of subtracting $n$ and adding $-n$ are equivalent, the general use of negative numbers has practically fused the two operations of addition and sub- 
traction into one. Similarly, dividing by $n$ is equivalent to multiplying by $\mathrm{I} / n$, and extracting the $n$th root is equivalent to raising to the $\mathrm{I} / n$th power. Hence the operation of division has been fused with that of multiplication, and the operation of extracting roots has been fused with that of raising to a power, through the general use of fractions. Notwithstanding these facts, there are advantages in preserving the six fundamental operations.

Each of the two operations, addition and subtraction, is said to be the inverse of the other. Similarly multiplication and division, and raising to powers and extracting roots, are two pairs of inverse operations. Sometimes the operations of addition, multiplication, and raising to powers are called the three direct fundamental operations while those of subtraction, division, and extracting roots are called the three indirect or inverse operations. The names of these operations are sometimes used with a more general meaning. In particular, the term multiplication is used in group theory to denote the combining or composing of two general operations.

It may appear strange to us who are so familiar with a multiplication table that the operations of doubling and halving should ever have occupied the distinction of special operations. When it is observed, however, that a complete mastery of a multiplication table up to 9 times 9 demands considerable intellectual application, and that such a mastery has become universal in civilized countries only in comparatively recent years, it becomes clear why methods which do not presuppose such a mastery were in demand in early times. 
The examples in the ancient Egyptian work by Ahmes, for instance, seem to imply that no multiplication table beyond doubling was presupposed by its author. To multiply a number by 13 he doubled, redoubled, and redoubled again. The sum of the last number, the number obtained by redoubling, and the original number gave the required $I 3$ times this number. Since any positive integer which is not a power of 2 is the sum of different powers of 2, including the zero power when the integer is odd, it is clear that we can multiply a given number by any positive integer by means of successive doubling and adding the required results.

Paciuolo states in his famous Summa de arithmetica, geometria, proportioni e proportionalita, printed at Venice in 1494 , that the earlier writers included doubling and halving among the operations, but that these are not essentially separate operations since they are included in multiplication and division. Notwithstanding the great popularity of this work, some of the later writers on arithmetic continued to regard doubling and halving as separate operations. While Paciuolo wisely combined doubling and halving with the more general operations, it is interesting to observe that he taught numerous methods for performing the same operation. For instance, he taught eight methods of multiplication.

As an illustration of his first method Paciuolo gave the following example: *

* In these illustrations we have followed Cantor's Vorlesungen über Geschichte der Mathematik, Vol. 2, r9r3, p. 3 rr. 


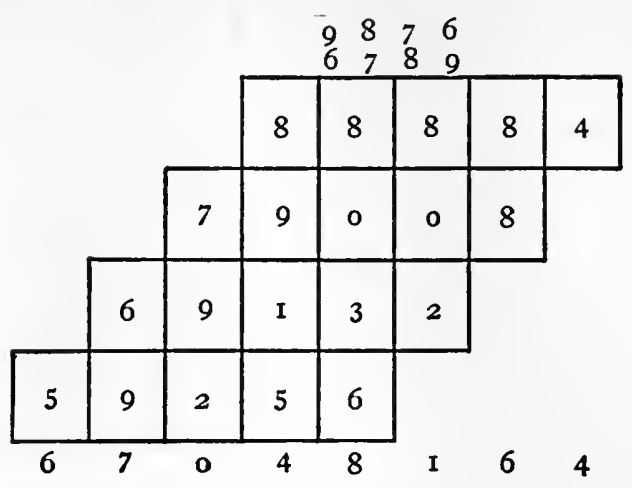

The second method is illustrated by the following example :

$$
\begin{array}{r}
9876 \\
6789 \\
\hline 61101000 \\
5431200 \\
475230 \\
\quad 40734 \\
\hline 67048164
\end{array}
$$

The third method consists merely of multiplying with 2 figures at the same time when these figures are small as II, I2, or I3. The fourth method is illustrated by the following example:

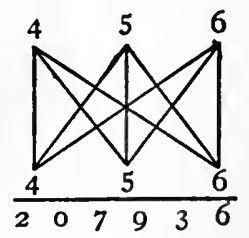

Paciuolo states that this method required somewhat more imagination and brain than the others, "vole alquanto 
piu fantasia e cervello che alcune degli altri," as is evident from the fact that the units, tens, hundreds, etc., are found separately and combined mentally. The fifth method is illustrated by the following example:

\begin{tabular}{|c|c|c|c|c|}
\hline I & 0 & 8 & 6 & 4 \\
\hline I & 6 & 2 & 9 & 6 \\
\hline 2 & I & 7 & 2 & 8 \\
\hline 2 & 7 & I & 6 & 0 \\
\hline
\end{tabular}

The sixth method differs from the preceding by drawing the diagonals of the rectangles, while the seventh method resolves the multiplier into factors. For instance, instead of multiplying by 24 he multiplies first by 4 and then he multiplies this product by 6 . Finally, the eighth method employs the separation of the multiplier into addends. To multiply by 24 according to this method he observes that $24=4+6+5+9$, and then he multiplies the given number by each of these addends, and adds the four products thus obtained.

It may be observed that the separate consideration of so many special methods of multiplication may be instructive for the teacher but it is apt to confuse the beginner. Moreover, some of these methods appear to be trivial modifications of others, and it would not be diff- 
cult to increase the number of these methods by further modifications. One advantage in studying various methods to perform the same operation is that such a study is apt to lead to a deeper insight into the real significance of the operation, and the advanced student can profitably consider the advantages and disadvantages of different methods for performing the same operation.

30. Systems of notation. - Our ordinary system of notation to the base io is so convenient and seems so natural that it appears somewhat surprising to find that it was generally introduced into Europe as late as the latter part of the Middle Ages. As this system is so much simpler than the Roman system, it is very interesting to note that the latter system gave way slowly and stubbornly even after the better system was known. In fact, the present system was not generally adopted in Europe before the sixteenth century, although it had been used several centuries earlier in the noted Liber Abaci of Leonardo of Pisa.

On further consideration we may be surprised to find so many other systems of notation in partial use. In measuring time, or angles, we say 60 seconds make a minute and 60 minutes make a degree. This furnishes evidence of a system of notation to the base 60 ; that is, of a sexagesimal system. The common terms dozen, gross, and score seem to point to remnants of other systems. These examples remind us of older civilizations, which gave way to better things but left behind some remnants which persist because we are not entirely practical. We often enjoy variety even at the expense of simplicity. This is illustrated by the fact that the 
Roman system of notation is still used to a considerable extent for various purposes.

Of the various systems, besides our common decimal system, the sexagesimal system may perhaps be the most interesting, in view of its very large base, and its extensive present use. Various views have been expressed as regards the reasons which led to the choice of this base. On this point there is not yet general agreement. Some years ago the view was generally held that this base was connected with a year of 360 days, but this assumption has now been abandoned by many.

In regard to the source from which the sexagesimal system spread over the entire world there seems to be no difference of opinion. The ancient Babylonians used this system in their astronomical work, and from there it spread with the introduction of Babylonian astronomical work into various countries. In a certain sense we are still paying respect to this ancient Babylonian civilization whenever we express time or angular measurement. It should however be noted that the persistence of this notation so long after our decimal notation has been generally adopted is evidence of its advantages. After the French revolution, efforts were made to use the decimal system of measuring angles throughout France, but notwithstanding this fact the sexagesimal system still persists even in this country of rapid changes.

The Tablets of Senkereh to which we referred in $\S$ I4 are also of great interest in connection with the question of systems of notation. The numbers on these tablets are written in the sexagesimal system, and they exhibit, to some extent, what is generally called positional arithmetic. 
That is, in the table of squares the numbers $1,4,9,16$, $25,36,49$ appear in the regular decimal form but instead of 64 we find I 4 , instead of $8 \mathrm{r}$ we find I $2 \mathrm{I}$, etc. It is important to observe that the symbol for the higher units preceded those for lower units. This is an illustration of a law, observed by Hermann Hankel, that in additive combinations of numbers the large units precede the smaller with only few exceptions. In our own system of numeration the smaller addends precede the larger from eleven to nineteen. For higher numbers the larger precede the smaller, as in twenty-five. It is interesting to compare the numerations in different languages as regards this custom.

Somewhat later than the date of the given tables the Babylonians possessed not only the positional system for positive powers of 60 but also for negative powers. In astronomical writings which appeared during the three centuries preceding our era we find such numbers as

$$
\frac{2}{60}+\frac{17}{60^{2}}+\frac{4}{60^{3}}+\frac{48}{60^{4}}+\frac{63}{60^{5}}+\frac{20}{60^{6}} \text {. }
$$

The denominators are, however, not expressed, but only the numerators are written in order. About the same time we find numbers of the form

$$
\text { IO } 4 \text { II } 32
$$

where it can be determined from the context that ro represents units, 4 represents $\frac{4}{60}$, while the larger space between 4 and II indicates that the denominator $60^{2}$ is missing. Hence the given number is equal to

$$
10+\frac{4}{60}+\frac{11}{60^{3}}+\frac{32}{60^{4}} \text {. }
$$


The missing of the units of a certain order was sometimes also denoted by the symbol <.*

Whether this symbol should be regarded as zero depends upon our definition of zero. If the symbol o merely indicates that a unit of a certain order is missing, it is not a number but merely represents the absence of a number. On the other hand, the $o$ as a number is a much more advanced concept. A difficult question in connection with the history of zero is to decide when it was first used as a number. It is known, for instance, that the Greek astronomers during the second century B.c. used o, the Greek omicron, to indicate the fact that a unit of a certain order was missing in their sexagesimal representation of numbers.

The most interesting fact about systems of notation has not yet been mentioned. It is the existence of special number symbols, dating back to the dawn of history. In fact, we do not know when such special symbols were first used, and their existence is so much the more striking since the development of other sciences was not aided by a special shorthand invented in such early times.

It is difficult to convey with sufficient force the great importance of the special symbols for numbers. Having been used to them from childhood, we seldom stop to consider how hard it would be to get along without them. They represent the first big step towards the thoughteconomy upon which most of the intellectual progress depends.

Numerous efforts have been made to exhibit the

* Cantor, Vorlesungen über Geschichte der Mathematik, third edition, Vol. 2 (1907), p. 31. 
advantages of systems of numeration and notation based on numbers other thanıo, and a considerable literature has been developed along this line. It is interesting to note that the first article in the Bulletin of the New York Mathematical Society is devoted to a consideration of "Octonary Numeration" by W. W. Johnson. The first volume of the noted German mathematical journal, commonly known as $\mathrm{Crelle}$, contains also an article along this line under the title "Ueber die Vergleichung der Verschiedenen Numerations-Systeme" by J. P. W. Stein. A consideration of the advantages of various systems of notation is generally interesting to students and leads to a better understanding of the common system.

31. The greater Fermat theorem. - According to the greater Fermat theorem, or the last Fermat theorem, the equation

$$
x^{n}+y^{n}=z^{n},
$$

where the exponent $n$ is a positive integer greater than 2, cannot be satisfied by substituting for $x, y, z$ three positive integers, or three positive rational fractions. This theorem was announced without proof by $\mathbf{P}$. Fermat (I60I-65) on the margin of a page of his copy of a work by the Greek mathematician Diophantus, as was observed in $\S 2 \mathrm{I}$ where the connection of this theorem with mathematical errors was considered.

About a century after Fermat had noted this theorem L. Euler ( $1707-83)$ proved it for all the cases when $n$ is a multiple of either 3 or 4 , and during the following century L. Dirichlet $(\mathrm{I} 805-59)$ and A. M. Legendre ( $75^{2-1833)}$ proved it for all cases when $n$ is a multiple 
of 5. The most significant step beyond the work of his predecessors was taken by E. E. Kummer (I810-93), who applied to this problem some of the elements of what has led to an extensive theory of algebraic numbers. By means of these elements Kummer was able to prove the truth of this theorem for all multiples of primes which do not exceed 100 and for all the multiples of many larger primes. In fact, Kummer thought for a short time that he had proved the general theorem.

The fact that such eminent mathematicians as Fermat, Euler, Dirichlet, Legendre, and Kummer were greatly interested in this problem was sufficient to secure for it considerable prominence in the mathematical world. Such an eminent body of scholars as the Paris Academy of Sciences offered, on at least two occasions, $185^{\circ}$ and 1853, the "grand prix des sciences mathématiques" (3000 francs) for a complete solution of this problem. Although a considerable number of competing memoirs were received by the secretary of this Academy on these two occasions, none of them seemed to be of sufficient merit to deserve the prize.

As Fermat stated that he did not furnish his wonderful proof of the theorem in question on account of the lack of space on the margin of the page, it might at first appear very unfortunate that we lost so much for such a trivial cause. On reflection it may, however, appear that it was really a gain instead of a loss. In fact, the proof of this theorem does not appear to be nearly as important as the new developments to which the efforts to prove it have led. In particular, the important theory of the Kummer ideals in number theory owes its early 
development entirely to an effort to find a general proof of this theorem, as was noted in $\S 2 \mathrm{I}$.

It may also be observed that a proof of the fact that the last Fermat theorem is true for a given prime number $p$ establishes it for all multiples of $p$. In fact, if the following equation

$$
x^{p}+y^{p}=z^{p}
$$

cannot be satisfied by rational values of $x, y, z$, then the equation

$$
x^{m p}+y^{m p}=z^{m p},
$$

$m$ being an arbitrary positive integer, can also not be satisfied by rational values of these variables. It is also easy to see that this theorem is true for all rational values of $x, y, z$, if it is true for all integral values of these variables.

While the greater Fermat theorem is of great scientific interest, it should not be assumed that its scientific importance alone has secured for it the prominent place which it now occupies in the history of mathematics. The popularity of this theorem is largely due to the magnificent prize (the largest that has ever been offered for work in pure mathematics), which is to be given for a proof of it, or for a complete determination of the values of $n$ for which it is true, in case it is not universally true.

This prize was established by a German mathematician named F. P. Wolfskehl (I856-rgo6), who bequeathed the large sum of 100,000 marks to the "Königliche Gesellschaft der Wissenschaften in Göttingen" for this purpose. The conditions under which the prize is to be awarded were published, among other places, in the Jahresbericht 
der Deutschen Mathematiker-Vereinigung, June, I908, page Ir . The following items may be of special interest. No manuscripts will be considered, but only printed articles or monographs. These articles or monographs must have appeared in regular periodicals or they must have been for sale in the open market. The prize will not be awarded for articles or monographs which have been before the public less than two years. It is suggested that five printed copies of the competing memoirs be sent by their authors to the said society at Göttingen, Germany.

It is interesting to note also that the competition for this prize is to be open for almost one hundred years unless some one succeeds in finding an acceptable solution before the expiration of this time; the latest date for awarding the prize being September 13, 2007. In announcing the prize the Göttingen Gesellschaft directed especial attention to the theory of algebraic numbers and algebraic number realms, since it appeared likely that developments along this line would lead to important results.

What seems to be an unfortunate consequence of this prize is that so many persons who have insufficient mathematical training to comprehend the true meaning of a mathematical solution have undertaken to prove the theorem in question, and have published their useless work. Even before the Göttingen Gesellschaft made public the conditions on which the prize would be awarded several hundred supposed proofs had been received, due to newspaper reports about the great prize.

Such erroneous publications are deplorable, not only 
because many of these persons could not easily spare the money wasted in this manner, but also because useless publications increase the burden of scholars and librarians. Those who possess little mathematical training but are really interested in trying to solve this theorem should first familiarize themselves with the numerous unsuccessful efforts, explained in a German periodical called Archiv der Mathematik und Physik, commencing with volume $x_{4}$, 1909 , page 284 .

The greater Fermat theorem is also of historic interest on account of the fact that it is a generalization of a very ancient problem which we proceed to consider. Special solutions of the equation

$$
x^{2}+y^{2}=z^{2},
$$

by substituting positive integers for $x, y, z$, are very ancient. Triplets of integers such as $3,4,5 ; 5,12,13$; 8, I $_{1}$ I7 $;$ etc., which satisfy the given equation when substituted for $x, y, z$ respectively, are known as $P y$ thagorean numbers. It should however not be inferred that Pythagoras was the first to consider such numbers. In fact, some of them were known long before the days of Pythagoras. General rules by means of which it is possible to determine any desired number of such triplets were given by Pythagoras, Plato, and others.

Fragments of an Egyptian papyrus, at least 4000 years old, contain the following equations:

$$
\begin{aligned}
(\mathrm{I})^{2}+\left(\frac{3}{4}\right)^{2} & =\left(\frac{5}{4}\right)^{2} \\
8^{2}+6^{2} & =10^{2} \\
(2)^{2}+\left(\frac{3}{2}\right)^{2} & =\left(\frac{5}{2}\right)^{2} \\
\mathrm{I} 6^{2}+12^{2} & =20^{2}
\end{aligned}
$$


It is interesting to observe that each of these equations can be obtained by multiplying each term of the equation

$$
4^{2}+3^{2}=5^{2}
$$

by the same number. It is also very interesting to observe that fractions appear among the terms of two of the given equations; since it furnishes further evidence of the fact that the Egyptians used fractions at an early date.

Pythagorean number triplets appear also in some of the Hindu writings which antedate the lifetime of Pythagoras. In an ancient Hindu writing we even find a method to construct a rational square which is equal to the sum of two rational squares, and, among others, the following Pythagorean number triplets :

$$
\begin{array}{rrr}
4, & 3, & 5 \\
12, & 5, & 13 \\
24, & 7,25 \\
36, & 15, & 39
\end{array}
$$




\section{CHAPTER V}

\section{Fundamental Developments in Geometry}

32. The Pythagorean theorem. - The Pythagorean theorem has an arithmetic as well as a geometric significance in elementary mathematics, and hence this theorem seems suitable to mark the transition from the former to the latter of these two subjects in tracing elements of the history of their development. The Pythagorean triangles, for instance, are right triangles the lengths of whose sides are Pythagorean numbers. If $a, b$, and $c$ represent, respectively, the two sides and the hypothenuse of a right triangle, the equation

$$
a^{2}+b^{2}=c^{2}
$$

represents a geometric theorem ; but if $a, b$, and $c$ represent the numerical measures of these sides, this equation represents an arithmetic theorem.

A rigorous proof of the Pythagorean theorem appears in Euclid's Elements. Just how much older the first rigorous proof of this theorem is we do not know. In the preceding section we observed that some Pythagorean number triplets are considerably older than Euclid's Elements, and we also find a statement of the Pythagorean theorem in one of the Hindu Sulba-Sutras, in the following form: "The diagonal of a rectangle produces what both the longer and the shorter side, each for itself, produce." This Sulba-Sutra is one of three works 
which contain methods for geometric constructions used in connection with Hindu religious rites, and which are supposed to contain rules employed at least as early as 800 B.c.*

The Pythagorean theorem, which may still be regarded as the most important theorem of elementary geometry, occupies an interesting position in the history of the early European universities. It was known as the "magister matheseos" during the Middle Ages, and represented about an average of normal mathematical attainments. In France and Germany it has been frequently called " the asses' bridge" or "pons asinorum" ("le pont aux ânes " and the "Eselsbrücke" respectively), while in England this term was applied to the theorem that the angles opposite the equal sides of an isosceles triangle are equal.

One of the most interesting features about the $\mathrm{Py}$ thagorean theorem is its relation to irrational quantities and irrational numbers. It has already been observed that some time before Euclid it was known that if two squares are such that the area of the one is exactly twice the area of the other, then the sides of these two squares are incommensurable, and that the former has for its side the diagonal of the latter. The introduction of the concept of irrationality into geometry is one of the most important steps in the early development of this subject.

It may be observed that this concept is not essential in the application of geometry to the measurement of areas. In fact, for practical constructions, such as the

- Cf. Bürk, "Das Apastamba-Sulba-Sutra," Zeitschrift der Deutschen Morgenländischen Gesellschaft, Vol. 55 (1901), p. 543. 
construction of buildings and bridges, or even for the finding of the distances in astronomy, the incommensurable quantities can readily be dispensed with. The most accurate measurements cannot reveal the existence of incommensurable magnitudes. In these magnitudes we have something which transcends the material needs of man and the laboratory methods of arriving at truths. A purely materialistic world has no need of the concept of irrationality.

On the other hand, this concept, when clearly apprehended, lays hold on our intellects and increases our own intellectual penetration to such an extent as to afford the keenest pleasure. The introduction of the concept of incommensurability into geometry lifted by one step this subject above the experiences of the senses which enable men to acquire knowledge from without, and turned the attention to deep intellectual penetration, resting on a solid foundation but transcending materialistic verification. The Greeks fully appreciated the great importance of this concept, and they were led to make remarkable discoveries under its inspiration. A new intellectual world was reached by them through this gateway.

A very large number of different proofs of the Pythagorean theorem have been given. As early as 1819 J. Hoffmann published 32 such proofs, and in 1880 a Russian work by J. Wipper, containing 46 proofs, was translated into German by F. Graup. A work published by $\mathrm{J}$. Versluys in 1914 contains 96 such proofs. ${ }^{*}$ It is

* This book was reviewed in the Zeitschrift für mothematischen und nalurwissenschaftlichen Unterricht, 1915, p. 276. 
of interest to note that somewhat extensive collections of such proofs are found in at least two American journals of elementary mathematics. In I860 J. M. Richardson published 28 proofs in volume 2, page 45 , of the Mathematical Monthly, and a considerable collection appeared in a few of the early volumes of the American Mathematical Monthly, under the heading "New and Old Proofs of the Pythagorean Theorem" by B. F. Yanney. Some of these proofs are but slight modifications of others, and it is difficult to say when the elements which enter into two proofs are sufficiently different to merit being classified as distinct proofs.

The Pythagorean theorem suggests a very easy method to construct right angles. In fact, if we tie four markers on a rope so that the distances between them constitute a Pythagorean number triplet and then attach the end marks to a fixed point, on a plane surface, the other marks being moved so that the rope between the marks is taut, there clearly results a right triangle. For instance, when this Pythagorean number triplet is 3, 4, 5, we have the following right triangle:

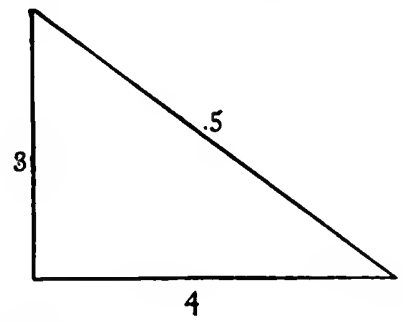

As the ancient Hindus were so very careful in the construction and the placing of their altars, it was necessary 
for them to be able to construct right angles. The need of constructing right angles seems to have been felt also in Egypt in very early times, and it is supposed that the Egyptians had specially trained men who made a business of accurate rope stretching as early as four thousand years ago.

It seems likely that such crude processes to construct right angles were employed long before the Pythagorean theorem was really proved, and that the truth of this theorem was assumed long before a rigorous proof was known. The ancient Hindus certainly used this theorem in their construction of similar plane figures whose areas have a given ratio; but no rigorous proof of it has yet been found in the writings of those whose culture is earlier than that of the Greeks.

Although the theorem in question is known as the Pythagorean theorem, no mention has as yet been made as regards the connection of Pythagoras with this theorem, except as to name. All seem to agree that Pythagoras was not the first to state this theorem. On the other hand, it still seems possible that the first rigorous proof of it was due to Pythagoras, even if some mathematical historians are inclined to deny this. One thing is, however, certain; viz., the school founded by Pythagoras did very much to increase the interest in problems directly connected with this theorem. Hence the association of the name of Pythagoras with this cornerstone of elementary geometry rests upon some solid foundation.

33. The area of the circle. - The term circle is used with two different meanings in elementary mathematics. 
Some writers use it to designate the curve called the circumference of the circle, while others use this term to define the surface inclosed by this plane curve.* With the former definition of circle it is not quite correct to speak of its area. It is, however, customary to speak of the area of a circle even when the circle has been defined as a curve. In this case the expression, the area of the circle, is used for the somewhat longer expression, the area inclosed by the circle.

The circle is one of the most important closed figures of geometry. Its symmetry and its simple definition appeal to all who have any taste for geometry. The fact that the area of a circle is larger than that inclosed by any other closed curve having the same perimeter surprises no one, even if its rigorous demonstration is difficult. On the other hand, it is not so evident that when the sides of a convex polygon are given this polygon has always its maximum area when all its vertices lie in the circumference of a circle; but the proof of this theorem is very simple if we assume the theorem stated in the preceding sentence.

In view of the great simplicity and elegance of this proof we shall give it here. Given any convex polygon whose vertices are not concyclic, and construct a polygon with the same sides in a circle such that all the vertices lie in the circumference of this circle. If, on the sides of the polygon whose vertices are not concyclic, we construct the arcs subtended by the corresponding sides of the concyclic polygon, the former polygon

* These different uses of the term circle appear already in Euclid's Elements. Cf. Heath, The Thirleen Books of Euclid, Vol. 2 (1908), p. III. 
will be inclosed by a curve whose perimeter is equal to the circumference of the circle in which the second polygon is inscribed. As the area inclosed by the former curve is less than that of this circle, and as the sum of the areas between the sides of the polygons and the bounding curves are the same in both cases, it results that the area of the former polygon must be less than that of the latter.

On account of the beauty and the simplicity of the circle it seems natural to assume that this curve was known in prehistoric times. The sun and the moon must have suggested it to many thoughtful minds long before the records which have come down to us were made. It is not known what may first have suggested the idea of comparing the area of a circle with that of a square, but in the ancient Egyptian work by Ahmes we find various problems in which it is assumed that the area of a circle is equivalent to that of a square whose side is $8 / 9$ of the diameter of the circle.

According to this rule the area of a circle whose radius is $r$ is $\frac{256}{81} r^{2}$, while the correct area is $\pi r^{2}$. Hence the ancient Egyptian rule is equivalent to assuming that

$$
\pi=\frac{256}{81}=3.16049+\text {. }
$$

While this is not a very close approximation to the value of $\pi$ (the exact value being 3.I4I59+), yet it is a very much closer approximation than the value used by some of the other ancient peoples. In fact, in Asiatic countries 3 was very commonly used to represent this value, as may be inferred from passages in our Bible. The following may serve as an illustration: "And he made a molten sea, ten cubits from the one brim to the other, 
round all about, and his height was five cubits; and a line of thirty cubits did compass it round about." - I Kings $7: 23$.

In Euclid's Elements no effort is made to find the area of the circle. In fact, in Euclid we do not find the measurement of surface, but only the comparison of surfaces. Shortly after Euclid there lived the greatest mathematician of antiquity; viz., Archimedes (287-2r 2 B.c.). In the work of Archimedes it is proved that the area of a circle is equal to that of a right triangle whose base is equal to the circumference of the circle and whose altitude is the radius of the circle.

Archimedes used circumscribed and inscribed regular polygons to find limits between which the value of $\pi$ must lie and thus he found a method which was practically the only one used for two thousand years, up to the invention of differential calculus, to find approximate values of $\pi$. The limits for this value, found by Archimedes, were as follows :

$$
3 \frac{1}{7}>\pi>3 \frac{10}{7}
$$

and the former of these approximations has been very commonly used for $\pi$ since the days of Archimedes, when the data involved in a problem are not very accurate.

There is a great difference between finding a method by which a square can be constructed whose area is exactly equal to that of a given circle, and finding a method by which a square can be constructed whose area differs from that of the circle by less than any given

* Cr. 2 Chron. 4:2. The Talmud also uses 3 as the value of $\pi$. 
amount greater than zero. The latter can be accomplished by the method used by Archimedes, as well as by many other known methods. The Greeks were interested in a method to accomplish the former by means of the rule and compass. This is known as one of the three great problems of antiquity and is commonly called squaring the circle; the other two of these problems are the duplication of a cube and the trisection of an angle.

The first of these three problems has perhaps received the largest amount of attention among people who did not fully comprehend the meaning of the questions involved in the problems. The "circle-squarers" have created a literature which contains many ridiculous claims. As early as I 775 the Paris Academy of Sciences found it necessary to announce that it would not examine any more papers claiming to have solved any one of the three problems of antiquity mentioned above. Some of the other European Academies soon thereafter made similar announcement in order to save their members from the drudgery of examining a large amount of useless matter, written by people unfamiliar with the real nature of mathematical problems.

The rigorous proofs of the fact that the solution of these problems is impossible by the methods specified is, however, quite modern. As regards the squaring of the circle, the irrationality of $\pi$ was first rigorously established by $\mathrm{J}$. H. Lambert in $\mathrm{r} 768$, and the fact that $\pi$ is a transcendental number, and hence cannot be a root of any algebraic equation with rational coefficients, was first established as recently as $\mathrm{I} 882$ by F. Lindemann. It is not difficult to prove that these algebraic 
results establish the impossibility of the given geometric constructions.

We are so accustomed to the use of the symbol $\pi$ for the ratio between the circumference and the diameter of a circle that we might be inclined to think this ratio had always been indicated in this way. Such is, however, not the case, but the general introduction of the symbol $\pi$ to denote this important ratio is largely due to the great Swiss mathematician L. Euler, who was the most prolific mathematical writer that ever lived, and who used this symbol consistently since 1737. Euler was, however, not the first to use $\pi$ with this signifcance. In fact, W. Jones used it with this meaning as early as 1706 .

34. Area and volume of the sphere. - Among all the solids the sphere is the most symmetrical. Diogenes Laertius stated that the Pythagoreans regarded the sphere as the most beautiful among the solids and the circle as the most beautiful among the plane figures. Archimedes proved some of the most important theorems in regard to the sphere, and exhibited relations between the sphere, circle, and cylinder which will probably always be regarded as belonging to the most beautiful theorems in elementary mathematics. In support of this statement it is only necessary to recall that Archimedes proved the following theorems :

The area of a sphere is equal to that of four great circles. This area is also equal to two thirds of the area of the circumscribing cylinder. The volume of a sphere is equal to two thirds of the volume of the circumscribing cylinder. The spherical area of a segment 
of a sphere is equal to that of a circle whose radius is equal to the distance from the pole of this segment to the bounding circle of this spherical surface.

These theorems have two properties which are extremely important in mathematics; viz., they can be stated briefly in a language that is commonly understood, and they convey useful but surprising facts. Moreover, the proofs are both elegant and simple. When Archimedes first observed the beautiful relation between the area of a sphere and that of a circle having the same diameter, and those existing between the sphere and the circumscribing cylinder, he naturally thought of the marvelous enrichment of intellectual life which a knowledge of these relations meant for all future generations. Although there has been a long period of time, since the days of Archimedes, during which these relations were practically forgotten, they were brought prominently to the front with the revival of learning.

We have already referred to the fact that Archimedes was the greatest mathematician of antiquity, but the given theorems are so extremely interesting that he seemed to have regarded them as his greatest discoveries. In fact, he desired that an image of a sphere inscribed in a cylinder should be engraved on his tombstone. A still greater tribute to his genius is, however, the fact that such an image has been engraved on the minds of millions of students since his days, and it seems likely that many millions of future students will be inspired by the same imprint, and will honor the great Greek mathematician by regarding it as one of their most interesting impressions relating to elementary mathematics. 
It should be observed that there are somewhat serious difficulties involved in the measurement of curved lines and curved surfaces. By measuring we generally mean that two things of the same kind are compared. As a rule, we think of a well-known unit of a given kind, with which we compare a thing of the same kind. In linear measurement this unit is commonly regarded as a segment of a straight line, while, in the measurement of surfaces, it is commonly a square whose side is such a linear unit.

In comparing the lengths of a curved line and a straight line, such as the circumference of a circle and its diameter, we are evidently dealing with things which are essentially different. Similarly, in comparing the surface of a sphere with that of a circle we are dealing with things of a very different kind. Hence such theorems as were expressed above encountered philosophical as well as mathematical difficulties. One of the great achievements of Archimedes was to widen the mathematical considerations as developed in Euclid's Elements and to bring such practical measurements as are exhibited in the given theorems clearly within the domain of mathematics.

The determination of the area of spherical triangles and spherical polygons led also to formulas of remarkable simplicity. In A. Girard's Invention nouvelle en l'Algèbre, I629, it is stated that " every spherical polygon, whose sides are arcs of great circles, contains as many degrees of surface as the number by which the sum of its internal angles exceeds the sum of the internal angles of a plane polygon with the same number of sides, if the surface 
of the sphere is equal to $720^{\circ}$." This beautiful theorem was not completely proved by Girard in the given work. Such a proof was, however, given a few years later by the Italian mathematician, B. Cavalieri.

35. Regular geometric forms. - Closely related to the circle and the sphere are the regular polygons and the regular polyhedrons, and these geometric forms are also of fundamental historic interest. Among the regular polygons the equilateral triangle, the square, and the regular hexagon are of especial interest since a floor can be completely covered with tiles having any one of these three forms. Ancient Babylonian and Egyptian measurements of area disclose the fact that the square whose side is equal to unity was used as a unit of measure in very early times. This results from the fact that the area of a rectangle was found by multiplying the numbers expressing the lengths of two adjacent sides.

The fact that the sides of a regular hexagon inscribed in a circle are equal to the radius of the circle is one of the beautiful elementary mathematical truths, whose influence on the early development of our subject can scarcely be overestimated. This fact may have led to the widespread use of 3 as the value of $\pi$, and the six equilateral triangles obtained by joining the vertices of the inscribed hexagon with the center of the circle, tended to awaken geometric interest. Since these elementary constructions directed attention to truths which can so easily be seen to belong to the geometry of precision (i.e. to the geometry which is more accurate than any measurements no matter how refined) they naturally assisted in the development of the concept of invisible 
mathematical truths, a concept of wonderful power in stimulating intellectual activity.

The great interest in the regular forms on the part of the ancient Greeks is partly portrayed by the fact that the last book of Euclid's Elements is devoted to regular polygons and to the five possible regular convex polyhedrons, known as the regular tetrahedron, the cube, the regular octahedron, the regular dodecahedron, and the regular icosahedron. These five solids are often called the Platonic solids, or the cosmic solids, and they entered into Greek philosophy as well as into Greek mathematics.

The cube whose edge is unity is the common unit of volume, and must have been known in prehistoric times. The 24 different movements of space which interchange the various parts of a cube but do not displace the cube as a whole constitute an important group of movements, and the study of this group has, in modern times, contributed a new element of interest to the cube.

Among the other cosmic solids it seems reasonable to assume that the regular tetrahedron (which is a special pyramid) and the regular octahedron (which is a double pyramid with a square base) were known to the ancient Egyptians. On the other hand, the regular icosahedron and the regular dodecahedron seem to have been discovered much later. It is probable that these solids were known by the early Pythagoreans, and some recent discoveries of figures in bronze and other material have led to the belief that the dodecahedron, at least, was known before the days of Pythagoras. At any rate we know that at the time of Euclid the five regular convex polyhedrons had assumed a prominent place in the 
geometrical acquisitions of the time, and Euclid observed that no more than five such solids can be constructed.

To exhibit more fully the interest which the ancient Greeks took in these solids, and to explain the term " cosmic solids," it may be desirable to refer to a groundless assumption of the ancient Greek philosophers to the effect that these solids represented the forms of the atoms of all matter. In particular, fire, air, water, and earth were supposed to be composed respectively of tetrahedrons, octahedrons, icosahedrons, and of cubes; while the universe was supposed to be inclosed by a regular dodecahedron. Although these assumptions were groundless they doubtless served to stimulate interest in these fundamental solids, and tended to direct attention to their many elements of symmetry.

In much later times these elements of symmetry led to an introduction of a dynamic property in the study of these solids, by noting the groups of movements under which these solids can be transformed into themselves. W. R. Hamilton, the founder of the theory of quaternions, presented, on November Io, I856, a paper to the Royal Irish Academy in which he considered the equations

$$
\mathrm{I}=i^{2}=k^{3}=l^{r}, \quad i k=l, r=3,4,5 .
$$

He observed that these equations are sufficient to restrict the elements $i, k, l$, when they are combined as regards multiplication, under the associative but not the commutative law, in every possible manner, so that the total number of the possible distinct products may be interpreted as representing movements of the regular polyhedrons. 
This opened up a new sphere of usefulness of the cosmic solids. In fact, each one of them may serve to illustrate a certain kind of calculus. Hamilton called the calculus associated with the regular icosahedron the "Icosian calculus" and observed that for the various values of $r$ in the above equations there results a " family of systems of noncommutative roots of unity, which are entirely distinct from the $i, j, k$, of the quaternions, though having some general analogy thereto; and which admit even more easily than the quaternion symbols do, of a geometrical interpretation." Various generalizations of the given Hamiltonian equations have led in recent years to results of unusual interest.

While an interesting and extensive history surrounds the regular polyhedrons, the history which surrounds the regular polygons is still more interesting and relates to developments extending over a long period of time. The dynamic property relating to the group properties of these figures, when we consider all the movements which transform the figures into themselves, are less interesting than those which relate to the group of movements of the cosmic bodies. In fact, in the present case, the group of movements is of order $2 n, n$ being the number of sides of the regular polygon, and this group is dihedral; i.e. one half of its operators constitute a cyclic subgroup while the remaining operators are all of order 2 and transform each operation of this cyclic subgroup into its inverse.

There are, however, other questions of the most interesting kind related to the regular polygons. The ancient Greeks, as is well known, limited themselves to the rule 
and compass in the elementary geometry constructions. By this means Euclid constructed, in his Elements, regular polygons of three, four, five, and fifteen sides. As it is always easy to construct a regular polygon having twice as many sides as those of a given regular polygon, Euclid's methods showed how to construct, by means of the rule and compass, regular polygons having any number of sides which can be represented by one of the following expressions :

$$
3 \cdot 2^{n}, 4 \cdot 2^{n}, 5 \cdot 2^{n}, 15 \cdot 2^{n} .
$$

The smallest numbers greater than 2 which are not one of these forms are 7, 9, II, I3, and I4. Efforts to find methods to construct by means of rule and compass regular polygons having a number of sides equal to one of these numbers failed, and the two thousand years following Euclid produced neither an increase in the number of the types of regular polygons which can be constructed in the given manner nor a theory exhibiting the true nature of the difficulty.

The problem appeared to be geometrical, but geometry seemed to provide no means for its solution. This may be partly due to the fact that elementary geometry did not possess an extensive connected algorithm such as elementary algebra had developed around the theory of equations. At any rate, this geometric difficulty was first solved by algebraic means.

It was one of the great achievements of C. F. Gauss (I777-I855) to prove (Disquisitiones Arithmeticae, § 7), by algebraic means, that a necessary and sufficient condition that a regular polygon of a prime number of sides 
can be inscribed in a circle by means of rule and compass is that this prime be of the form

$$
2^{m}+\mathbf{I}
$$

In particular, he proved that it is possible to inscribe a regular polygon of 17 sides, and from his developments it results that a necessary and sufficient condition that a regular polygon of $m^{\prime}$ sides can be inscribed in a circle is that $m^{\prime}$ is a number having one of the following forms,

$$
p_{1} \cdot 2^{n}, 4 \cdot 2^{n}, p_{1} \cdot p_{2} \cdot \cdots \cdot p_{\lambda} \cdot 2^{n},
$$

where $p_{1}, p_{2}, \cdots, p_{\lambda}$ represent distinct prime numbers which are all of the form $2^{m}+1$, and $n$ is a positive integer or zero.* $^{*}$

While Gauss furnished a definite answer to the question whether a regular polygon of a given number of sides can be inscribed in a circle, it should not be inferred that he solved all the interesting questions relating to regular polygons. In fact, his beautiful results tended to emphasize other far-reaching questions. Among these are those which relate to a determination for what values of $m$ a number of the form $2^{m}+\mathrm{I}$ is a prime number.

It is very easy to see that $m$ must be a power of 2 , for if it were not a power of 2 it would be either odd or the product of an even and an odd number; but this could not be prime since $k^{2^{n+1}}+\mathrm{I}$ is clearly divisible by $k+\mathrm{I}$. Hence the question arises for what values of $\lambda$

$$
2^{2^{\lambda}}+I
$$

is prime. Such numbers are called Fermat numbers since Fermat seems to have supposed that all such

* Cf. L. E. Dickson, Monographs on Topics of Modern Mathematics, I9r r, p. 379 . 
numbers were prime, and these Fermat numbers have a very interesting history.

36. The triangle. - The triangle is such a simple figure that one might at first think that only a few facts could result from its study. The intellectual penetration of such a simple object would seem to require very little in the way of preliminary study, and it might appear that such a penetration would have required the strength of only a few specially gifted men.

Such views are soon shattered if one begins to reflect on the fact that the measurement of the triangle has led to numerous special books under the title of trigonometry, and that the tables used in solving triangles have been constructed at a vast expense of energy and perseverance. A still greater blow to the view that only a small amount of knowledge could center in such a simple figure results when one meets the statement that in about 1885 there arose in France the so-called newer geometry of the triangle, which concerns itself with the remarkable points, lines, circles, etc. of the triangle.*

Investigations relating to the triangle began very early. The ancient Egyptian work by Ahmes contains geometrical figures which seem to represent isosceles triangles, and the area of these triangles is expressed as equal to the product of one half of the base and one of the two equal sides. This result would clearly be correct if the unit area were a parallelogram having its sides equal to unity and its acute angles equal to the equal angles of the isosceles triangle. If the unit area is assumed to be a square

- Felix Müller, Führer durch die mathematische Litcratur, 1909, p. 146. 
with unity for a side, the results obtained by Ahmes were evidently not quite exact.

One of our most useful trigonometric formulas giving the exact area of a triangle whose sides are equal to $a$, $b, c$, in the form

$$
\sqrt{s(s-a)(s-b)(s-c)},
$$

where $s=\frac{1}{2}(a+b+c)$, is given by the noted Greek engineer and surveyor Hero of Alexandria (about roo B.c.), and is still commonly known as Hero's theorem. It is a very remarkable fact in the history of mathematics that this formula was discovered so early.

A systematic development of fundamental properties of the plane triangle is found in Euclid's Elements. Here we find, for instance, the elementary theorems relating to certain congruence of triangles and to the fact that the sum of the angles of a plane triangle is independent of the shape of the triangle if the usual Euclidean postulates are adopted.

The theorem that the angles opposite the equal sides of an isosceles triangle are equal to each other, and those relating to the fact that if two triangles have two corresponding sides equal but the included angles unequal then the one which has the greater included angle has the greater third side, and conversely, were also proved by Euclid. In fact, we find here the ordinary school geometry treatment of the plane triangle, including the Pythagorean theorem, as was noted in $\S 32$.

The Elements of Euclid do not contain the corresponding elementary theorems on the spherical triangles. In fact, this treatment seems to have been first developed several centuries later by Menelaus (about roo A.D.), who 
modeled his treatment of the spherical triangle after the Euclidean treatment of the plane triangle.

Menelaus developed a kind of spherical trigonometry and proved that the sum of the angles of a spherical triangle exceeds $180^{\circ}$. He also established, for the spherical triangle, the fundamental transversal theorem known by his name. The theorem states that if the three sides of a spherical triangle whose vertices are $A, B, C$ (or these sides produced) are cut in the points $D, E, F$ by a great circle then

chord $2 A D \cdot$ chord $2 B E \cdot$ chord $2 C F$

$$
=\operatorname{chord} 2 D B \cdot \operatorname{chord} 2 E C \cdot \operatorname{chord} 2 A F \text {. }
$$

The corresponding theorem for the plane triangle is used in proving this theorem, but it was not explicitly established in the known works of Menelaus. It is interesting to note that the Greeks developed spherical trigonometry more extensively than the simpler plane trigonometry. This seems to have been due to the use of spherical trigonometry in the study of astronomy.

The great importance of the triangle is partly due to the fact that it may be said to constitute the atom of figures bounded by straight lines in the plane, as well as of those bounded by great circles on the sphere. A polygon can be broken up into triangles. Moreover, the plane triangle is completely determined by its sides and hence it enters so prominently into the theory of constructions.

Its rigidity when the sides are given must have appealed to the carpenters in early times and must have tended to 
arouse special interest in this figure. The constancy of the sum of its internal angles, under the Euclidean assumptions, is one of those elementary mathematical facts which tended to awaken intellectual activity in the early stages of mathematical development.

It has already been noted that the construction of the tables of the trigonometric functions was associated with the study of the triangle. The vast body of truths involved in known relations between trigonometric functions is also associated with the triangle, even if these developments have progressed far beyond direct usefulness in the triangle.

In fact, the trigonometric functions find many applications in physics, in chemistry, and in other subjects, and it is only necessary to recall the use of these functions in integral calculus to exhibit the remoteness from the triangle of some of the uses of the trigonometric functions even in pure mathematics. The fact that these functions had their origin in the study of the triangle and that the term triangle is incorporated in the name, naturally leads us to use the triangle as a kind of central notion in all these developments.

The newer geometry of the triangle has led to the discovery of a vast number of new properties as well as to the re-discovery of some properties recorded in various of the older mathematical periodicals. A number of these properties are associated with the symmedian or Lemoine point. This point has been named in honor of E. Lemoine (I840-I9I2) because of the important discoveries relating thereto which were made by Lemoine, who has been called the founder of the geometry of the 
triangle.* In Germany the given point is also known as the Grebe point. In $x 893 \mathrm{~J}$. S. Mackay gave a short historical sketch of this point in which he directed attention to the fact that it was noted in volume III, I803, of the Mathematical Repository.

The present reference to the newer geometry of the triangle is intended to direct attention to the fact that in the most elementary parts of mathematics progress even along the older lines of work is still possible. A number of the results of this newer geometry are found in Casey's Sequel to Euclid, I888. If the triangle has become the center of such a vast field of knowledge, it is easy to see that the more complex figures will lead to very much more extensive results. In fact, the triangle serves as a most instructive instance of how mathematical study deepens intellectual penetration. There is a great difference between what the mathematician and what the uneducated man sees in the triangle!

* L'Intermediaire des Mathématiciens, Vol. 19 (I912), p. 49. 


\section{CHAPTER VI}

\section{Fundamental Developments in Algebra}

37. Introduction. - Algebra is the leading thought economizer of mathematics, and mathematics is the leading thought economizer among the sciences. There are few features of algebra which throw so much light on its general development as the fact that it embodies remarkable achievements in the economical use of thought, and that these achievements involve a great range in their degrees of difficulty. The special language of algebra is both concise and clear, and its symbols for unknowns cultivate a wholesome admission of temporary ignorance as regards one or more elements involved in the questions under consideration.

Algebra is concerned with the study of rational integral functions, or polynomials, in one or more variables. It originated in the study of equations, and the theory of equations has always constituted a central place in the development of algebra. Equations of the first degree are solved in the ancient Egyptian work written by Ahmes. On fragments of papyri which are probably older than the work of Ahmes, statements equivalent to the solution of the system of two simultaneous equations

$$
x^{2}+y^{2}=100, \quad y=\frac{3}{4} x,
$$

have been found, cf. $\S 28$. Even special systems of $n$ equations involving $n$ unknowns were solved at an early 
date. A Greek named Thymaridas gave a rule for solving the following system :

$$
\begin{gathered}
x_{1}+x_{2}+x_{3}+\cdots+x_{n}=s, \\
x_{1}+x_{2}=a_{1}, x_{1}+x_{3}=a_{2}, \cdots, x_{1}+x_{n}=a_{n-1} .
\end{gathered}
$$

Whether these early developments in the theory of equations should be regarded as belonging to arithmetic or to algebra depends upon the somewhat arbitrary line between these subjects which one may choose to adopt. In the useful Encyklopädie der Elementar-Mathematik by Weber and Wellstein, for instance, the solution of the linear and the quadratic equations in one unknown are classed under arithmetic. In the large mathematical encyclopedia entitled Encyclopédie des Sciences Mathématiques the following statement is made: "It is convenient, in arithmetic, to denote any number whatever by a letter, it being understood that this letter ought to denote a single and the same number when one remains in the same subject. The first traces of an arithmetic calculus with letters is found among the Greeks; one finds more of it among the Hindus." *

These statements may suffice to show that the study of the early history of algebra is complicated by the fact that there is no generally accepted line of division between algebra and arithmetic. In speaking of fundamental developments of algebra it is therefore assumed that some of these developments would be classed by others under the term arithmetic.

In a general way it may be said that the development of mathematics on an arithmetic-algebraic foundation

* Tome I, Vol. r, p. 22. 
was inspired, in the sixteenth century, by the general solution of the cubic and the biquadratic equations by the Italian mathematicians: Ferro, Tartaglia, Cardan, and Ferrari; it was rooted in the In artem analyticam isagoge by Vieta, 1591, and in the Invention nouvelle en l'algèbre by Girard, I629; and it was established on a solid foundation in the Géométrie by Descartes, 1637 .

In his In artem, Vieta used consistently letters not only, as had been done previously, to represent unknowns, but also to represent the knowns, and he thus introduced the calculus of letters, which he denoted by the term logistica speciosa to distinguish it from the calculus of numbers, which he called logistica numerosa. In a later work he pointed out the relations between the coefficients and the roots of an equation whenever these roots are positive. Girard considered negative and even imaginary roots, and he was the first to state the theorem that every equation has as many roots as its degree. For the general equation

$$
\begin{array}{r}
x^{n}-a_{1} x^{n-1}+a_{2} x^{n-2}-a_{3} x^{n-3}+\ldots \mp a_{n-1} x \pm a_{n} \\
=\left(x-x_{1}\right)\left(x-x_{2}\right) \ldots\left(x-x_{n-1}\right)\left(x-x_{n}\right)=\circ
\end{array}
$$

he also found the following four important relations :

$$
\begin{aligned}
x_{1}+x_{2}+\ldots+x_{n-1}+x_{n} & =a_{1} \\
x_{1}{ }^{2}+x_{2}{ }^{2}+\ldots+x_{n-1}{ }^{2}+x_{n}{ }^{2} & =a_{1}{ }^{2}-2 a_{2} \\
x_{1}^{3}+x_{2}^{3}+\ldots+x_{n-1}{ }^{3}+x_{n}^{3} & =a_{1}^{3}-3 a_{1} a_{2}+3 a_{3} \\
x_{1}{ }^{4}+x_{2}{ }^{4}+\ldots+x_{n-1}{ }^{4}+x_{n}{ }^{4} & =a_{1}{ }^{4}-4 a_{1}^{2} a_{2}+4 a_{1} a_{3} \\
& +2 a_{2}{ }^{2}-4 a_{4}
\end{aligned}
$$

The Géométrie of Descartes contains the important rule of signs according to which the number of positive 
roots of a numerical equation cannot exceed the number of variations in the signs of its coefficients, and the number of negative roots cannot exceed the number of permanences of sign. It also contains the term imaginary with its present significance, but it is most noted on account of its influence in uniting the domains of algebra and geometry, and thus giving rise to analytical geometry. As long as geometry and algebra were divided, they made comparatively little progress; but after the common ground between them was bridged, both of them took on new life and a vigorous new development.

The invention of the analytic geometry serves as an instance of the importance of working in the fields where two subjects overlap or where these subjects do not yet touch each other. These fields seem, in general, to be the most promising for the investigator who has a broad general knowledge of both of the fields involved. By utilizing the methods of both fields and modifying them, if necessary, to meet new conditions, the investigator is doubly armed and more than doubly efficient in certain directions. The progress in this intermediate field is likely to react very forcibly on the developments of the fields concerned, as was the case with algebra and geometry after the invention of analytic geometry.

38. Fundamental theorem of algebra. - The funda-. mental theorem of algebra affirms that a polynomial of the form

$$
a_{0} x^{n}+a_{1} x^{n-1}+a_{2} x^{n-2}+\cdots+a_{n}
$$

where the coefficients are any numbers (real or complex) and $a_{o} \neq 0$, has at least one zero. That is, there is at least one number which has the property that if it 
substituted for $x$ in $(A)$ this polynomial will be equal to $o$. Hence the fundamental theorem is sometimes stated in the form that the equation obtained by assuming that such a polynomial as $(A)$ is equal to $\circ$ must always have at least one root.

In the third book of his Géométrie ( 1637 ) Descartes had already observed that when $a_{1}$ is a zero of $(A)$ then this polynomial is divisible by $x-a_{1}{ }^{*}$ As the quotient is evidently a similar polynomial of degree $n-\mathrm{I}$, it results directly that if the fundamental theorem is established, then the polynomial $(A)$ can always be written in the following form :

$$
a_{o}\left(x-a_{1}\right)\left(x-a_{2}\right) \cdots\left(x-a_{n}\right) .
$$

Hence it results that this polynomial has $n$ zeros, provided we can prove that it has always at least one zero. Moreover it is very easy to see that it could not have more than $n$ distinct zeros. In view of the simplicity of these additional facts, the fundamental theorem is sometimes stated in the form that the polynomial $(A)$ has exactly $n$ zeros.

The fundamental theorem of algebra is often called d'Alembert's Theorem, since the noted French mathematician J. d'Alembert ( $17 \mathrm{I} 7-83$ ) published the first proof of it, which was however not entirely correct. It is very interesting to observe that the first rigorous proof of this theorem was given by a young man and in a doctor's dissertation. C. F. Gauss ( $1777-1855)$ was only 22 years old when he published this proof in his doctorate

* Special cases of this important theorem are found in the Libro de Algebra (1567) by the noted Portuguese mathematician Pedro Nuñez. Cf. Bibliotheca Mathematica, Vol. 8 (1907-08), p. 154 . 
thesis at the University of Göttingen, Germany. In giving this rigorous proof Gauss naturally directed attention to the inaccuracies in the earlier proofs. Besides d'Alembert, L. Euler (I 707-83), J. L. Lagrange

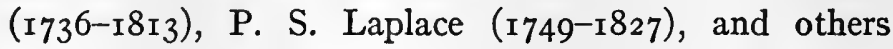
had published inaccurate proofs of this important theorem.

If the coefficients in the polynomial $(A)$ are all real, then its complex zeros, if it has any such zeros, must occur in pairs such that one is the conjugate of the other.* From this fact it results directly that this polynomial can then be resolved into real factors whose degrees do not exceed 2. This theorem is very important in those subjects in which complex numbers are avoided, as is commonly done, for instance, in our first courses in the differential and integral calculus. When the coefficients of $(A)$ are rational integers and $(A)$ can be resolved into factors with rational coefficients, then the coefficients of the factors of $(A)$ may be so chosen that they are rational integers. This theorem was also proved by Gauss at an early age, as it appears in his Disquisitiones Arithmetica. Cf. $\S 40$.

While the first rigorous proof of the fundamental theorem of algebra marks a great triumph in overcoming algebraic difficulties, it marks also one of the most characteristic mathematical triumphs, since it raised much more difficult questions than it answered. It settled once for all the question whether a polynomial in one unknown has at least one zero, but it emphasized the more difficult question of developing a method for finding this

* C. Maclaurin, London Philosophical Transactions, Vol. 36 (17 29), p. 59. 
zero. About a quarter of a century after Gauss found a rigorous proof of the fundamental theorem, the noted Norwegian mathematician N. H. Abel (1802-29) proved that rational operations combined with root extraction do not suffice to find the roots of a general equation whose degree exceeds 4 .

This important proof again raised more difficult questions than it surmounted, since it naturally led to the inquiry as regards the conditions which such polynomials must satisfy in order that their roots can be found by rational operations and root extraction. Very important advances along this line were inaugurated about the time of Abel's death, when another mathematical genius of the first rank became immortal through fundamental discoveries which he did not live to complete. Some of these discoveries exhibited the fact that many of the most fundamental difficulties in the theory of algebraic equations can be reduced to questions in the theory of substitution groups, and E. Galois ( $\left.18 \mathrm{II}^{-}-32\right)$ made the relation between algebraic equations and this theory sufficiently clear during his short scientific career to open the way for many workers in the rich and fertile domain of algebra known as the theory of substitutions.

The enrichment of algebra indirectly due to the fundamental theorem of algebra is very great as might be expected from the name of this theorem. The direct usefulness of this theorem is, however, also very great, since it enables us to express so briefly a very fundamental fact. The ancient Greeks did not consider more than one root of a quadratic equation even when this equation had two positive roots, but the Hindus and the Arabs 
knew that some equations can have more than one root. During the Middle Ages the Italian mathematician H. Cardan $\left(I_{50 I-76)}\right.$ observed that a cubic equation can have three roots, and that a biquadratic equation can have four roots. About half a century later the noted French mathematician F. Vieta (I540-1603) constructed an equation of the fifth degree having five roots.

In his well-known Invention nouvelle en l'Algèbre, I629, A. Girard stated already that, since some equations admit as many roots as their degrees, it is desirable to say that every equation has as many roots as its degree, and to introduce impossible solutions equal to the number of the degree of an equation diminished by the number of its possible solutions, in case the number of the latter solutions is less than the degree. Many of the early writers, including I. Newton, said simply that an equation cannot have any more roots than its degree. This practice is followed in some of the elementary textbooks of the present day. In particular, the equation $x^{2}+2 x+\mathrm{I}=0$ may be said to have only one root or two equal roots. The latter is, however, the more common mode of expression.

A large number of different proofs of the fundamental theorem have been given by various writers. Gauss himself gave four such proofs in the years 1799,1815 , I8r6, and 1849 . An analysis of some of the most important of the proofs of this theorem is given in tome I, volume 2, of the Encyclopédie des Sciences Mathématiques, page 189. Notwithstanding the numerous simplifications, these proofs are still somewhat difficult for young students. It is, however, not very difficult to give an 
intuitive proof by assuming that it is self-evident that there is a $(\mathrm{I}, \mathrm{I})$ correspondence between the real numbers and the points of a line. Even such intuitive proofs are generally reserved for students who have attained some mathematical maturity in view of their great demand on the faculty of abstraction.

One of the very interesting things about the fundamental theorem is its closure property. That is, if the coefficients of a rational integral function are ordinary algebraic numbers the zeros of this function are also such numbers. We therefore remain in this number realm by performing the operation represented by the algebraic equation obtained by equating this function to zero. This operation is sometimes called the most general algebraic operation. In its most elementary form, when the equation reduces to a binomial equation, this operation reduces to root extraction. Hence the operation of solving an equation in one unknown may be regarded as an extension of the operation of root extraction.

The ancient and medieval mathematicians did not know any algebraic operations besides those which are rational, with the exception of root extraction. On this account they were unable to solve the general equations whose degrees exceed 4. In fact, no one succeeded in furnishing an explicit solution of such an equation before 1858. In this year the noted French mathematician C. Hermite (1822-190I) found a method by means of which he could express a root of the general equation of the fifth degree in terms of certain functions known as elliptic functions. More recently it has been proved that 
a root of the general equation of degree $n$ can be represented in terms of its coefficients by means of certain functions called Fuchsian functions.

39. Determinants. - One of the most useful modern tools in algebraic work is furnished by the theory of determinants. Not only has this theory led to conciseness and clearness, but it has also led to new advances and deeper penetration. The earliest developments along this line are commonly credited to G. W. Leibniz, who is also generally regarded as one of the founders of the infinitesimal calculus. A manuscript due to Leibniz, dated $\mathrm{i} 678$, and a letter from Leibniz to G. F. A. de l'Hospital in 1693 contain some developments along this line.

In $175^{\circ} \mathrm{G}$. Cramer published a rule for finding the unknowns in a system of $n$ linear equations involving $n$ unknowns, and our common method for finding these unknowns by means of determinants is commonly called Cramer's Rule. This rule is of fundamental importance in the history of the theory of determinants, and Cramer's results were favorably received by contemporaneous mathematicians, while the work of Leibniz along the same line seems to have been forgotten until about a century later. On this account Cramer is often regarded as the founder of the theory of determinants.

Various early French writers extended the results of Cramer. Among these are Bézout, Vandermonde, Laplace, and Cauchy. The last one of these published in 1815 a very fundamental article on the theory of determinants in which he placed this subject on a firm basis as an independent theory. The inherent excellence of this article and the prestige of Cauchy served to 
secure for this subject more co-workers and to bring it to the attention of a larger public.

The term determinant was used by Gauss in his Disquisitiones Arithmetica, 1801, in the form "determinans," but it was here used for the special determinants of quadratic forms of two or three variables. Cauchy used as synonyms the terms determinants, resultants, as well as alternate functions, and the common use of the term determinant with its present significance for this function was largely due to the fundamental article by C. G. J. Jacobi which appeared in Crelle in $184 \mathrm{r}$. This extensive article by Jacobi marks one of the great advances in the theory of determinants. Just as the big memoir of Cauchy made the year $18 \mathrm{r} 5$ memorable in the history of determinants so this article of Jacobi marks the year $\mathrm{r} 84 \mathrm{r}$ as especially significant in this history.

The great usefulness of determinants even in somewhat elementary work led to the publication of special textbooks on this subject. Writers do not agree as to what should be called the first special book on this subject. In $185 \mathrm{I} \mathrm{W}$. Spottiswoode published in London a monograph of 63 pages, entitled Elementary Theorems Relating to Determinants. It consists of a preface which gives a brief historical sketch of the subject, and ten short chapters.

Some regard this as the first book on the subject. On the other hand, many are inclined to regard the more extensive and more accurate Italian work by F. Brioschi, which appeared in Pavia in 1854 under the title $L a$ Teorica dei Determinanti, e le sue Principali Applicazioni, as the first published book on this subject. This work 
was translated into French and into German in $185^{6}$, and it was soon followed by a number of other books on this subject. Especially noteworthy among these is the German work by R. Baltzer which appeared in 1857 and contained a large number of historical notes.

It is interesting to note that the development of the subject of determinants was carried on mainly in the periodicals for about a century before a separate treatise appeared on this subject. Both of the two fundamental monographs by Cauchy and Jacobi appeared as journal articles. In fact, a revised edition of Spottiswoode appeared in Crelle in 1856, five years after the first edition had appeared as a separate publication.

This constitutes further evidence of the great usefulness of journals in advancing mathematical knowledge. Most of the pioneer work is commonly published in the journals, since such work generally precedes those developments which are adapted to publication in book form. p. In recent years abstraction in the subject of determinants has led to a very extensive theory known as the theory of matrices. The square array of elements used to represent a determinant has been extended to a rectangular array, and a very useful calculus of such rectangular arrays has been developed.

Two English mathematicians, J. J. Sylvester and A. Cayley, took a very prominent part in the early work along this line, and the introduction of the term matrix with its technical meaning seems to be due to the former.* Although the notations for matrices and determinants

* J. J. Sylvester, An Essay on Canonical Forms, London, 1851; Phil. Mag., I852, p. 335 . 
are commonly somewhat similar, and some of the laws of operations are the same in the two subjects, yet these subjects are very different.

The distinction between the theory of determinants and the theory of matrices deserves especial emphasis in view of the fact that many good writers have confused these terms. Even in one of the very best modern books on determinants, viz., Kowalewski's Einführung in die Determinantentheorie einschliesslich der unendlichen und der Fredholmschen Determinanten, I909, "the whole chapter on orthogonal determinants is really a chapter on orthogonal matrices; the only fact proved, and the only non-trivial fact which can be proved, about an orthogonal determinant (i.e., the determinant of an orthogonal matrix) being that it is equal to $\pm \mathrm{r} . "$

"Properly regarded, the theory of determinants is hardly more than a shadow of the theory of matrices, and just so far as one attempts to ignore this fact does the subject become an artificial one or, at best, a tool for other investigations. Every book on determinants must be dominated more or less by the conception of the matrix, which first appears as an inanimate object, a mere rectangular array of quantities from which determinants, whose vanishing or non-vanishing are observed, or whose values are used, are cut out. Later, however, the matrix appears as an animated being, capable of combination by addition and at least two kinds of multiplication with its kind, and it is in this aspect that the conception becomes a highly fruitful one." *

* M. Bôcher, Bulletin of the American Mathematical Society, Vol. I7 (I9r I), p. 134. 
Another important abstraction in the theory of determinants has led to abstract formal definitions of this subject. Such definitions were given by Weierstrass and by Kronecker,* and they mark an important stage in the development of the subject. The early history of the theory of determinants has recently been made more easily accessible by two large volumes due to Thomas Muir, which were published under the general title The Theory of Determinants in the Historical Order of Development, I906 and I9II.

In the first of these two volumes the writings up to I84I are considered, while the second volume is devoted to publications which appeared from $\mathrm{I} 84 \mathrm{I}$ to $\mathrm{I} 860$. In view of the fact that it is so difficult to present the early developments of a subject without conveying too much or too little, the general plan followed in these volumes is " to reproduce the exact words of the authors where essential parts of the theory are concerned." Muir has also published very extensive lists of writings on determinants. The fifth of these lists appeared in the Quarterly Journal of Mathematics, volume 42, I9I I, page 343, and it contains references to the earlier lists, which appeared in the same periodical.

40. Numerical equations. - Equations in which at least one of the coefficients is denoted by a letter are called literal equations. Those in which every coefficient is a given number are called numerical equations. Every literal equation represents any one of an infinite system of numerical equations. Hence literal equations tend to

* Cf. G. Frobenius, Crelle, Vol. I29 (1905), p. I79, in regard to the question of priority involved. 
economize thought as they enable us to treat some of the difficulties relating to an infinite number of equations at one time. This generality tends to more intense application, and hence it seems often more simple to treat a general case than a special one.

Another advantage in dealing with literal equations is due to the fact that the literal coefficients maintain their identities during the process of solution, while numerical coefficients unite into masses giving no clue as to their components. This loss of identity in numerical work is the source of brevity as well as of obscurities.

On the other hand, the special numerical equations present many avenues of attack which cannot be used in the case of the literal equations. The great importance of the numerical equations has led to an extensive literature involving some methods of great generality and elegance. Among these, the method of determining the number and location of all the real roots by means of Sturm's Series deserves especial emphasis.

The earliest equations used by mathematicians were naturally numerical equations. Such equations appear already in the ancient Egyptian work by Ahmes, as well as in the writings of the ancient Greeks. The use of a special symbol for an unknown number marks a very important advance, but a much more difficult step in advance was taken when letters were introduced to represent any one of an infinite number of known numbers.

Naturally this step came long after the first use of a special symbol to represent an unknown number. In fact, the introduction of the systematic use of letters to 
represent known numbers is generally credited to the French mathematician F. Vieta ( $1540-1603$ ), who used letters for this purpose in his well-known In artem analyticam isagoge (I59I). It was, however, J. Hudde who first used intentionally the same letter to represent both a positive and a negative number, in his De reductione aquationum (I657). Before this time a given letter represented generally only a positive number. If a letter like $p$ was employed to represent a positive number, - $p$ was employed to represent a negative number.

The use of letters to represent knowns as well as unknowns is of fundamental importance in the development of algebra. In fact, much of the progress in algebra started with the introduction of letters to represent known numbers, and hence the work of Vieta plays such a fundamental rôle in the history of algebra. Notwithstanding this fact, the theory of numerical equations constitutes also an important part of algebra, which is not devoid of theorems of great generality and wide usefulness. It may be first noted that in proving some general theorems we may assume that the coefficients of such an equation are real, for if they were complex the equation could be written in the form

$$
\phi(x)+i \psi(x)=0,
$$

where both $\phi(x)$ and $\psi(x)$ have only real coefficients.

If both members of the last equation are multiplied by $\phi(x)-i \psi(x)$ there results an equation having only real coefficients, and which includes all the roots of the original equation among its roots. Hence it results that if we can find all the roots of every rational integral 
function of $x$ with real coefficients we can also find those of such a function with complex coefficients.

It is also important to observe that any real root of $\phi(x)+i \psi(x)=0$ is a common root of the two equations $\phi(x)=0$ and $\psi(x)=0$, and hence it is a zero of the highest common factor of $\phi(x)$ and $\psi(x)$. In view of these facts, and for the sake of brevity, we shall assume in the rest of this section that all the coefficients of the rational integral function in one unknown under consideration are real numbers, and we shall consider the equation formed by setting this function equal to 0 .

In 1829 C. Sturm published a very useful method to find the number of real roots lying between two arbitrary real numbers. This method soon became very popular, and it has continued to be the most elegant theoretic method pertaining to the solution of a numerical equation in one unknown. This method involves the finding of a series of polynomials in one unknown whose number does not exceed the degree of the original equation increased by one. These polynomials are derived from the original polynomial by certain rational operations and are called Sturm's Series.

If any two real numbers $a$ and $b$ are substituted for $x$ in Sturm's Series the difference between the number of variations of sign in the series when $a$ is substituted for $x$ and the number when $b$ is substituted for $x$ is exactly the number of the real roots of the original equation, whose values lie between $a$ and $b$. While Sturm's Series enables us to locate all the real roots with certainty it must be admitted that the labor involved in finding this series is sometimes too great for 
practical purposes, and hence other devices are often employed to locate these roots.

A very useful theorem relating to the solution of numerical equations appeared in No. 42 of the Disquisitiones Arithmetice of Gauss, in the following form: If the coefficients $A, B, C, \cdots, N ; a, b, c, \cdots, n$ of two functions of the form

$$
\begin{aligned}
& x^{m}+A x^{m-1}+B x^{m-2}+C x^{m-3}+\cdots+N \\
& x^{n}+a x^{n-1}+b x^{n-2}+c x^{n-3}+\cdots+n
\end{aligned}
$$

are all rational but not all integral, and if the product of $(P)$ and $(Q)$ is represented as follows

$$
x^{m+n}+A^{\prime} x^{m+n-1}+B^{\prime} x^{m+n-2}+\cdots+Z^{\prime},
$$

then it is not possible that all of the coefficients $A^{\prime}, B^{\prime}, \cdots Z^{\prime}$ are integers. Hence it results directly that if the equation

$$
f(x)=x^{n}+a_{1} x^{n-1}+a_{2} x^{n-2}+\cdots+a_{n}=0,
$$

in which all of the coefficients $a_{1}, a_{2}, \cdots, a_{\mathrm{n}}$ are integers, has rational roots these roots, must be integers. As they must also be divisors of $a_{n}$, all the rational roots of such an equation can frequently be found by a few trials. This special case had been treated by earlier writers, including Descartes.

When the degree of $f(x)$ exceeds 2 it is generally most convenient to determine the irrational roots of $f(x)=0$ by methods of approximation. A considerable number of such methods have been published. The general aim is to simplify the calculations involved. Theoretically the matter is very simple. 
In fact, it is only necessary to observe that if $f(a)$ and $f(b)$ have opposite signs then there is an odd number of real roots of $f(x)=0$ between the numbers $a$ and $b$, and vice versa. After $a$ and $b$ are so determined that only one real root lies between them and that is irrational, these numbers may be so selected successively that they differ from each other by decimals of higher and higher orders, and hence this irrational root can be determined to any desired degree of accuracy.

A considerable number of machines have been devised for the purpose of solving rapidly different numerical equations. In fact mechanical devices for the solution of the cubic equation associated with the Delian problem were known already to the ancient Greeks.

During the latter part of the nineteenth century a number of new mechanisms designed to solve numerical equations in one unknown as well as systems of equations in any number of unknowns were described in various journals. Some of these involve the theory of electricity and hydrostatics, while others were purely mechanical devices. One of the most noteworthy of the latter type is due to L. Torres and is described in Le Calcul Simplifié by M. d'Ocagne, I905, page I 23.

The ancient Greeks solved the quadratic equation by geometric methods. Such solutions appear in Euclid's Elements and in Euclid's Data. The Arabs used geometric methods to construct the roots not only of quadratic equations but also of certain cubic and biquadratic equations. The fact that we still use the geometric language, square and cube, to represent the second and the third degrees respectively, is evidence of the promi- 
nence of the geometric methods in the early development of the solutions of equations.

Starting with Descartes, the concept of function plays a more and more prominent rôle in the methods of solving numerical equations. Instead of confining the attention to the construction of the roots of $f(x)=0$, the attention is focused on the different possible values of $f(x)$ when different values are assigned to $x$. These values are represented graphically by constructing the locus of $y=f(x)$.

In this construction it may evidently be assumed that the coefficient of the highest power of $x$ in $f(x)$ is unity. When this is done $f(x)$ is completely determined by $n$ distinct points which satisfy $y=f(x)$. Hence the complete graph of any numerical quadratic can be found by means of the parabola $y=x^{2}$, constructed once for all.

In fact, it is only necessary to plot two points satisfying the equation $y=f(x), f(x)$ being the numerical quadratic in question, and then to place the parabola $y=x^{2}$ in such a position that its axis is parallel to the $y$-axis, the two given points lie on the curve, and the curve is concave upwards. If the quadratic has real roots, their values will be represented by the abscissas of the points where this parabola cuts the $x$-axis.

The complete graph of $f(x)$ evidently gives us much more information than is needed for the solution of the equation $f(x)=0$, but in mathematics we generally ought to know much more than what is actually needed, in order to understand more fully what is actually needed. Hence the graphic methods of representing 
functions whose zeros are required are in line with the general motive in mathematics to arrive at the required results as a special case of something much more general.

Mathematical facts are social facts. Their true meanings become clear only when their functions as members of the society to which they belong are clearly exhibited. Hence it results that an increase in mathematical knowledge tends to throw additional light on the previous knowledge, and that there is no upper limit to the desirable mathematical attainments for those who aim at a deep penetration into the elements of mathematics.

41. Domains of rationality. - The term division is used with two entirely different meanings in elementary mathematics. Sometimes we say that a given number $a$ can be divided by every number $b$, with the single exception that $b$ cannot be o. At other times we speak of division as if no numbers except rational integral numbers existed. In the latter sense we say, for instance, that the divisors of 6 are $\pm 1, \pm 2, \pm 3, \pm 6$.

In fact, we sometimes even restrict ourselves to positive integers in seeking the divisors of a given positive integer ; for instance, when we define a perfect number as a number which is equal to the sum of all of its divisors which are less than the given number. In a similar manner the term division is used in two senses in regard to algebraic expressions.

Although this ambiguity as regards the term division must have been felt for a long time, it is only in comparatively recent times that serious efforts have been made to remove it. These were probably due to the fact 
that larger questions, involving this ambiguity, began to present themselves. In the solution of algebraic equations the work of N. H. Abel (r802-29), as well as that of E. Galois ( $18 \mathrm{II}-32)$, directed especial attention to what should be regarded as known when certain quantities are given. The work of C. F. Gauss in number theory raised the same questions. In fact, these authors directed attention to the totalities obtained by performing upon certain numbers or symbols the four rational operations, - addition, subtraction, multiplication, and division, division by zero being excluded.

The term domain of rationality is due to $\mathrm{L}$. Kronecker (1823-9r), and the concept which it implies was greatly emphasized in much of the work of Kronecker. If a symbol $R$, which obeys the ordinary laws of algebra, is combined with itself (and with the expressions which result from such combinations) by addition, subtraction, multiplication, and division (division by zero being always excluded) in every possible way, there results a certain totality of expressions which evidently has the important property that no additional expression results from the rational combinations of the expressions of the totality. This totality is known as the domain of rationality constituted by $R$, and it is commonly denoted by $(R)$.

If $R=\circ$ this domain involves the single symbol $\circ$. In all other cases it involves an infinite number of expressions. If $R=\mathrm{I}$ the domain in question is clearly composed of all the rational numbers and the same domain results if $R$ is any other rational number. That is $(\mathrm{I}) \equiv(n), n$ being any rational number except $\mathrm{o}$. 
Various other terms have been used to denote practically the same concept as is denoted by the term domain of rationality. Among these terms those of field, realm, and corpus are especially well known. To understand the bearing of this concept it should be noted that the $n$th roots of unity form a closed totality as regards the two operations of multiplication and division, but they do not form a closed totality as regards the operations of addition and subtraction. On the other hand, the set of eight numbers

$$
-\mathrm{I},-2,3,4, \frac{1}{2}, \frac{3}{2}, \frac{2}{3}, \frac{1}{3}
$$

forms a closed totality as regards the operations of subtracting from 2 and of dividing 2 , as may be readily verified. Similarly the six expressions

$$
\sin ^{2} A, \cos ^{2} A, \sec ^{2} A, \csc ^{2} A,-\tan ^{2} A,-\cot ^{2} A
$$

form a closed totality as regards the two operations of subtracting from unity and dividing unity.

The concept of domain of rationality becomes clearer if it is used in connection with factoring an expression. For instance, if we are asked to factor the expression $x^{2}+\mathrm{I}$ it is evident that this is impossible in the domain unity. It is even impossible in the domain composed of all the real numbers. On the other hand, if we consider the smallest domain which contains $i=\sqrt{-\mathrm{I}}$; that is, the totality of the numbers $a+b i$, where $a$ and $b$ are rational numbers, it is clear that the given expression can be factored in this domain, its factors being $x+i$ and $x-i$. The expression $x^{2}+4$ can also be factored in the same domain, but $x^{2}+2$ cannot be factored in this domain. 
If a number, or an expression, cannot be factored in a certain domain it is said to be irreducible in this domain. A very elementary but somewhat general theorem in regard to an expression which is irreducible in the domain unity is known as the SchoenemannEisenstein theorem, which affirms that if $p$ is a prime number, and if $a_{0}, a_{1}, a_{2}, \cdots, a_{n}$ are integers, all except $a_{0}$ being divisible by $p$ but $a_{n}$ being not divisible by $p^{2}$, then $f(x)=a_{0} x^{n}+a_{1} x^{n-1}+\cdots+a_{n}$ is irreducible. ${ }^{*}$

Another very elementary theorem relating to the subject of reducibility is that the ordinary prime numbers which are of the form $4 n+\mathrm{I}$ can be resolved into two integral $\dagger$ factors in the domain generated by $i$, while those of the form $4 n$ - I cannot be thus factored. For instance, $5=(2+i)(2-i)$, but 7 is not the product of two integers in the domain generated by $i$.

The concept of domain of rationality may enter even into the questions of elementary geometry when we regard the plane as a number plane. The question arises what kinds of number planes are necessary for the construction required in the various problems under consideration. In fact, we may raise the larger question in regard to the number spaces in which all the ordinary constructions in our elementary geometry are possible.

"If we select three non-collinear points $A, B, C$ at pleasure, with the single limitation that the ratios of the distances $A B, A C, B C$ are algebraic numbers, and regard as existing in space only those points $M$, for which

* Cf. Schoenemann, Crelle, Vol. 32 (1846), p. 100.

$\dagger$ An algebraic integer is a root of the equation $f(x)=0$, when all its coefficients are rational integers and the first coefficient is unity. 
the ratios $A M, B M, C M$ to $A B$ are likewise algebraic numbers, then is the space made up of points $M$, as is easy to see, everywhere discontinuous; but in spite of this discontinuity, and despite the existence of gaps in this space, all constructions that occur in Euclid's Elements, can, so far as I can see, be just as accurately effected as in a perfectly continuous space; the discontinuity of this space would not be noticed in Euclid's science, would not be felt at all." *

42. Invariants. - In the study of elementary analytic geometry it is desirable to determine the fundamental properties of the curves represented by the general equation of the second degree in two variables, which may be written as follows :

$$
a x^{2}+b x y+c y^{2}+d x+e y+f=0 .
$$

By assigning to the various coefficients of this equation different real numerical values, there results a multiply infinite number of different numerical equations, each of which represents a certain locus, real or imaginary. To study this multiply infinite system of equations it is necessary to devise some method by which we can reduce the system to a finite number of standard forms. This is accomplished by means of linear substitutions and by noting the geometric meaning of these substitutions.

This simple and well-known instance of the use of linear substitutions directs attention to the importance of these substitutions as an instrument for reducing a complex problem to a much simpler one, which is one of the main functions of mathematics. This importance

* Essays on the Theory of Numbers. By R. Dedekind, 1909, p. 37. 
was noted very early in special cases. In considering the representation of an integer by the following quadratic form *

$$
a_{0} x^{2}+2 a_{1} x y+a_{2} y^{2}
$$

Lagrange ( $1736-1813$ ) observed that its discriminant $a_{0} a_{2}-a_{1}{ }^{2}$ remained invariant if $x$ is replaced by $x+\lambda y . \dagger$ Gauss ( $1777-1855)$ used the general linear substitution in two variables and proved that the discriminant of the given form is an invariant under such a substitution.

Numerous other instances of the early appearance of invariants have been noted, but the subject of invariants was moved into a much more prominent place in the mathematical literature through the work of the two great contemporary English mathematicians, J. J. Sylvester (1814-97) and A. Cayley (1821-95). The latter is frequently called the founder of the theory of invariants, which relates not only to algebra but permeates many other mathematical disciplines.

Different methods have contributed to its development; some of these are algebraic, while others are more closely related to geometry and to function theory. This variety in methods of approach makes it often difficult to observe the connection between results obtained in different ways, and this difficulty has been offered as the chief reason why a knowledge of the theory of invariants is not more common.f

* The term form in algebra is commonly used for a rational integral bomogeneous function of $n$ variables. When $n=2$ the form is said to be binary and when $n=3$ it is said to be ternary, etc. Some writers, including Kronecker, use the term form even when the function is not homogeneous.

$\dagger$ Berlin Mem., 1833, p. 265.

$\ddagger$ W. F. Meyer, Allgcmeine Formen- und Invariantentheorie, 1909, Einleitung. 
An invariant of an algebraic form, or of a geometric figure, is not an intrinsic property of this form or of this figure, but it depends upon the transformation or the set of transformations which are under consideration. For example, if our set of transformations is composed of displacements, the properties of two straight lines being parallel or perpendicular to each other are invariant properties; but when we consider the totality of all collineations, these properties are not invariant, and hence the algebraic function of the coefficients whose vanishing exhibits these properties is not an invariant under the latter transformations. The theory of invariants is therefore concerned with static properties which are intimately connected with the dynamic properties of transformations and groups of transformations.

It should be emphasized that a rational function of the coefficients is called an invariant even when this function is not left entirely unchanged under certain transformations. In fact, a rational function of the coefficients of a form or of a system of forms which is merely multiplied by the $k$ th power of the determinant of transformation, when these forms are subjected to any non-singular linear transformation, is called an invariant of weight $k$ of the form or of the system of forms. To distinguish this type of invariants from those which are not changed at all they are called relative invariants, while the latter are called absolute invariants. When all the determinants of the linear transformations under consideration are equal to unity, then the relative invariants clearly reduce to absolute invariants.

A fundamental problem in the theory of invariants is 
the determination of the independent invariants of a given form. For instance, the form

$$
a_{0} x^{2}+2 a_{1} x y+a_{2} y^{2}
$$

has only one invariant under the linear homogeneous transformations of its variables; viz., the discriminant $a_{0} a_{2}-a_{1}^{2}$, in the sense that all the other invariants of this form are functions of its discriminant.

The two simultaneous linear forms $a_{0} x+a_{1} y, b_{0} x+b_{1} y$ have also only one simultaneous invariant; viz., their resultant $a_{0} b_{1}-a_{1} b_{0}$. On the other hand, the two simultaneous quadratic forms

$$
\begin{aligned}
& a_{0} x^{2}+2 a_{1} x y+a_{2} y^{2} \\
& b_{0} x^{2}+2 b_{1} x y+b_{2} y^{2}
\end{aligned}
$$

have the following three invariants $a_{0} a_{2}-a_{1}^{2}, b_{0} b_{2}-b_{1}^{2}$, $a_{0} b_{2}-2 a_{1} b_{1}+a_{2} b_{0}$. The earliest treatise on the theory of invariants was Salmon's Lessons Introductory to the Modern Higher Algebra, London, 1859. A brief modern introduction to the subject is furnished by the monograph entitled Algebraic Invariants, by L. E. Dickson, New York, I9i4.

43. Binomial theorem. - In some histories of mathematics there appears the statement that the binomial theorem was discovered by I. Newton, and that this discovery was regarded as so important that the binomial formula was selected from among the many important discoveries of Newton to be engraved on his monument in Westminster Abbey. F. Cajori has made a careful study in regard to the latter part of this statement and reached the conclusion that the binomial formula prob- 
ably did not appear on Newton's monument.* The fact that it was reported to have been thus engraved may, however, serve to direct attention to the importance of this discovery in the eyes of Newton's contemporaries.

It is therefore of especial interest to consider the part Newton took in the development of the important theorem in question. This will throw some light on the fact that brief historic statements are so often misleading, since they frequently credit one man for work done by a number of different individuals. In the present instance it should be said that special cases of the binomial formula were known long before Newton's days, and that B. Pascal, in particular, had done much work along this line. In fact, J. Bernoulli gave Pascal the credit for having discovered the binomial formula for a general exponent, but this was probably not correct.

It is, however, well established that the first complete proof of the binomial formula for all real numbers is not due to I. Newton, but to L. Euler, who gave such a proof in I773. Newton seems to have been the first to state this formula explicitly in the following form:

$$
(\mathrm{I}+x)^{m}=\mathrm{I}+\sum_{n=1}^{n=m} \frac{m(m-\mathrm{I}) \cdots(m-n+\mathrm{I})}{\mathrm{I} \cdot 2 \cdot \ldots \cdot n} x^{n} .
$$

When $m$ is not a positive integer the summation extends to $n=\infty$ instead of to $n=m$. Newton considered the case when $m$ is any real number and concluded that the formula is true for all such values without giving a real demonstration of this fact.

* F. Cajori, Bulletin of the American Mathematical Sociely, Vol. I (I895), p. 52 . 
Although Euler gave a complete and elegant proof of this formula when $x$ and $m$ are any real numbers, there still remained the question whether the formula is also true when $x$ and $m$ are complex numbers. Two other very prominent mathematicians supplied this part of the proof of the general formula under consideration. In the first place, A. L. Cauchy studied the case when $x$ is a complex number and proved that the second member of this formula, from $n=\mathrm{I}$ to $n=\infty$, is a converging series representing the first member whenever the absolute value of $x$ is less than $\mathrm{I}$.

Finally, N. H. Abel considered the case when $m$ is also a complex number $p+i q$, and published a classic memoir in the first volume of Crelle in which he proved that the second member of the given formula is absolutely convergent whenever the absolute value of $x$ is less than I. This memoir is fundamental not only on account of the fact that it contains a proof of the given formula but also because it includes a study of continuity of functions defined by series. It has been republished in Ostwald's Klassiker der exakten Wissenschaften, No. 7 .

These developments may serve to show how imperfectly such a brief statement as "Newton discovered the binomial theorem" exhibits the actual situation. With almost equal justice one might say that Euler, Cauchy, or Abel discovered this theorem. In fact there are still other circumstances which tend to diminish Newton's claims along this line.

In the famous Arithmetica integra published by $\mathbf{M}$. Stifel in $\mathbf{5} 544$ there occurs a theorem, without proof, 
which gives the binomial coefficients of the $m$ th power of a binomial in terms of those of the $(m-1)$ th power; and more than four centuries earlier, the well-known Arabian mathematician, Omar Alkhayami, made a statement in his algebra which seems to imply that he was able to determine the coefficients of the successive terms in the expansion of a binomial raised to any positive integral power.

The binomial coefficients for small positive integral values of $m$ were also used by Stifel, Vieta, and others to formulate rules for the extraction of various roots of numbers. Such rules can be readily formulated, but the corresponding operations soon become very tedious. In fact, even for the extraction of the cube root the operations are somewhat laborious. Since logarithms have come into general use these rules to extract roots beyond the square root have little practical value, but the close connection between them and the binomial theorem tends to increase the difficulty to decide who should be credited with the discovery of this theorem. While it is thus often difficult to determine who should be regarded as the discoverer of a given theorem or formula, it is usually much more difficult to determine who should be regarded as the founder of a large subject.

Hence it may be surprising to find that some subjects are said to have their particular birthdays. In a letter from Sir W. R. Hamilton to P. G. Tait, dated October I5, 1858, we read as follows: "To-morrow will be the $15^{\text {th }}$ birthday of the quaternions. They started into life, or light, full grown, on the I6th of October, I843, as I was walking with Lady Hamilton to Dublin, and came up to 
Brougham Bridge, which my boys have since called the Quaternion Bridge. That is to say, I then and there felt the galvanic circuit of thought close; and the sparks which fell from it were the fundamental equations between $i, j, k$; exactly such as I have used them ever since." * In a less emphatic manner Jacobi called the 23d of December, 175I, the birthday of Elliptic Functions, because on this day a work by the Italian mathematician Fagnano, which had been sent to the Berlin Academy, was handed to Euler for review. The study of this work led Euler to his important investigations on elliptic integrals and to the discovery of the addition theorem. $\dagger$ Hence such birthdays may have significance even if they represent only a part of the truth.

After considering various facts relating to the discovery of the binomial theorem the reader may perhaps continue to say "Newton discovered the binomial theorem," but what a difference between the meaning of this statement to such a reader and to one who knows no more about the history of this theorem than this brief statement conveys! The enrichment of brief statements is one of the happy results of study, and this is especially true as regards historical questions. This enrichment is not only a source of pleasure, but it is often, as in the present case, essential for the purpose of arriving at the true situation.

* Life of Sir William Rowan Hamilton by R. P. Graves, Vol. 2 (1885), p. 435. † Encyklopädie der Mathematischen Wissenschaften, Vol. 2, Part 2, p. 183. 


\section{CHAPTER VII}

\section{Twenty-five Prominent Deceased Mathematicians}

44. Introduction. - Thousands have contributed materially to the development of mathematics, and hundreds have contributed to such a marked degree that their works deserve to be studied by themselves. As was stated in $\S \mathrm{I}_{5}$, the collected works of about 300 different mathematicians have already been published, and some of the most important works still await separate publication.

In view of these facts it is clear that a list of twentyfive prominent names cannot include all those which the student of mathematics will frequently meet. This small list may, however, serve to make a good beginning, as it was selected with a view to include only those of unusual prominence in one or more extensive fields of mathematics.

While the theorems discovered and the methods invented are of greater importance than the biographies of the discoverers or of the inventors, yet some account of the men involved adds interest, and hence such an account may serve to make it easier for the reader to get a clear notion of the developments made at various periods. Such a knowledge tends also towards a closer correlation between mathematical developments and other activities. Mathematical eminence depends more 
upon the character of the new results obtained than upon the number of these results, and some of the most eminent mathematicians have produced much less than others who may be less noted.

In recent times coöperation between different investigators is becoming more and more necessary in view of the large amount of labor involved in developing the extensive new fields. Hence mathematical eminence frequently implies leadership and influence in attracting successful workers into particular fields. As the developed part of mathematics increases, the newer methods and instruments of work naturally call for more extensive applications, and hence for more workers. It remains, however, true that leadership here implies superiority of insight and actual proof of ability on the part of the leaders, since those who follow do so by their own choice and are free to change from one leader to another.

The following brief biographical sketches are arranged in chronological order according to the dates of birth of the various subjects of these sketches. As regards nationality, the first four belonged to the Greek Schools; Vieta, Descartes, Fermat, Cauchy, Galois, Hermite, and Poincaré were French; Leibniz, Gauss, Steiner, Weierstrass, and Kronecker were German; while Newton, Hamilton, Sylvester, and Cayley were English.

Euler was a Swiss, but he spent a great part of his life at Berlin and at Petrograd. Lagrange and Cremona were Italians, but the scientific life of the former was largely spent at Berlin and at Paris, and he is often classed with the French mathematicians. Abel and Lie were Norwegians who received a part of their scientific train- 
ing in France and Germany, and Lie was professor at the University of Leipzig for a number of years. As a matter of fact, mathematical activities are cosmopolitan and questions of nationality play a minor rôle.

This list of names furnishes, however, further evidence of the centralization of mathematical advances in the past. With our better facilities of communication and travel it appears likely that these centralizations will be less pronounced in the future. In fact there are many evidences at present of a world-wide coöperation in advancing mathematical knowledge. It is to be hoped that this will result in the improvement of quality as well as in the increase in quantity, so that mathematics may continue to hold its eminent place in the sum of the human knowledge which is a source of intellectual delight and of physical comfort.

45. Euclid. - One of the most noted mathematical names is that of Euclid, but this name is not coupled with any extensive biography. In fact, we have practically no definite knowledge in regard to the life of this eminent Greek scholar, but a very large number of unreliable and conflicting statements have been published. Even the dates of his birth and his death are not known.

The great and permanent reputation of Euclid is mainly due to the fact that he is the author of a treatise on elementary mathematics commonly called Euclid's Elements. It is frequently called a geometry, but a considerable part of it is arithmetic and number theory. These subjects are, however, treated from a geometric point of view. 
The parts of Euclid's Elements which are devoted to what we now commonly regard as elementary geometry have doubtless been the most influential. In fact, these parts have served as models for textbooks for more than two thousand years. In recent years our school geometries have not generally followed so closely in the footsteps of Euclid's Elements as had been done earlier.

It should not be inferred that Euclid developed all of our elementary geometry without having some earlier models to follow. As a matter of fact, it is well known that earlier Greek treatises have existed. The earliest of these according to Proclus was due to Hippocrates of Chios, who flourished in the second half of the fifth century B.C.

Euclid's Elements seem to have been so much superior to those composed by earlier writers that they made these earlier treatises unnecessary. At any rate, none of them were preserved. This fact is perhaps one of the greatest tributes to the genius of Euclid. It should be observed that little is known in regard to what parts of the Elements are actually due to Euclid and what parts are due to earlier writers. Hence it is not possible to form a reliable estimate of Euclid as a mathematician, since the creative faculty should always be considered first in forming an opinion about the greatness of a mathematician.

Euclid had the good fortune to be associated with the establishment of the first great university; viz., the University of Alexandria, which was opened about 300 B.C. in the city founded by Alexander the Great on a mouth of the Nile. After the death of Alexander, Ptolemy selected Alexandria as the capital of his king- 
dom, and he soon began to erect university buildings on land adjoining his palace.

By means of this university Ptolemy attracted learned men of various kinds to Alexandria, and thus made it the intellectual center of the world. As a teacher in this university Euclid enjoyed unusual opportunities, which should be considered in thinking of the great mathematical influence which he has exerted.

It may be observed that the fact that Euclid's Elements superseded the less perfect works of his predecessors, and that these works consequently have entirely disappeared appears to have advantages, since it has relieved the succeeding mathematicians from the trouble of studying these earlier imperfect works. This relief should have enabled these mathematicians to devote their attention to the more important work of advancing mathematical knowledge. From this point of view our modern tendency to accumulate facts at an enormous rate, and to make as many as possible of these facts available by means of indexes and other works of reference, might be regarded as unfortunate, since it might appear to be a method tending to preserve the good and the bad with almost equal care instead of letting the law of the survival of the fittest work naturally. In fact, some seem to have regarded the historical tendency of our age with misgivings on the ground that it tends to nurture what nature should be permitted to kill to make room for better things.

Although there is much to be said in favor of these views, yet there is also very good argument on the other side. In particular, the given case of Euclid's Elements 
is not entirely clear. While these Elements have doubtless preserved the best mathematics of their times, they were followed by a period of stagnation, and it is not at all established that some of the less perfect works which were lost would have been less effective in starting young men in active scientific careers. The complete oversight of the less perfect may be a sign of stagnation, and hence our modern interest in preserving so much may be a sign of a very healthy condition.

Euclid wrote several works besides the Elements. Some of these seem to be lost while others are still extant. Among the latter are the Data, On Divisions (of figures), and Optics. One of the lost works was called Pseudaria and seems to have been especially useful for the beginner in elementary geometry. A considerable amount of controversial literature exists in regard to the lost books of Porisms, which were conjecturally restored by Simson and Chasles. The works and traditions about Euclid are discussed in the Introduction to the Thirteen Books of Euclid's Elements by T. L. Heath, rgo8.

46. Archimedes. - The brief characterization "Archimedes $(287-212$ B.c.) was the greatest mathematician of antiquity" is sufficient to direct our attention forcibly to one of the most important names in the history of mathematics. Although we know somewhat more about the life of Archimedes than about that of Euclid, yet the well-established facts relating to the life of Archimedes are few. For instance, all agree that he perished in the sack of Syracuse (2 22 B.c.) but a number of different and contradictory accounts of the manner in which he met death have been published. 
"An extraordinarily large proportion of the subject matter of the writings of Archimedes represents entirely new discoveries of his own. Though his range of subjects was almost encyclopedic, embracing geometry (plane and solid), arithmetic, mechanics, hydrostatics, and astronomy, he was no compiler, no writer of textbooks; and in this respect he differs even from his great successor Apollonius, whose work, like that of Euclid before him, largely consisted in systematizing and generalizing the methods used, and the results obtained, in the isolated efforts of earlier geometers. There is in Archimedes no mere working up of existing materials; his objective is always some new thing, some definite addition to the sum of knowledge, and his complete originality cannot fail to strike any one who reads his works intelligently, without any corroborative evidence such as is found in the introductory letters prefixed to most of them." *

One marked feature about most of the work of the Greek mathematicians is that they give results only, without any indication as to the methods used to arrive at these results. Hence the reader is often led to admire these results rather than to meditate on their connections and possible extensions. Fortunately Archimedes wrote a treatise on method, in which he indicates by what means he arrived at some of his most important results. This treatise was supposed to be irretrievably lost until I906, when a copy of it was found at Constantinople by the noted scholar of the works of Archimedes, J. L. Heiberg.

This work on method shows that Archimedes used the elements of what is equivalent to the integral calculus

* The Works of Archimedes, by T. L. Heath, I897, p. xxxix. 
of modern times. In fact, some of the work of Archimedes previously known gave evidence of the use of an integral calculus method, but his treatise on method exhibits this fact more clearly and shows that Archimedes regarded this as a useful and general method which was likely to lead to other important results.

A few of the most beautiful discoveries of Archimedes, relating to the area and volume of a sphere, were mentioned in $\S 34$. It is interesting to observe that while the discoveries in mechanics and in mechanical devices seemed to have contributed most forcibly towards the local reputation of Archimedes, he himself seems to have delighted mostly in those relating to pure mathematics, as may be seen from the fact that he desired to have engraved on his tombstone the figure of a sphere inscribed in a cylinder, together with an inscription giving the ratio which the surface and the volume of the cylinder bear to the corresponding elements of the sphere.

Cicero, when quæstor in Sicily, identified the tomb by means of this inscription, and, as it was in a neglected state, he restored it. The works of Archimedes have been made more readily accessible to English readers through the scholarly efforts of T. L. Heath, who edited them in 1897 in modern notation and with introductory chapters, and in I9I 2 added as a supplement an English edition of the Method of Archimedes.

47. Apollonius of Perga. - Apollonius of Perga (in Asia Minor) lived in the latter part of the third century and the earlier part of the second century B.c. He is best known as the author of a great work on Conic Sections, consisting of eight books. It is interesting to note 
that three of the twenty-five names selected for this chapter relate to the third century B.c. These names mark this century as the most important in the early history of mathematics. In fact, this century stands out in the history of mathematics as a high peak which is preceded by several centuries of increasing elevations and is followed by almost twenty centuries marked by only a few noteworthy eminences. Most of the latter are noticeable only on account of the fact that they are surrounded by such low general mathematical attainments.

The treatise on Conic Sections by Apollonius was based on similar works of earlier writers, but it was much more complete than these earlier treatises and, like Euclid's Elements, it soon became the standard work relating to the field concerned. In recognition of the merits of this work, Apollonius was called by his contemporaries and successors the "great geometer."

Only seven of the original eight books have survived; four of these have come down to us in the original Greek, while the remaining three were preserved in Arabic translations. The style of Apollonius is such that his work is somewhat difficult to read for the modern student, and this may account for the fact that his treatise on Conic Sections has not been commonly followed as a model in the production of textbooks. In this respect it differs widely from Euclid's Elements.

It is of interest to note that Apollonius made use of coördinates and transformation of coördinates. He was, however, not the first to use coördinates, but the same point of view appears in earlier works on Conic Sections. "Thus Menæchmus (a contemporary of Plato) used the 
characteristic property of the parabola which we now express by the equation $y^{2}=p x$, referred to rectangular axes. He used also the property of the rectangular hyperbola which is expressed in our notation by the equation $x y=c^{2}$, where the axes of coördinates are the asymptotes. Archimedes too used the same form of equation for the parabola." *

The coördinate systems used by the Greeks were, however, different from the general systems used in our modern analytic geometry, since the former were confined to special lines related to the figures in question.

The developments of the Conic Sections due to the ancient Greeks became very useful two thousand years later when it was found that the planets of our Solar System move in orbits which are approximately conic sections. This is a very interesting example of the permanent value of developments of pure mathematics. The ancient Greeks emphasized the fact that mathematical knowledge should be pursued for its own sake rather than with a view to direct applications, and this ideal may partly explain their extraordinary progress and the great beauty of their results. Since their day these results have become useful in various subjects of applied mathematics.

Very little is known in regard to the life of Apollonius. He studied at Alexandria in northern Egypt, which was then the most noted center of learning. Euclid was the first noted teacher of mathematics at Alexandria and established the study of pure mathematics in this intellectual center, where there was a large library containing

*A Aollonius of Perga, by T. L. Heath, 1896, p. cxv. 
about 600,000 rolls. After his sojourn at Alexandria, Apollonius returned to Pergamum, where he wrote his Conic Sections.

He wrote a number of shorter works. Some of these are now known only by their titles, while several others have been restored by various writers. In 1896 the treatise on Conic Sections was "edited in modern notation with introductions including an essay on the earlier history of the subject " by T. L. Heath. It may be added that Apollonius used the terms parabola, ellipse, and hyperbola for the curves now known by these terms.

48. Diophantus of Alexandria. - The three Greek mathematicians which have been noticed - Euclid, Archimedes, and Apollonius - were closely related in time and in general type of work. On the other hand, Diophantus (about 300 A.D.) represents the mathematical development which came about six centuries later.

While the earlier Greek writers confined themselves almost exclusively to geometric methods, Diophantus used algebraic methods. He is preëminently the Greek writer on algebra. Practically nothing is known about his life. Even the period at which he lived is a subject on which very different views have been expressed. To distinguish him from other writers who were called Diophantus, he is often called Diophantus of Alexandria.

Probably most students meet the name of Diophantus for the first time in connection with a certain method, known as Diophantine Analysis, of solving indeterminate equations. It is a singular fact that this method, which admits only integral values for the unknowns, is not the one commonly employed by Diophantus. 
In fact, Diophantus sought solutions involving rational fractions as well as integers, but he did not give negative numbers as solutions. He did, however, work with differences. For the multiplication of differences he gave the rule: "A subtracted number multiplied by a subtracted number gives an added number, and a subtracted number multiplied by an added number gives a subtracted number."

Probably the most important feature of the algebraic work of Diophantus is the fact that he used abbreviations for words and thus developed a kind of symbolic algebra. Equality is denoted by the letter $\iota$, and subtraction is represented by an inverted $\psi$ but there is no special sign for addition beyond juxtaposition. In the manuscripts the symbol for subtraction is commonly written in the form $\Lambda$. A special symbol is used for the unknown and various quadratic equations are solved, but only one solution is obtained for such an equation even where the equation has two positive roots.

When the two roots are negative or irrational the equation is rejected as an "impossible" equation. In the extant part of his work he solves only one cubic equation, viz., the equation

$$
x^{2}+2 x+3=x^{3}+2 x-3 x^{2}-\mathrm{I}
$$

which arose in the solution of the problem to find a right-angled triangle such that the sum of its area and hypotenuse equals a square, and its perimeter equals a cube.

The development of algebraic notation has been divided, by Nesselmann, into three stages. The first is rhetorical 
algebra, where the algebraic reasoning is expressed in words without the use of symbols. This stage is represented by Ahmes and by most of the early Greek writers who preceded Diophantus, as well as by many later writers.

The second stage is called syncopated algebra, and represents the use of abbreviations for the operations and quantities which occur frequently. Modern algebra, which has a language of its own, is called symbolic algebra. According to this classification the arithmetica of Diophantus may be called syncopated algebra. The bulk of this work consists of problems leading to indeterminate equations of the second degree.

The arithmetica of Diophantus is also valuable on account of its theorems in number theory. Among these are the following: No number of the form $8 n+7$ can be the sum of three squares and no number of the form $4 n+3$ can be the sum of two squares. The results obtained by Diophantus along this line are of great historic interest in view of the fact that the beautiful theorems on number theory due to Fermat seem to have started from these results.

49. Vieta. - F. Vieta is sometimes called the father of modern algebra, since he was the first to use letters consistently for both the known and the unknown quantities. The use of these letters was, however, restricted by Vieta to positive numbers. J. Hudde seems to have been the first to have used purposely the same letter to represent both positive and negative numbers, in his De reductione aquationum, 1657 .

Vieta was born in 1540 near Rochelle, France, and died in Paris in 1603 . He was educated for a lawyer 
and spent a considerable part of his life in public service. His great work entitled, In artem analyticam isagoge, was published in I59I and is largely devoted to the application of algebra to the solution of geometrical problems.

The following incident, which added greatly to Vieta's mathematical reputation, throws also some light on the conditions existing in his days. An ambassador from the Netherlands remarked to King Henry VI that France did not have any geometrician who was able to solve a problem propounded in 1593 by his countryman, Adrian Romanus, to all the mathematicians of the world, and which required the solution of an equation of the 45th degree. Whereupon the king summoned Vieta and informed him of the challenge. Vieta was able to furnish two solutions in a few minutes, as the problem was related to some work done earlier by Vieta on the expression of $\sin n \theta$ in terms of $\sin \theta$ and $\cos \theta$.

The ancient Greeks, before Diophantus, distinguished between numerical calculation, which they called logistica, and a study of the properties of numbers, which was called by them arithmetic. Vieta used the terms logistica numerosa and logistica speciosa for numerical calculations and for literal calculations respectively, and thus emphasized the calculations by means of letters. $\mathrm{He}$ also emphasized the desirability of working with homogeneous equations.

The geometrical methods of the earlier Greeks naturally led to equations in which each term was of the same degree. To combine areas and lines seemed to have no meaning, but the later Greeks, like Heron and Dio- 
phantus, used also non-homogeneous equations. Vieta may have been led to emphasize the desirability of working with homogeneous equations through the study of Greek writers who had not always followed this rule.

50. Descartes. - Our common rectilinear system of coördinates is commonly called the Cartesian System of Coördinates in honor of Descartes whose Latin name was Cartesius. It should, however, not be inferred that Descartes developed this system completely. As a matter of fact, the introduction of systems of coördinates began in antiquity and was not completed before Introductio in analysin infinitorum, I748, by L. Euler. While both Descartes and Fermat made great forward steps towards the establishment of our modern system of coördinates, certain remarks of Descartes show that he was in reality far from the complete modern notion of coördinates.*

Notwithstanding this fact, Descartes is commonly called the founder of analytic geometry. It should be observed, however, that the man who is called the founder of a large mathematical subject is generally not the one who first worked in this particular field nor the one who developed many finishing touches, but the one who made the earliest extensive advances. In this sense we speak of Newton and Leibniz as the founders of the infinitesimal calculus, of Gauss as the founder of number theory, and of Cauchy as the founder of determinants and the theory of substitutions.

René Descartes was born near Tours on March 3I, 1596, and died on February I I, I650, at Stockholm,

- Cf. Encyclopedie des Sciences Mathématiques, tome 3, Vol. 3, p. 17. 
where he had gone a few months earlier on the invitation of Queen Christina. He was a noted philosopher as well as a mathematician. In 1637 he published an extensive work under the title Discours de la méthode pour bien conduire sa raison et chercher la vérité dans les sciences. An appendix to this work was called La Géométrie and contains the developments which won for him the renown as founder of analytic geometry. La Géométrie is the most important mathematical work of Descartes, and it became very influential also in fixing algebraic notation. For instance, the use of the last letters of the alphabet for the unknowns and the first for the knowns was introduced by this work.

It is also important to observe that Descartes represented the product of $a$ and $b$, where $a$ and $b$ correspond to the lengths $L$ and $L^{\prime}$, by a length which has the same ratio to $L$ as $L^{\prime}$ has to the unit length. This was a great advance over Vieta and the ancient Greeks, who represented the product by an area when each of the factors represents a length.

Although the title of La Géométrie would indicate that it was a work confined to the study of geometry, yet this is not the case. It is largely devoted to algebraic questions and is very important in the history of the theory of equations. In particular, it contains the famous Rule of Descartes giving an upper limit to the number of positive and negative roots of a numerical equation by means of the number of variations or permanences of the signs of its coefficients. It also contains the theorem that the polynomial $f(x)$ is divisible by $x-a$ whenever $a$ is a zero of this polynomial. 
A special case of this theorem is found in the work of Cardan, and it is possible that Descartes had become acquainted with this special case during his travels in Italy. He traveled considerably and used this means to become acquainted with the advances that had been made in the various countries.

51. Fermat. - The name of Fermat has become expecially well known in recent years on account of the large mathematical prize for a proof of Fermat's greater theorem, which was explained in $\S 3 \mathrm{I}$. To students of elementary number theory the smaller Fermat theorem (viz., the theorem that

$$
a^{p-1}-\mathrm{x}=k p
$$

whenever $p$ is a prime number and $a$ is not divisible by $p$ ), and its various generalizations is also well known. In view of the fundamental importance of this theorem it seems unfortunate that it is called the smaller Fermat theorem. Fermat has, however, many other serious claims to a prominent place among the great mathematicians of all times. His contributions were so numerous and important that he has been called by $\mathbf{M}$. Cantor and others the greatest French mathematician of the seventeenth century, notwithstanding the fact that Descartes and Pascal lived in the same century.*

Pierre de Fermat was born near Toulouse in 1601 and died at Castres in 1665. He published only one paper, but he was in scientific correspondence with leading mathematicians of his day and thus exerted great influence. He worked in various fields with great suc-

* Bulletin of the American Mathematical Society, vol. 7 (1901), p. 160. 
cess, but he is especially well known on account of the theorems in number theory which he wrote without proof on the margin of his copy of Diophantus. By means of these theorems, which were influential in directing the attention of later mathematicians to this field, Fermat did much to awaken an interest among his contemporaries and successors in this fundamental subject. Some of the leading later mathematicians have supplied proofs for theorems announced by Fermat.

In analytic geometry Fermat went beyond Descartes and he describes more clearly than the latter did how to find the equation which corresponds to a geometric figure. His method of determining maxima and minima and the tangents anticipates the infinitesimal calculus, and he is sometimes called one of the founders of this subject as well as one of the founders of analytic geometry.

His work in the theory of probability is so important that he is commonly regarded as sharing with Pascal the honor of founding this subject. The well-known Pell's equation was studied by Fermat and should really be called Fermat's equation as is done by some modern writers. A part of Fermat's works was published by his son Samuel, who also published the copy of Diophantus which contained numerous important marginal notes due to his father. Recently more complete works of Fermat, edited by Paul Tannery and Charles Henry, have been published in four volumes under the auspices of the French Minister of Public Instruction.

52. Newton. - Isaac Newton is the earliest English mathematician in our list of twenty-five, and he repre- 
sents an unusual breadth of scientific attainments, which has made his name one of the most prominent in scientific literature. His discoveries relating to the law of gravitation in our solar system tended to emphasize the importance of mathematical methods and helped to gain a more general appreciation of the usefulness of mathematics in the study of the physical world.

While Newton's developments in mathematics were very significant, his methods directed attention to a need for more extensive developments, and this fact was a still more significant feature of his work. Notwithstanding the fact that he made important mathematical contributions, he left the world with a greater hunger for new developments in mathematics than he found it. In particular, he founded the subject of celestial mechanics, whose development led to important mathematical advances.

He was born in Lincolnshire, near Grantham, on January 5,1643 (N. S.), ${ }^{*}$ and died at Kensington, London, on March 3I, I727. He was educated at Cambridge and was appointed professor of mathematics in the University of Cambridge to succeed Isaac Barrow, who, in October, $\mathrm{r} 669$, had resigned the Lucasian chair in favor of Newton. In I696 he was appointed to an important government position and moved to London, where he resided until his death.

Although he had serious controversies with Leibniz, Hooke, and others, his discoveries were at once appreciated and won for him great fame, which involved him in

* Some writers say that Newton was born in 1642 . This is due to the fact that they use the old style of reckoning time. According to this style Newton was born on December 25, 1642 . 
much correspondence. The following modest statement throws light on his character : "I do not know what I may appear to the world; but to myself I seem to have been only like a boy, playing on the seashore, and diverting myself in now and then finding a smoother pebble, or a prettier shell than ordinary, whilst the great ocean of truth lay all undiscovered before me."

Newton began his work as professor in the University of Cambridge by lecturing on optics, and his investigations in this field soon led to the discovery of the decomposition of a ray of white light into rays of different colors by means of a prism. During the ten years from I673 to I683 his professional lectures were on algebra and the theory of equations, and the substance of these lectures was embodied in his Arithmetica Universalis, published in $\mathbf{1 7 0 7}$.

This algebra contains a considerable number of new results, including the elegant formulas, still known by his name, to express the sums of the various powers of the roots of an equation in terms of the elementary symmetric functions of these roots. The use of a general literal exponent in the form $a^{m}$ was also introduced by Newton, Descartes having confined himself to the use of this notation for special values of $m$, such as $a^{3}, a^{4}, \cdots$. In place of $a^{2}$ Descartes used $a a$ in his geometry. Newton's connection with the binomial theorem was considered in $\S 43$.

In 1684 Halley came to Cambridge to consult Newton about the law of gravitation, and the conversations with Halley induced Newton to take up anew this great subject. This led to his noted Principia, the first book of which was presented to the Royal Society in April, 
1686. The second and third books followed soon thereafter, and the publication was completed, with the assistance of Halley, in the summer of 1687 .

While many of the results contained in this great classic were obtained by analysis, they are presented by means of ancient geometric methods, and hence the work is more difficult to read than if more modern methods had been employed. It exhibited, however, the extraordinary ability of Newton to cast into classic form difficult proofs obtained by more powerful modern methods, and it constitutes one of the most influential works ever produced.

Newton's great mathematical reputation is largely due to the fact that he was one of the founders of infinitesimal calculus. It has already been observed that Fermat used methods very closely connected with those of infinitesimal calculus and hence he is sometimes called the founder of this subject, but most writers agree that the honor of founding this subject really belongs to Newton and Leibniz. The question of priority as regards these two investigators has led to an extensive literature. It seems to be commonly accepted now that Newton's first work along this line preceded that of Leibniz, but that Leibniz used the better notation and was an independent discoverer.

The controversy as regards priority with respect to the invention of the calculus was made a national question, and English mathematicians were led to adopt Newton's notation and methods (called the method of fluxions) instead of adopting the better notation devised by Leibniz. Hence the English mathematicians did not coöperate actively in the developments of the infinites- 
imal calculus, which so largely engaged the attention of the eminent continental mathematicians, such as Bernoulli, Euler, and Lagrange, during the eighteenth century. This isolation of English mathematicians was removed in the nineteenth century by their acceptance of the notation of Leibniz.

53. Leibniz. - G. W. Leibniz is the first German mathematician in our list of twenty-five, and his name is closely connected with that of Newton in view of their work as founders of the infinitesimal calculus and the controversies as regards the question of priority. The prominent place held by Leibniz in the history of mathematics is, however, not entirely due to the rôle which he played in founding one of the most important mathematical subjects.

He did important work along other lines. For instance he is the earliest known writer on determinants, and was one of the founders and the first president of the Berlin Academy of Sciences, which was established in I 700 under the name Societät der Wissenschaften, being modeled after the Paris Academy and the Royal Society of London, which were founded about thirty-five years earlier.

Leibniz was born in Leipzig in 1646 and died in Hanover in I716. He attended the University of Leipzig and later went to Jena to study under Erhard Weigel, a mathematician and philosopher, who was noted for his influence as a teacher but was acquainted only with elementary mathematics. In fact, only elementary mathematics was taught in German universities at that time, so that Leibniz had to secure a knowledge of advanced mathematics on his own initiative. 
He was greatly aided in doing this by his opportunities to meet French and English mathematicians while he was in the diplomatic service of German officials. $\mathrm{He}$ thus brought back to Germany the mathematical advances made in other countries, and helped to create a greater mathematical interest in his own country. He was elected to membership both in the Paris Academy and in the Royal Society of London.

The name of Leibniz is also prominent in the history of calculating machines, on the improvement of which he spent large sums of money. In fact, it is said that he spent about twenty thousand dollars in his efforts to perfect his machine, but failed because the necessary mechanical skill was lacking in his day. The most important elements of the modern calculating machines were devised by Leibniz; but it should be observed that he was not the first one working in this field. In fact, B. Pascal constructed a calculating machine in 1642 , which attracted considerable attention and which was greatly improved by others.

Leibniz had a very extensive correspondence with the prominent mathematicians of his day and gained renown as a philosopher as well as a mathematician. He contributed extensively to the important periodical called Acta Eruditorum which was established at Leipzig in I682 by Otto Mencke and served the same purpose in Germany that the Journal des Sçavans was serving so well in France since 1665 .

54. Euler. - Leonhard Euler was born in Basel, Switzerland, in 1707 and died in Petrograd, Russia, in I783. He and J. Steiner are the only Swiss mathemati- 
cians in our list, and both of them spent most of their lives away from their native land. They are, therefore, practically international mathematicians. Euler was the most prolific mathematical writer of all times, and the vastness of his works caused a long delay in their publication.

After several unsuccessful attempts to publish his collected works, the project was finally undertaken, in September, rgog, by the Swiss Society of Naturalists, aided by learned societies in various countries and by popular subscriptions. This project was afterwards supported, as noted in $\S 9$, by an international society, organized especially for this purpose.

A considerable part of Euler's work relates to the development of important results following from the use of the differential and the integral calculus, which was then a new subject. He revised and extended nearly all the branches of pure mathematics which were then known, and he did also very much towards the developments of applications of mathematics in various fields. He introduced the symbol $i$ for $\sqrt{-I}$ and had the courage to use imaginary exponents. In particular, he arrived, in 1748 , at the celebrated formula

$$
e^{i x}=\cos x+i \sin x
$$

for $x=\pi$, this becomes

$$
e^{i \pi}=-\mathbf{I}
$$

which is one of the most remarkable formulas in all mathematics.*

* Klein, Famous Problems in Elementary Geometry, 1897, p. 59; translated by W. W. Beman and D. E. Smith. 
The great volume of Euler's writings is partly due to the fact that he went into great details, and presented even the simpler matters with considerable completeness. It is sometimes said that his writings read like novels. Most of the later writers on mathematics have cultivated a much more concise style which enables them to present their results more briefly. On the other hand, it should be observed that if the works of Euler could have been presented concisely, they would still have been extensive in view of their richness in new results.

He was well acquainted with the writings of earlier mathematicians. In particular, he proved a considerable number of the theorems on number theory which had been announced by Fermat. He gave also the first satisfactory treatment of logarithms by abandoning the older theory that a number had a unique logarithm, and substituting for it the view which is still held that every number has an infinite number of logarithms. He introduced the method of using an integrating factor in the solution of differential equations, was the first to develop a theory of continued fractions, and to study surfaces of the second order systematically.

Euler was the son of a minister named Paul Euler, who was so much interested in mathematics that he followed lectures on this subject in the University of Basel, and he started his son Leonhard in the study of this subject. At an early age Leonhard Euler entered the University of Basel and became a favorite pupil of John Bernoulli, who was one of the noted mathematicians of his day.

At the age of twenty he went to Petrograd and re- 
mained there until I74I, when he was called to Berlin as a member of the Berlin Academy. In I 766 he returned to Petrograd and remained there until his death, about seventeen years later. Through overwork he became blind in one eye in 1735 and in 1766 he became entirely blind, but he continued his scientific work vigorously until his death.

55. Lagrange. - J. L. Lagrange was born at Turin, Italy, in 1736 and died at Paris in 1813 . Like Euler, Lagrange spert most of his life under the direct patronage of foreign potentates. When Euler returned to Petrograd in 1766 he pointed out that Lagrange was the most worthy man in Europe to fill his place. After learning that d'Alembert would not accept the position, Frederick the Great sent a message to Turin, expressing the wish that the greatest king of Europe might have the greatest mathematician of Europe at his court.

Lagrange accepted the invitation and remained at Berlin for about twenty years, until after the death of Frederick the Great. In 1787 Lagrange went to Paris at the request of Louis XVI, where he spent the remainder of his life. On the establishment of the École Polytechnique in 1797 he was made professor in this institution, and his lectures there were models of clearness and completeness.

$\mathrm{He}$ is frequently called the founder of modern mathematics and is commonly regarded as the greatest mathematician of the eighteenth century. In style he is much more concise than Euler, but his works were prepared with great care. In the theory of equations, for instance, his great memoir entitled Réflexions sur la résolution 
algébrique des équations reviews the work done by earlier writers and lays the foundation for important advances. Many of the leading later writers on this subject have received inspiration either directly or indirectly from this memoir, which contains, among other things, the beginnings of the extensive subject of substitution groups and the classification of rational functions of more than one variable.

The great-grandfather of Lagrange was a Frenchman who came to Italy as an officer in the army. The father was a paymaster in the army and had been wealthy, but lost most of his property by speculation. Hence Lagrange was thrown on his own resources. At the early age of nineteen he sent a solution of the isoperimetrical problem to Euler, in which he announced the principle of the calculus of variations.

This memoir inaugurated a new period in the calculus of variations and was esteemed very highly by Euler, who observed that the methods of Lagrange were more general than his own. His success in mathematics was so great that at the age of twenty-six he had already won a place as one of the leading mathematicians of Europe, but his excessive work impaired his health and he was subject to periods of great melancholy.

While he lived at Berlin he was a favorite of Frederick the Great, who had frequent conversations with him in regard to the advantages of perfect regularity of life, and when he went to France he received many tokens of great honor. A striking evidence of the respect in which he was held by the French was given in 1796 when the French commissary in Italy was ordered to attend in full 
state on Lagrange's father, and to tender the congratulations of the Republic of France on the achievements of his son, who "had done honor to all mankind by his genius, and whom it was the special glory of Piedmont to have produced." His works were published in fourteen volumes under the auspices of the French Minister of Public Instruction.

56. Gauss. - C. F. Gauss was born at Brunswick, Germany, in 1777 and died at Göttingen in 1855 . Hence his scientific life belongs principally to the first half of the nineteenth century. His father was a bricklayer, and Gauss owed his early educational advantages to the duke of Brunswick, whose attention had been called to the very marked ability displayed by Gauss in his studies. He entered the University of Göttingen, but in those days mathematical instruction in the German universities was very elementary. Gauss devoted himself privately to the study of theory of numbers and made many important discoveries while a student at Göttingen.

In his doctor's dissertation he published, in I 799, the first rigorous proof of the Fundamental Theorem of Algebra, which establishes the fact that every rational integral function in one variable has at least one zero, and is one of the first important proofs relating to existence theorems. This brilliant discovery was followed two years later by his great work on number theory, which appeared under the title Disquisitiones Arithmetica, and contained a large number of new results as well as new general methods. In particular, the theory of congruences is fully developed here for the first time, and the symbol $\equiv$ is used to denote a congruence. 
He next turned his attention to the computation of orbits of bodies in the solar system and met with marked success. His investigations were of such unusual importance that his fame spread rapidly, and, in 1807 , he obtained an offer of a chair in Petrograd, but he refused this to accept the position of Director of the Göttingen Observatory, which position he held until his death. His work in applied mathematics was perhaps as important as that in pure mathematics, and he is one of the last of the great mathematicians who were able to work productively in all the different fields of this subject known in their day. The rapid growth of mathematics in later years has made it more and more necessary for mathematicians to restrict themselves to certain parts of the mathematical sciences.

The Disquisitiones Arithmetica of Gauss has furnished the starting point for numerous investigations in the theory of numbers. In particular, the fundamental law of quadratic reciprocity, which is proved rigorously in this work, but had been stated earlier by Euler and Legendre, has been extended and proved in different ways by a number of different writers including Eisenstein, Liouville, Le Besgue, Kummer, and others. Gauss himself gave seven or eight proofs of this theorem, which he regarded as the gem of higher arithmetic.

Gauss was the first to develop a real theory of errors, and he introduced into Germany the geometric theory of complex numbers. He was also the first to use the term complex to represent such numbers, or rather to represent these numbers and the real numbers together. The term complex was used earlier in connection with poly- 
nomials. Even S. F. Lacroix ( $1765-1843$ ) used sometimes in his algebra the term complex quantity (quantité complexe) for a polynomial.* The important work of Gauss in connection with inscribing a regular polygon in a circle was noted in $\$ 35$.

It is interesting to add that Gauss valued his discoveries in regard to the regular polygons so highly that he expressed the wish that his tombstone should bear the figure of a regular polygon of seventeen sides. According to $\mathrm{H}$. Weber this wish was not complied with, but on a monument erected in honor of Gauss at Braunschweig this wish was fulfilled. Cf. Encyklopädie der Elementar-Mathematik, by Weber and Wellstein, vol. I, 1906, p. 362. The said wish of Gauss is similar to that which Archimedes is believed to have expressed.

57. Cauchy. - A. L. Cauchy (I789-I857) was a contemporary of Gauss and he was almost as preëminent among the French mathematicians of his age as Gauss was among the German mathematicians of his period. One of the greatest common contributions of these leaders was the general introduction of the complex numbers. These numbers had been used earlier by various writers, but their legitimacy remained somewhat in doubt for a long time. Even Gauss did not express himself clearly on this point in his early work notwithstanding the fact that he raised objections to the term impossible numbers, which was still used for these numbers.

In France, Cauchy did much to spread the theory of Argand in regard to these numbers, and he gave a new proof of their legitimacy by his theory of algebraic equiv-

* Cf. Encyclopeddie des Sciences Malhémaliques, Tome I, Vol. 2, p. 3. 
alences, published in 1847 , according to which congruences modulo! $i^{2}+\mathrm{I}$ take the place of equations of rational integral functions of $i$.

The vast extensions resulting from the general introduction of complex numbers opened up broad fields of work into which Cauchy entered with enthusiasm. In his Analyse algébrique of I82I he gave the first rigorous theory of the elementary functions, and established rigorous theorems in reference to the infinite series of complex numbers.

At the same time there arose in Germany a school of combinatory analysis which was antagonistic to the critical methods of Cauchy and Abel, but the latter were finally received with great favor also in Germany. In I825 Cauchy proved the fundamental theorem now known as Cauchy's Integral Theorem, which is one of the most important theorems in the theory of functions of a complex variable. He also established on a sound basis the important theory of differential equations.

Cauchy wrote very extensively, and, in regard to the extent of his writings, he should probably be classed next to Euler. His works in twenty-seven volumes are being published since 1882 under the auspices of the French Minister of Public Instruction. In addition to his fundamental work in the theory of functions and infinite series, he wrote on a large number of other subjects in pure and applied mathematics. His writings on the theory of substitutions were so important that he is commonly regarded as the founder of this subject.

Cauchy was educated in the Ecole Polytechnique of Paris and started out as a civil engineer, but he soon 
abandoned this profession and devoted himself to teaching and investigating. He lost the respect of many scientists by accepting in $18 \mathrm{I} 6$ a seat in the French Academy which had become vacant by the expulsion of a very noted French geometrician named Monge. The following extract from a letter written in 1826 by Abel, who was a student at Paris at that time, is of interest: "Cauchy est fou et il n'y a rien à faire avec lui, bien qu'il soit en ce moment le mathématicien qui sait comment il faut traiter les mathématiques. Ses travaux sont excellents, mais il écrit d'une manière très confuse." *

58. Steiner. - Jacob Steiner (I796-I863), like Euler, was born in Switzerland, but spent most of his life away from his native land. The biography of Steiner contains several very unusual facts. In the first place, he learned to write after he was thirteen years of age, and his mathematical training was practically confined to his independent discoveries in geometry.

Although he became professor of mathematics in the University of Berlin, he remained practically ignorant of all mathematical subjects except geometry. He spent three years as a student in the University of Heidelberg, but studied nothing about differential calculus or about number theory, and his attainments in algebra extended only to the solution of the quadratic equation. $\dagger$

Steiner was the son of a small farmer and he worked on the farm of his father until he was fourteen years old. He had some trouble in persuading his father to allow

* Niels Henrik Abel Mémorial, publie a l'occasion du centenaire de sa naissance. Correspondance, p. 45.

† E. Lampe, Bibliotheca Mathematica, Vol. I (1900), p. I29. 
him to go away to study. In I82I he came to Berlin, where he taught in several schools without much success. In his private studies he was, however, very successful, and he began to publish in the year ( 1826 ) when the noted German mathematical journal known as Crelle's Journal was started. He soon became well known for his remarkable discoveries in synthetic geometry. In 1834 he was elected to a chair (ausserordentliche Professur) in the University of Berlin, and in the same year he was elected as a member of the Berlin Academy.

In 1832 he published his Systematische Entwickelung der Abhängigkeit geometrischer Gestalten von einander, which created a new era in geometry. This was followed by numerous other publications, in which he exhibited not only great originality but also great power. In his lectures at Berlin University he practically confined himself to presenting results due to himself, and he came in much closer touch with his students than most of the other professors of his day. $\mathrm{He}$ was inclined to criticize his students very severely, and in this way discouraged some from attending his courses. Those who persevered had, however, excellent opportunities to get started in his own line of work and he thus inaugurated a Steiner School of geometers.

He was inclined to speak very plainly and to be easily offended, and thus he made friends and enemies rather freely. In his biographical sketch of Steiner, Emil Lampe relates the following incident which throws light on his character. One evening he met Jacobi, who used to be a very good friend of Steiner, but the two great mathematicians disagreed and parted while they were 
both angry. Soon after Jacobi reached his home he received a message from Steiner asking him to fight a duel with pistols. Jacobi thereupon sent Steiner the following message: "If you are tired of life buy yourself a pistol, and fire a ball into your head. You do not need me for that." This ended the matter. Original in his investigations, and original in his life, Steiner stands out as one of the most unique characters among the great mathematicians.

59. Abel. - Although N. H. Abel (I802-I829) died before he was twenty-seven years old, yet he is one of the most important mathematicians of the nineteenth century. An offer of a chair in the University of Berlin was sent to him but this failed to reach him before his death. It is, however, a strong testimony of the high standing which Abel had reached at such an early age. He was the son of a Norwegian pastor and studied so successfully at the University of Christiania that he received in 1825 a stipend from the Norwegian government to study mathematics in France and in Germany.

He spent about a year and a half in these countries, and published various articles in the newly established Crelle Journal. Among these was the first rigorous proof of the fact that it is impossible to solve the general equation whose degree exceeds four by means of rational operations and the extraction of roots.

Early in 1826 Abel wrote to his friend Holmboe that there were few infinite series whose sums had been obtained in a rigorous manner; and hence what he regarded as most important in mathematics seemed to 
him to be without foundation.* He paid a great deal of attention to the rigorous treatment of infinite series, and his labors along this line supplemented those of Cauchy.

In particular, Abel gave a rigorous treatment of the binomial theorem, when the exponent is a complex number, while Cauchy had considered it when the base was complex but the exponent real, as was noted in $\S 43$. Abel also directed attention to an incorrect theorem announced by Cauchy which was based on the erroneous idea that every series which converges in the neighborhood of a point must always converge uniformly in the neighborhood of this point.

In the theory of elliptic functions the work of Abel was epoch-making, as he was the first one to call attention to the importance of studying the inverse problem of the elliptic integral; and he observed the double periodicity of the resulting functions. In all his work he took general and broad viewpoints, and hence he opened up fields which are not yet exhaustively investigated. In particular, he was one of the first to employ the concept of number realm.

Two editions of his collected works have been published, and a large memorial volume, including his correspondence, was published at the celebration of the one hundredth anniversary of his birth. These publications are evidences of the high position which he holds in the minds of his countrymen, and in the eyes of the mathematical world.

60. Hamilton. - W. R. Hamilton was an Irishman and is the only representative of that nation in our list.

* Niels Ilcinrik Abel Memorial, Correspondance, I902, p. I6. 
As regards his early training and general scholarship, he was very different from Steiner. It is said that he could read Latin, Greek, French, and German with facility when he was only seven years old, and that at thirteen he was familiar with as many languages as he was years old.

Another singular fact in his career is that he was elected in 1827 to the chair in Astronomy at the University of Dublin, while he was still an undergraduate, with the understanding that he should be left free to pursue his own line of study. He was born in Dublin on August 4, 1805, and died there on September 2, 1865.

Hamilton is best known on account of his discovery of quaternions, in 1843 , which constitutes the first example of a number system in which the operation of multiplication is non-commutative. Shortly after this discovery H. Grassmann of Germany published his noted work Die lineale Ausdehnungslehre, Leipzig, 1844, to which he was led by geometric considerations, and which has also proved to be a very fertile subject, especially in the domain of geometry.

These works have been the main sources of an extensive literature on complex number systems, and the attention of mathematicians was directed to this line of work largely through the Theorie der complexen Zahlensysteme, Leipzig, $\mathrm{I} 867$, by $\mathrm{H}$. Hankel. To Hamilton is due one of the most interesting theories of ordinary complex numbers; viz., the theory which regards these numbers as pairs of real numbers. The notion of a complex number of order $n$ is also due to him.

As was stated in $\S 35$ Hamilton presented to the 
Royal Irish Academy a paper entitled $A$ new system of roots of unity, ${ }^{*}$ in which he considered the equations

$$
\mathbf{I}=i^{2}=k^{3}=\lambda^{\mathrm{r}}, \quad i k=\lambda, r=3,4,5 .
$$

$\mathrm{He}$ observed that these equations are sufficient to restrict the elements $i, k$, when they are combined as regards multiplication under the associative law in every possible manner, so that the total number of the distinct products may be interpreted on the regular polyhedrons. The case when $r=5$ received especial attention, and this case is also considered very briefly in a note which appeared about a month later, December, 1856 , under the title: Memorandum respecting a new system of roots of unity, in the London, Edinburgh, and Dublin Philosophical Magazine.

By making $r=4$ he " obtains other symbolical results which are interpreted by the (regular) octohedron and the (regular) hexahedron," and by making $r=3$, he obtains results which are " almost too simple to be interesting" and which have their corresponding geometrical interpretation in the theory of the regular tetrahedron.

These facts suffice to make it evident that Hamilton at this early date was familiar with the properties of the groups of the regular solids, as generated by two operators or elements, and that he proved that these groups may be completely defined by the orders of their two generating operators and the order of their product. His form of statement of these results coincides with that now employed with the exception of the use of certain terms. Hamilton did not use the technical term group, and he

- Proceedings of the Royal Irish Academy, vol. 6, 1853-5, p. 415. 
evidently was in search for things lying beyond these groups, just as his main interest as regards quaternions was beyond the quaternion group. The said discoveries seem to entitle Hamilton to be regarded as one of the founders of abstract group theory.

61. Galois. - Evariste Galois is the only noted mathematician who died before he was twenty-one years old. It was observed that Abel died when he was but twenty-six years old, and it seemed remarkable that he was able to do enough work in his short career to entitle him to a permanent place among the leading mathematicians of all times, but in the case of Galois the wonder is many times greater, especially if it is remembered that the last two years of his short life were largely devoted to political matters.

It is clear that the reputation of a man who lived only such a short time must rest on the importance of the work which he inaugurated rather than upon the extent of the work actually accomplished. In mathematics it is a common experience that as theories grow in extent the reputation of mathematicians whose names are fundamentally attached to these theories grows likewise.

The name of Galois is fundamentally attached to several theories, but especially to the theories of algebraic equations and of groups. The vigorous growth of these theories since the death of Galois has kept his name prominently before the mathematical public. This vigorous growth should, however, not be regarded as accidental, but it is an expression of the great importance of the work inaugurated by Galois, and of his deep in- 
sight into the main difficulties which prevented an earlier development along this line.

Galois was born near Paris on October 25, I8I I. He was wounded in a duel on May 30, I832, and died from this wound the following morning. At the age of fifteen he began to give evidence of his extraordinary mathematical ability. The elementary books on algebra did not satisfy him, but he studied the classic works of Lagrange which enabled him to enter deeply into modern developments of this subject. At seventeen he seems to have been in possession of some of his fundamental results which he began to publish about this time. Altogether he published only five short mathematical articles, - two in Gergonne's Annales de Mathématiques and three in the Bulletin de Ferussac. He was aware of his extraordinary ability, and the resulting pride brought him into trouble in the Ecole Polytechnique and in other places. He took a deep interest in politics and he was imprisoned for supposed political offenses. His short life was unusually stormy, ending with a duel to which we have already referred.

An extensive biography of Galois prepared by Dupuy appeared in the Annales de l'Ecole Normale Supérieure, I896, pages I95-266. The works of Galois seem to have received little attention until 1846 when they were published by Liouville with an appreciative introductory note in volume II of the Journal de Mathématiques. This publication made them readily accessible, and soon thereafter mathematicians in various countries undertook to complete and to extend the theories due to Galois. 
Prominent among these mathematicians were E. Betti of Italy and L. Kronecker of Germany; but to C. Jordan of France is especially due the credit of extending the results due to Galois and of exhibiting their great fertility. The great Traité des Substitutions of 1870 was called by its author, with unusual modesty, a commentary on the work of Galois. In I908 Jules Tannery published the unfinished manuscripts of Galois as a testimony of great respect for the genius all of whose thoughts were highly' prized by later mathematicians.

62. Sylvester. - In addition to the fact that J. J. Sylvester was a great mathematician, his name is of peculiar interest to Americans because he contributed powerfully to the advancement of mathematics by his influence on the early development of mathematical investigation in America. By many he is regarded as the man who really inaugurated investigation in advanced mathematics in our country during the years (1876-83) which he spent in America as Professor of Mathematics in Johns Hopkins University.

His high appreciation of the importance of investigation, and of the desirability of having professorships in our leading universities filled only by men who were actively engaged in research, made a strong impression on his students, and, through them, on a large body of American educators.

Soon after his arrival at Johns Hopkins University he helped to establish, in 1877 , the American Journal of Mathematics, which was devoted from its beginning to the interests of mathematical investigation, and which has maintained very high standards. Sylvester was its 
first editor and contributed liberally to its pages. Through his large acquaintance with prominent mathematicians he was able to secure important contributions from foreign mathematicians, and thus to set high standards for the young investigators of our country.

Sylvester was born in London, England, on September 3, 1814, and he died in the same city on March 15 , 1897. In 1840 he came to America as professor in the University of Virginia, but he soon got into trouble with a student and suddenly decided to return to England, where he occupied various positions. When Johns Hopkins University was started, he returned to America to become its first professor of mathematics.

The following advice given by President D. C. Gilman to the Trustees of Johns Hopkins University on the choice of a professional staff indicates that Sylvester came to Johns Hopkins under favorable conditions. "Enlist a great mathematician and a distinguished Grecian; your problem will be solved. Such men can teach in a dwelling house as well as in a palace." *

In 1883 Sylvester returned to England to accept the position of Savilian Professor of Geometry at Oxford, succeeding Professor Henry Smith, who was especially noted for his work in the theory of numbers. Sylvester was a very inspiring teacher, manifesting a keen desire to advance his subject and to lead his students to problems which promised important results. He is especially well known scientifically for his work in the theory of invariants, but various other fields of algebra were enriched by him.

- Report of the President of Johns Hoplins University, I 888, p. 29. 
One peculiarity of Sylvester's writings, noted in $\S 20$, is the introduction of numerous new terms. He was inclined to lay undue stress on the importance of the particular work under consideration, and his writings are often very flowery but somewhat disconnected and hence difficult to read.

63. Weierstrass. - Weierstrass was born in Ostenfelde, Germany, on October 3I, I8I 5 , and died at Berlin on February I9, 1897. During the years $1834-38$ he studied law and finance at the University of Bonn, and later during $1838-40$ he studied mathematics privately under Gudermann at Münster. Many mathematicians of the first rank gave evidence of their unusual mathematical abilities at an early age. Galois, Gauss, and Abel are instances of this kind.

On the other hand, there are those who abandoned other lines of work to turn to mathematics, learning their special aptitudes along this line, at a later period. Weierstrass belongs to the latter class, as he turned to mathematics at an age which exceeded that reached by Galois and at which Gauss had already completed his monumental work called Disquisitiones Arithmetica.

Weierstrass constitutes an exception to the supposed rule that elementary teaching is distasteful to those who are specially gifted as regards research ability. $\mathrm{He}$ spent a number of years as a teacher of secondary mathematics and began his work as instructor in the University of Berlin in 1856 in connection with a large amount of teaching in a technical school.

It was not until 1864 that he received a full professorship at the University of Berlin and could thus devote 
all of his time to advanced mathematics. He continued to look back on his more elementary teaching experience with pleasure and had little sympathy with those young men who sought to avoid such experience.

Weierstrass published little compared with the large number of his new results and new methods. He endeared himself to his students by the great liberality with which he allowed them to develop important theories which he himself had started but could not take time to finish. As an instance of this kind we may cite the doctor's dissertation of Sophie Kowalewski (1850-9I), who was one of the most noted women among mathematicians up to her time.

When her noted dissertation was published Weierstrass said that he was glad that this investigation, which had been planned by him for a long time but for which he could not spare the time, was completed.* In her interesting biography of Sophie Kowalewski, Anna Charlotte Leffler remarks that the entire scientific work of Sophie Kowalewski was only the development of the ideas of her great teacher, Weierstrass. While this tribute may be too favorable as regards the work of Weierstrass in this connection, it is an evidence of the high regard entertained by the students of Weierstrass towards their teacher.

While Weierstrass worked in many different fields of mathematics, his work in the theory of functions is probably best known. His example of a continuous function without a derivative, or a continuous curve without a

* E. Lampe, Jahresbericht der Deutschen Mathematiker-Vereinigung, Vol. 6 (1899), p. 41. 
tangent, made a profound impression when it first became known, and it constitutes one of the most striking results in the history of mathematics.

He recognized early the need of greater rigor in mathematics and he is regarded as the greatest exponent of the recent tendency termed by F. Klein " arithmetizing of mathematics."* His theory relating to the irrational numbers is of fundamental importance in the modern theory of these numbers, and he gave an abstract definition of determinants of order $n$ as a function of $n^{2}$ independent variables satisfying three characteristic conditions, which is frequently but falsely attributed to Kronecker. This error occurs, for instance, in the Encyclopédie des Sciences Mathématiques, tome I, volume I, page $90 . \dagger$

64. Cayley. - The biography of Cayley is especially interesting to English readers in view of the fact that Cayley comes next to Newton among the noted English mathematicians in our list, and he comes first among the English mathematicians who have advanced modern mathematical theories. In common with Vieta, Fermat, Sylvester, and Weierstrass, Cayley studied law in his early years.

During the fourteen years which Cayley spent in the practice of law he wrote between two and three hundred mathematical papers, and these include some of his most important discoveries. He regarded his legal occupations as the means of providing a livelihood, and he preserved with great care a portion of his time for mathematical

* Bulletin of the American Mathematical Socicty, Vol. 2 (1896), p. 241.

† Cf. G. Frobenius, Crelle, Vol. I29 (I905), p. I79. 
investigations, refusing a considerable part of the legal work which came to him.

Arthur Cayley was born at Richmond, England, on August r6, r82r, and died at Cambridge on January 26, r895. He was educated at Trinity College, Cambridge, and in $\mathbf{1} 863$ he was called to the newly established Sadlerian Professorship of Pure Mathematics in the University of Cambridge, which position he held until his death. The duty of the incumbent of this position was " to explain and teach the principles of pure mathematics, and to apply himself to the advancement of that science." Few men were better qualified than Cayley was for such a position, and few men have carried out more completely the duties implied in the acceptance of such a position.

He wrote only one book on mathematics, viz., a Treatise on Elliptic Functions, which was published in I876, and contains a considerable amount of new matter. On the other hand, he wrote an unusually large number of papers on a great variety of different topics, - including the subject of quantics, geometry, theory of matrices, symmetric functions, theory of invariants, etc. The number of these papers is almost a thousand, and they have been collected and published in the form of thirteen large volumes. The large subject with which Cayley's name is perhaps most intimately connected is the theory of algebraic invariants, but he contributed to almost all the other known subjects in pure mathematics. In particular, he is generally credited with the introduction of the absolute into geometry.

Cayley endeared himself especially to Americans by 
the fact that he lectured for a time at Johns Hopkins University during its early years, when Sylvester was doing such fundamental work to establish mathematical research in this country. Cayley and Sylvester were students at Cambridge at the same time and formed then a lifelong friendship, which was doubtless increased by their interest in common subjects of research. In the theory of algebraic invariants they were both among the earliest to make important contributions, and, during the fifties, while Cayley was practicing law and Sylvester was an actuary in London, they were in the habit of walking around the courts of Lincoln's Inn discussing the theory of invariants and covariants which was then occupying the attention of both of them, although they were both engaged in other work for a livelihood.

While Cayley and Sylvester would doubtless have become great mathematicians under almost any circumstances, the time at which they lived seemed to be especially ripe for great advances by English mathematicians. The dispute between Newton and Leibniz had resulted in an isolation of English mathematicians, since these adopted the less convenient notation of Newton as well as his conservative geometrical methods, and thus failed to join directly in many of the active advances which were being made on the Continent. The disadvantages of this isolation were fully realized at the time Cayley and Sylvester began their scientific work, and the general appreciation of the analytical methods developed on the Continent created a healthy atmosphere for the exercise of their special gifts along this line. 
65. Hermite. - Two fundamental results due to Hermite are of almost popular interest ; viz., a proof of the theorem that the number $e$ which plays such an important rôle in many mathematical developments is really transcendental, and a solution of the general equation of the fifth degree by means of elliptic functions. The method used by Hermite in 1873 to prove that $e$ is transcendental was employed by Lindemann in $\mathrm{r} 882$ to prove that $\pi$, the ratio of the circumference of a circle to its diameter, is also a transcendental number.

The great importance of these results led to a number of simplifications in their proofs. In view of the fact that the numbers $e$ and $\pi$ enter even into our secondary mathematical work, and that the different kinds of numbers, - real and complex, rational and irrational, algebraic and transcendental, - enter so fundamentally into mathematical considerations, the earliest proof of the transcendency of $e$ naturally marks an epoch in the history of mathematics. This is a special case of the theorem that the equation

$$
X_{1} e^{x_{1}}+X_{2} e^{x_{2}}+\cdots+X_{r} e_{r}^{x_{r}}=0
$$

is impossible when $x_{1}, x_{2}, \cdots, x_{r}$ are distinct algebraic numbers, and the algebraic numbers $X_{1}, X_{2}, \cdots, X$ are not all equal to zero.

The complete solution of the quintic by means of elliptic functions was a feat which aroused almost as much interest as the proof that $e$ is a transcendental number. In the early part of the nineteenth century Abel had put an end to the persistent efforts to solve the general quintic, and equations of higher degrees, by means of rational 
operations and root extractions, since he succeeded in giving a proof of the impossibility of such a solution. This naturally opened the question as to whether other methods could lead to this goal, and Hermite's success in regard to the quintic in $185^{8} 8$ has been followed by other far-reaching developments along this line, which have established the fact that a root of the general equation of degree $n$ can be represented in terms of the coefficients by certain functions called Fuchsian functions.

Charles Hermite was born in Dienze on December 24, I822, and died in Paris, January I4, I90I. He studied at an early age some of the works of such great masters as Lagrange and Gauss, and contributed two short articles to the first volume of the Nouvelles Annales de Mathematiques, founded in 1842 . In 1843 he communicated to the German mathematician Jacobi the results which he had obtained relative to the division of Abelian functions and received the following encouraging reply: "Do not be troubled if some of your discoveries are to be found in my former researches. As you commence where I finish, there is necessarily a small region of contact. In the future, if you honor me with your communications I shall have only to learn."

In 1862 a chair was created for Hermite at the Ecole Normale, in Paris, and a little later he became professor also at the Ecole Polytechnique and at the Faculte des Sciences. He was a very inspiring teacher and conducted his students rapidly into the newer developments which had been opened by Gauss, Abel, Jacobi, and Cauchy. In his earlier lectures at the Faculté des Sciences, beginning with 1869 , he treated the theory of equations; but 
in 1875 he abandoned algebra and devoted himself to integral calculus and the theory of functions. He was not a prolific writer but most of his writings deal with questions of great importance and methods of great originality and of wide usefulness. His collected works in 4 volumes were edited by Emile Picard.

66. Kronecker. - In his interesting sketch of the life and work of Kronecker, published in volume 2 of the Jahresbericht der Deutschen Mathematiker-Vereinigung, $\mathrm{H}$. Weber refers on page I9 to the fact that Kronecker remarked in an address, "The integers were made by God, all else is the work of man." This statement sounds the keynote of the ideals towards which Kronecker was striving in his mathematical work; viz., to reduce everything in mathematics to the theory of natural numbers.

Not only in algebra but also in the theory of functions he aimed to exhibit clearly the arithmetical foundation. He regarded a function as rational only when its coeffcients are also rational numbers, and, according to his view, a rational integral function with numerical coeffcients had to have integral coefficients.

Kronecker introduced the expression "domain of rationality," and exhibited many of the advantages resulting from the explicit use of this concept, which appeared already in the works of Abel, Galois, and Gauss. The general theory of algebraic numbers was established on a new basis in his noted Festschrift $z u$ Berrn Ernst Eduard Kummer's fünfigjährigem DoctorJubiläum, I882; and the developments in the theory of algebraic equations due to Galois were not only 
extended by Kronecker, but they were approached from a somewhat different point of view as a result of the more explicit use of the concepts relating to the domain of rationality.

Leopold Kronecker was born near Breslau, Germany, on December 7, 1823, and he died at Berlin on December 29, I89I. In 186I he was elected a member of the Berlin Academy of Sciences. This position entitled him to lecture at the University of Berlin and he availed himself of this opportunity, beginning in the winter semester of I86I-62.

The main subjects of his lectures were number theory, determinants, and algebra. These lectures soon attracted a number of students of unusual ability not only from the other German universities but also from foreign countries. In 1883 he was appointed professor in the University of Berlin, which position he held until his death.

In Weber's biographical sketch of Kronecker, to which we referred above, there appears a very queer misstatement which has been repeated by other writers; viz., the statement, "Galois was first mentioned by Kronecker in a letter to Dirichlet, dated March 3, 1856." Contrary to this statement by $\mathrm{H}$. Weber the name of Galois, and the Galois theory of equations, are mentioned by Kronecker in an article which appeared in the Bericht über die zu Bekanntmachung gecigneten Verhandlungen der K. P. Akademie der Wissenschaften zu Berlin for 1853 . This proves that Kronecker became acquainted with the works of Galois at an early date, at least, before he published his first paper on the solution of algebraic equations. 
67. Cremona. - The word Cremona is met frequently in the form of an adjective in mathematical literature. We speak of a Cremona congruence, a Cremona curve, a Cremona group, a Cremona substitution, a Cremona transformation, etc. The student of projective geometry is likely to have received inspiration and pleasure"from the reading of Cremona's Elements of Projective Geometry, which has been translated into various languages.

The student of the history of mathematics is, however, mostly interested in Cremona in view of the important position which he filled in bringing about the great geometrical advances in Italy during the second half of the nineteenth century. While at the beginning of this century Italy had very little mathematical standing, the end of the century found Italy in the lead along geometric lines. This change was largely influenced by the work of Cremona.

Luigi Cremona was born in Pavia on December 7, 1830, and died in Rome on June 10, 1903. He was elected as Professor of Geometry in the University of Bologna in 1860 and many of his brilliant discoveries were made soon thereafter. In 1873 he was appointed Professor of Higher Geometry in the University of Rome and Director of the reorganized Engineering School. Most of his important publications precede this appointment, as the administrative and political duties seemed to have consumed most of his energies during his later years. He was very influential in bringing about reforms in the secondary schools of Italy, and became a leader in questions of mathematical pedagogy as well as in those relating to the advancement of knowledge. 
Cremona is the only one in our list of twenty-five who can be called an Italian mathematician without reserve. It is true that Lagrange was born and educated in Italy, but he had French ancestors, and he did a great part of his scientific work in Germany and in France. In view of his French ancestry and the fact that he spent the latter part of his life in France, teaching in the French institutions and identifying himself so fully with the French people that his collected works were published under the auspices of the French government, it is perhaps natural to think of Lagrange as a French mathematician.

Cremona, on the other hand, was fully identified with Italian institutions and with Italian public interests. In his early life he even joined the Italian army in defense of his country against foreign aggression, and, in the latter part of his life, he was a great leader in the educational work of his country. The wonderful mathematical advances which Italy made since the middle of the nineteenth century were largely guided by Cremona, Brioschi, and Beltrami.

68. Lie. - The importance of the group concept in algebraic work was brought to the general attention of mathematicians through the work of Abel and Galois during the first half of the nineteenth century. The fertility of this concept in other lines of work was made clear in the early part of the second half of the nineteenth century by the work of Jordan and others. It was, however, not until Lie and Klein had selected this concept as the centralizing and unifying element of their work that the wide applications of the group concept became generally known and the value of the 
methods arising from its explicit use began to be generally appreciated.

Lie permitted his whole soul to be permeated with the group concept, and energized by its influence he devoted his life with perseverance and great effectiveness to an exposition of various far-reaching mathematical theories from this new point of view. "The groups do everything" was the somewhat exaggerated yet inspiring maxim by which he inflamed himself and the students who were attracted to him through his ability and success.

M. S. Lie was born on December $17, \mathrm{I}_{442}$, in Nordfjordeide, Norway, and died in Christiania on February I8, I899. For six and one half years beginning with 1859 he was a student at the University of Christiania, but he did not become especially interested in mathematics. In fact, after leaving the university, he was thinking about devoting himself to astronomy. A few years later, he began to devote himself to the private study of mathematics, reading the classic works of Duhamel, Lamé, Chasles, Monge, and Poncelet. $\mathrm{He}$ became deeply interested and soon began to make original contributions.

In 1869 , he went to Berlin, having received a stipend from the University of Christiania as a result of his successful investigations. Here he met Klein, and both of them went to Paris later, coming under the influence of Jordan, Darboux, and others. The common scientific interests of Klein and Lie led to several papers which they published jointly. While Lie was in Paris he made, in July, 1870, the remarkable discovery of a contact- 
transformation by which a sphere can be made to correspond to a straight line.

In 1872 Lie became professor in the University of Christiania. This special position did not imply that he was expected to give lectures in the University, but permitted him to devote all his time, undisturbed by teaching duties, to his investigations. In 1873 he made the beginning of his extensive theory of transformation groups, and in $1873-74$ he determined all the finite point and contact transformations of the plane.

In 1876 he helped to organize a new journal of mathematics entitled Archiv for Mathematik og Naturvidenskab, and ten years later he accepted a call to assume the duties of a professorship in the University of Leipzig as a successor to F. Klein, who had accepted a call to go to Göttingen. It was at Leipzig where Lie came in contact with a number of students whom he started in his own work. Among these students there were a number of foreigners who were attracted by his great reputation.

We referred above to Lie's absorbing interest in group theory, but it should not be inferred that this theory, in its abstract form, was his chief interest. It served often as a guiding principle where the development of other theories was his main objective. $\mathrm{He}$ was especially interested in the theory of differential equations and regarded this theory as the most important among all mathematical subjects.

To make progress in this theory was Lie's chief aim from the beginning to the end of his very productive career. Both his geometrical developments and his theory of continuous groups were subsidiary to this end. 
His great fame led the Norwegian government to make special efforts to secure his return to his own country, and shortly before his death he did return to accept a very honorable position created for him in the University of Christiania.

69. Poincaré. - Notwithstanding the rapid increase in the number of prominent mathematicians during the latter half of the nineteenth and the beginning of the twentieth century, and the tendency to withhold full scientific recognition until after the death of an author, yet Poincare stood at the beginning of the twentieth century as the one man of whom eminent scholars did not hesitate to speak publicly as the greatest living mathematician. Both in pure and in applied mathematics Poincaré worked with remarkable success, and, during the latter part of his life, he devoted considerable attention also to philosophical questions.

By his popular treatment of such fundamental questions as the foundations of geometry and the value of science, he did much to spread scientific knowledge and to popularize our science, whose beauties are too apt to escape the attention of the world, and hence they are often in greater need of clear exposition than are the important applications. These beauties were emphasized in the philosophical work of Poincaré.

He was born at Nancy, France, April 29, 1854, and died at Paris on July ז7, I9г2. He was educated successively at the Lycée de Nancy, l'Ecole Polytechnique and at l'Ecole Nationale Supérieure des Mines, receiving his doctor's degree from the University of Paris in 1879. He was a very bright student and received 
first rank at the entrance examination of l'Ecole Polytechnique. At the early age of 32 he was elected as a member of l'Académie des Sciences, and in view of this occasion he prepared, in $\mathrm{r} 884$, a statement entitled "Notice sur les travaux scientifiques de M. Henri Poincaré."

Although this "Notice" was written less than five years after Poincaré had begun the publication of his researches, it reviews a large number of his published articles along the following three lines: (I) Differential equations, (2) General theory of functions, (3) Arithmetic or the theory of numbers. He emphasizes the fact that he did not pursue his researches in these three directions independently of each other, but that the results obtained along these various lines threw light on each other, and that his work along each one of them was greatly aided by the work along the other lines.

The breadth of scholarship exhibited by Poincare in his early writings and his great ability to observe relations between apparently widely different subjects became still more pronounced as he grew older, but we observe even at this early date a mind of very broad sympathies and of extraordinary ability to generalize. His principal writings may be classed under the following four headings : pure mathematics, analytic and celestial mechanics, mathematical physics, and the philosophy of science.

In I909 Emile Borel published, in the journal called La Revue du Mois, an article on the method of Poincaré. Parts of this were translated for the first article in the Bulletin of the Calcutta Mathematical Society. In view 
of the great importance of the method of work, we quote parts of this translation.

The method of Poincaré is essentially active and constructive. $\mathrm{He}$ approaches a question, acquaints himself with its present condition without being much concerned about its history, finds out immediately the new analytical formulas by which the question can be advanced, deduces hastily the essential results, and then passes to another question. After having finished the writing of a memoir, he is sure to pause for a while, and to think out how the exposition could be improved; but he would not, for a single instance, indulge in the idea of devoting several days to didactic work. Those days could be better utilized in exploring new regions.

All this is not specially applicable to mathematics. Let us examine more closely the mechanism made use of for discovery. The essential feature of that mechanism is, as we have already pointed out, the construction of new formulas. It is not useless that some stress is laid on this point, for this constructive power is the essential trait of the genius of Poincaré. The non-mathematical readers can be made to understand all this by means of a comparison. They know what arithmetical calculation is, and are often led to believe that mathematicians are in the habit of making interminable additions, multiplications, etc., and also extractions of cube roots.

In reality, arithmetical operations are unique combinations of integral numbers formed of units which are all equal to one another. These operations can be compared to the construction of regular walls by means of bricks of uniform sizes. The work requires only some patience and a little care. On the contrary, analytical operations make use of extremely numerous materials, and their variety is comparable to those of structures where stone, marble, wood, iron, etc., are used. These operations are as different from each other as cuirassé is from a Gothic church. They have also with the architectural constructions this in common, that an impression of beauty is produced by the simplicity and elegance of the essential lines, without exhibiting any of the efforts by means of which the result has been obtained. 
Poincaré was a great pioneer, boldly entering into unexplored regions and noting some of the most important objective points and then leaving to others the details of organization. In the words of Borel he was more of a conqueror than a colonizer, and he attached little importance to conceptions which cannot be realized in a concrete form. In this respect he may be compared with men of action; his method of work was too active to leave much room for such reflections as do not lead to concrete results.

On January 28, ıฏ゚9, Poincaré was received as member of l'Académie Française, and on this occasion M. Masson, Directeur de l'Académie, delivered an address in which he entered into many details of Poincaré's career. A translation of a part of this address appeared in the Popular Science Monthly, September, I909, page 267. A sketch of Poincaré's career may also be found in the Independent, October 5, I9II, under the general title of "Twelve Major Prophets of To-day." An elementary article by Poincaré on the foundations of geometry appeared in the Monist, October, 1898 , and a number of his other articles have been translated into English from foreign journals.

Poincaré won great fame in connection with his prize memoir relating to the problem of three bodies. In I885 King Oscar II of Sweden offered a prize for the solution of a question in reference to this general problem, and one half of this prize was awarded to Poincaré for his article entitled, "Sur le problème des trois corps et les équations de la dynamique," published in the Acta Mathematica in I890. In the Bibliotheca Mathematica 
for 1904, page 198, Eneström calls attention to the interesting fact that the copy of this memoir for which the prize had been actually awarded contained a serious error, and that the given published article was really prepared for the press after the prize had been awarded.

Among the other prizes received by Poincare we mention the gold medal of the Royal Astronomical Society of London, the Bolyai prize of the Hungarian Academy of Sciences, the Sylvester medal of the Royal Society of London, and the Lobačevsk $\ddot{y}$ gold medal of the Kasan Mathematical Physics Society. In addition to these foreign prizes Poincaré received two prizes from the Paris Academy and a gold medal from the French Association for the Advancement of Science. He received an honorary doctor's degree from each of the following universities: Cambridge, Christiania, Oxford, Glasgow, Brussels, and Stockholm.

1. To those who would like to establish a connection between the university athlete and intellectual greatness, between physical powers and the intellectual giant, Poincaré was a decided disappointment. He was only about 5 feet 5 inches in height, was somewhat stooped, at least in the latter part of his life, and his weight was about I54 pounds. Even as a child he was rather weak and did not generally engage in the rougher sports of the boys of his age. He cared little for politics and achieved his greatness solely through his scholarly services. When he entered the French Academy he was told that he was born a mathematician and would die a mathematician. $\mathrm{He}$ had, however, the good fortune to live in a country 
where mathematical attainments are held in high esteem even by the general public.

Poincaré wrote a number of books especially on mathematical physics, but the three books which are perhaps the most commonly known deal with philosophical questions and bear the following titles, respectively: $L a$ Science et l'Hypothèse, La Valeur de la Science, and Science et Methode. In regard to the first of these, the Director of the French Academy said at the time when Poincare entered this academy that the circulation of 16,000 copies of his La Science et l'Hypothèse had increased his personality tenfold.

He was fond of traveling, and many Americans recall his visit to the St. Louis Exposition, in 1904, where he delivered an address entitled, "The Present and the Future of Mathematical Physics." This address was translated for the Bulletin of the American Mathematical Society by J. W. Young, and published in the February, I906, number of this journal. Poincaré visited all the countries of Europe and also some of the countries of Africa. He was married and had four children - three daughters and a son.

The great mainspring of Poincaré's activity was seeking the truth. This made his life both simple and beautiful. Seeking the truth implies an open acknowledgment of ignorance. In fact, one of the strongest mathematical methods consists of putting an $x$ for the unknown; but how could we put an $x$ for the unknown unless we were willing to admit that we are ignorant in regard to its value. Every one who has worked in elementary algebra knows that much is frequently gained by admitting our 
ignorance and by calling some particular ignorance $x$ and another particular ignorance $y$, etc. Even in his mature years Poincaré could honestly ask the question "La terre tourne-t-elle?" Things that are commonly accepted as true but have not been fully established, frequently offer the most important fields of research, and the great investigator does not always accept the views of the masses as evidence of truth.

At the funeral of Poincaré the French Minister of Public Instruction remarked that all his work, all his life, was animated by a prepossession, which he expressed in this thought: "The search for truth must be the goal of our activity; it is the only end that would be worthy of it." 


\section{APPENDIX}

\section{BRIEF LISTS OF IMPORTANT WORKS}

THE following lists of books were prepared with a view to the interests of those who have only a slight acquaintance with the general mathematical literature, and hence these lists include only a few of the most important works along the various lines indicated. As the lists are intended mainly for English readers, books in this language were given preference; but the most important works in a few other languages were also included, since all mathematical students are naturally interested in the best works along various lines, and the advanced students should be able to read works in more than one language.

In order to enable the reader to form some idea of the books which have been listed brief notes have been added after their titles. Regular elementary textbooks were not included, since the number of these is so very large and reliable information in regard to them is more easily accessible than in regard to works which are used less commonly. The students of mathematics who do not have ready access to large libraries cannot be too careful about the selection of the books for their private collections, since their progress depends very much upon the kind of tools they have in the form of books. Nearly every book on advanced mathematics is worth much more to the earnest student than its price. The main question 
is to select those books which will enable him to use his time in the most profitable way.

\section{A. Bibliographites aNd Encyclopedias}

I. Royal Society of London Catalogue of Scientific Papers, I800-1900. Subject Index, volume I, pure mathematics. Cambridge University Press, I908. Pp. lviii +666 .

This is the most useful extant general bibliography of the mathematical literature which appeared in the periodicals during the nineteenth century. The articles are classified according to a schedule adapted from schedule $A$ of the International Catalogue of Scientific Literature. There are " 38,748 entries referring to 700 serials." See $\S \mathbf{1 3}$.

\section{Répertoire Bibliographique des Sciences Mathé-} matiques. Paris, Gauthier-Villars, I894-

A card catalogue, each card containing about ten entries. The cards are sold in packages of 100 at 2 francs per package. They give the titles of the mathematical publications, pure and applied, beginning with 1800 , and the historical literature beginning with 1600 . Up to 1914 twenty packages containing about 20,000 entries had appeared. Hence these cards contained at that time only about one-half as many entries as the Subject Index noted above. See $\S 18$.

3. Mathematischer Bücherschatz. By E. Wölffing. Leipzig, B. G. Teubner, I903. Pp. xxxvi + 4I6.

This work aims to be a classified bibliography of the most important books and monographs on pure mathematics which appeared during the nineteenth century. While the Royal Society Index noted above is devoted to the periodical literature, the present work is devoted to the non-periodical literature of the 
nineteenth century. Although it is less complete and less carefully edited than the given Index, it is, nevertheless, very useful for the purpose of finding non-periodical publications which appeared during the given period. A second volume dealing with applied mathematics has been announced. See $\S \times 3$.

4. Bibliography of the Teaching of Mathematics, I900r9r2. By D. E. Smith and C. Goldziher. U. S. Government Printing Office, I9r2. Pp. 95.

A classified list of 1849 entries of articles and works on the teaching of mathematics published from rgoo to I9I2, but excluding regular textbooks. It appeared as Bulletin, I9r2, No. 29, United States Bureau of Education, and is very useful for the purpose of studying this important period in the history of teaching.

5. International Catalogue of Scientific Literature. A : Mathematics. Published annually by the Royal Society of London, beginning with the year rgor.

Gives a list of the articles which appear from year to year, arranged alphabetically according to authors and also according to subject matter. Lists the titles and places of publication of books and articles, but does not give any reviews. It constitutes the first volume of a set of seventeen which are issued annually and include the material collected by regional bureaus established in more than thirty coöperating countries.

6. Jahrbuch über die Fortschritte der Mathematik. Berlin, Georg Reimer, r871-

Annual critical review of the principal articles and books on pure and applied mathematics. The reviews are written in German, but relate also to works published in other languages. It uses a special mode of classification. See $\S \mathbf{r}$.

7. Revue semestrielle des Publications Mathématiques. Amsterdam, Delsman en Nolthenius, 1893- 
Semiannual review of books and articles on pure and applied mathematics. The reviews appear in the same language as that used in the book or article whenever this language is English, French, or German. In case the original is in some other language the review is generally in French. The classification is very minute, being in accord with the system adopted at the international conference on mathematical bibliography held at Paris in 1889 under the presidency of H. Poincaré. See $\S$ II.

8. Bibliography of Non-Euclidean Geometry. By D. M. Y. Sommerville. London, Harrison and Sons, I9II. Pp.xii +403 .

Titles of about 4000 publications, divided roughly as follows: theory of parallels, 700; foundations of geometry and noneuclidean geometry, 1600 ; geometry of $n$-dimensions, 1800 . It is divided into three parts; viz., chronological catalogue, subject index, and author index. This is a very useful bibliography of the vast subject considered.

9. Führer durch die mathematische Literatur. By Felix Müller. Leipzig, B. G. Teubner, 1909. Pp. x +252 .

This work aims to be a guide through the mathematical literature especially for those who have only a meager knowledge of this literature. Hence it aims to give only the most important references to books and to the periodical literature, with emphasis on the bistory of the various subjects. The explanations are brief but valuable.

ro. Encyclopédie des Sciences Mathématiques pures et appliquées. Paris, Gauthier-Villars; Leipzig, B. G. Teubner, I904-

When the first number of this great encyclopedia appeared, it was expected that the entire work would cover only about 8000 pages and would be completed in about 12 years, but the plan was 
gradually extended, and the time required to complete the work has also been extended. The encyclopedia aims to meet needs of all mathematical students and of all teachers of this subject. About 5000 pages appeared during the first ten years after the publication began. This is the most complete mathematical encyclopedia that has been undertaken up to the present time, and when it is completed it will probably be the most useful mathematical work for reference.

II. Encyklopädie der Mathematischen Wissenschaften mit Einschluss ihrer Anwendungen. Leipzig, B. G. Teubner, I898--

The publication of this work began six years earlier than that of the French edition just noted. The parts of the French edition which have appeared are generally much more complete than the corresponding parts of the German edition, upon which most of them were based; but the German edition has at present the advantage of a more advanced stage of publication. See $\S 13$.

12. Enciclopedia delle matematiche elementari. An elementary encyclopedia in Italian which is being published by Hoepli of Milan, Italy.

13. Repertorium der höheren Mathematik, Zweite Auflage. Leipzig, B. G. Teubner, r9ro-

A very useful brief encyclopedia in four volumes, based on the noted Italian work, entitled "Repertorio di matematiche superiori," by E. Pascal. The first two volumes appeared in I9ro. Despite the fact that the publishers had announced at various times that the other two volumes would appear at earlier dates they had not appeared in the summer of I9I5.

14. Encyklopädie der Elementar-Mathematik. By $\mathrm{H}$. Weber and J. Wellstein. Leipzig, B. G. Teubner, I903-

A work devoted to the more elementary parts of mathematics and employing superior methods in treating many subjects. 
Three volumes, entitled respectively, Elementare Algebra und Analysis, Elementare Geometrie, and Angewandte ElementarMathematik.

15. A Mathematical and Philosophical Dictionary. By C. Hutton, London, 1795-6; new edition, 1815. 2 vols. Pp. viii $+760,627$.

Valuable chiefly on account of its historical articles, which were carefully written. It contains some other articles which are still useful.

16. New Mathematical and Philosophical Dictionary. By P. Barlow. London, I8r4. About 800 pages.

This is a briefer dictionary than Hutton's, upon which it was based. It contains a considerable number of biographical sketches and was intended to be popular. Its pages are not numbered.

I7. Mathematical Dictionary and Cyclopedia of Mathematical Sciences. By C. Davis and W. G. Peck. New York, 1867.

An elementary work involving little that is of interest to the advanced student, but it is of historic interest, especially to the American student.

I8. Synopsis der höheren Mathematik. By J. G. Hagen. Berlin, 189I-1906.

This is one of the most useful and most comprehensive mathematical works produced in America, having been written while its author was Director of the Georgetown Observatory at Washington, D. C. It was printed in Germany and in the German language. As it is based on books rather than on journal articles, it naturally devotes relatively more space to the older results than could otherwise have been expected. It is, however, very useful for the purpose of learning the most fundamental facts in regard to a large number of subjects in pure mathematics. The work consists 
of three large volumes aggregating about 1300 pages, and bearing the following headings: Arithmetische und algebraische Analyse, Geometrie der algebraischen Gebilde, and Differential- und Integralrechnung.

19. A Synopsis of Elementary Results in Pure Mathematics. By G. S. Carr. London, F. Hodgson, I886. Pp. xxxvi +935 .

Mainly a work of formulas relating to the various subjects of pure mathematics from elementary algebra to differential equations and solid analytical geometry. It contains also various useful tables and a valuable index. It is one of the best of the collections of formulas relating to elementary pure mathematics, and many of the more difficult formulas are followed by suggestions as to methods of proof.

20. Die mathematischen Wissenschaften. Leipzig, B. G. Teubner. I9I2-

This is a series of five monographs on mathematics which constitute a part of the extensive work entitled Die Kultur der Gegenwart, and are intended to exhibit the significance of mathematics in our modern civilization. These monographs were prepared under the general direction of $F$. Klein.

Many of the general encyclopedias contain also important mathematical articles. This is especially true of the Encyclopadia Britannica, which includes contributions by some of the foremost English mathematicians as well as by some foreigners. Attention has been directed to historical errors appearing in the eleventh edition of this standard work, ${ }^{*}$ but these errors affect only slightly the usefulness of the work for the advanced student. A large number of special bibliographies and older encyclopedias

* Cl. Science, Vol. 34 (r9r r), p. 76r. 
exist, but the above list is supposed to include the most useful works of this type for the modern student.

\section{B. Histories}

I. A Short Account of the History of Mathematics. By W. W. R. Ball. London, Macmillan and Co., I888-

A brief popular history of mathematics which reached its fifth edition in $19 \mathrm{x} 2$, and was translated into Italian $1903-04$ and into French 1906-07. Each of these translations appeared in two volumes and contains numerous additions and some corrections. The popularity of Ball's work should not be regarded to imply that it is an unusually reliable history of our subject. In fact, the student of the history of mathematics should cultivate the habit of getting his information at the sources whenever possible, since so many statements in some of the most popular histories are misleading.

2. A History of Elementary Mathematics, with hints on methods of teaching. By Florian Cajori. New York, The Macmillan Co., I896. Pp. viii + 304.

A concise and readable history of the developments in elementary arithmetic, algebra, geometry and trigonometry in various periods, with suggestions in regard to the teaching of these subjects.

3. A History of Mathematics. By Florian Cajori. New York. The Macmillan Co., 1893. Pp. xiv +422.

A brief general history of mathematics which has been reprinted several times but not sufficiently revised. The parts which deal with the history preceding the nineteenth century are largely based on Cantor's Vorlesungen. It is written in an interesting style and emphasizes the recent mathematical developments. 
4. The Teaching and History of Mathematics in the United States. By Florian Cajori. U. S. Bureau of Education, 1890. Pp. 400.

A useful work relating to the development of mathematics in our country and the courses offered in our early universities.

5. A History of the Study of Mathematics at Cambridge. By W. W. R. Ball. Cambridge University Press, I889. Pp. xviii +264 .

Presents a clear view of the teaching and study of mathematics at this university during medieval and later times, and considers the influences which led to improvements of mathematical conditions.

6. A Brief History of Mathematics. A translation by Beman and Smith of Fink's Geschichte der ElementarMathematik. Chicago, Open Court Publishing Co., I903. Pp. xii +333 .

A concise history of arithmetic, algebra, geometry, and trigonometry, with a list of brief biographical notes on a considerable number of mathematicians.

7. A History of Japanese Mathematics. By Smith and Mikami. Chicago, Open Court Publishing Co., I904. Pp. vii +288 .

Traces the development of Japanese mathematics from the earliest period to the.introduction of Occidental mathematics into Japan.

8. The Development of Mathematics in China and Japan. By Y. Mikami. Leipzig, B. G. Teubner, r9I3. Pp. viii +347 .

This useful monograph was also published in the Abhandlungen zur Geschichte der mathematischen Wissenschaften. Heft XXX. 
This series of monographs was started in 1877 , and includes a large number of very useful memoirs on historical questions. Most of the memoirs are in the German language.

9. History of Modern Mathematics. By D. E. Smith. New York, John Wiley and Sons.

The present monograph appeared in 1896 as the last part of Higher Mathematics edited by M. Merriman and R. S. Woodward. A fourth edition of 8I pages appeared separately in I906, but the work was not revised sufficiently to bring it up to date.

Io. Vorlesungen über Geschichte der Mathematik. By Moritz Cantor. Leipzig, B. G. Teubner, I888-

This well known work in four large volumes is devoted to the developments in pure mathematics which precede the nineteenth century. The first three volumes were written by Cantor himself, while volume 4 is composed of ten monographs, written by ten different authors. Cantor wrote the last and briefest of these monographs. Numerous corrections to this work have been published in the Bibliotheca Mathematica.

II. Vorlesungen über Geschichte der Trigonometrie. By A. von Braunmühl. Leipzig, B. G. Teubner, I900-03.

This work appeared in two volumes, each containing about 260 pages. The first volume treats the subject up to the discovery of logarithms, while the second starts with this discovery and its influence on the later development of trigonometry. It gives a fairly extensive account of the history of this special subject and was prepared with great care. See $\S \mathrm{I}$.

12. Geschichte der Elementar-Mathematik in systematischer Darstellung. By J. Tropfke. Leipzig, Veit and Co., 2 vols., I902-03.

The first volume contains viii +332 pages and is devoted to arithmetic and algebra. The second volume contains viii +496 
pages and treats geometry, logarithms, trigonometry, series, analytic geometry, conic sections, etc. This was a very good work at the time it was published, but it is getting too old to be entirely reliable.

13. Geschichte der Mathematik. By S. Günther and H. Wieleitner. Sammlung Schubert. Nos. XVIII, LXIII. Leipzig, 1908, I9Ir.

This valuable history aims to occupy an intermediate place between such extensive works as the history by $M$. Cantor and the very brief histories. It was planned by $S$. Günther and A. von Braunmuihl, but the latter died before his part was finished. The first part treats the history from the oldest time to Descartes, while the second part is devoted to developments in arithmetic, algebra, and analysis since the time of Descartes.

14. The Hindu-Arabic Numerals. By D. E. Smith and L. C. Karpinski. Boston, Ginn and Company, I9II. Pp. vi + r6o.

This little volume gives a very valuable discussion of one of the special subjects in the history of mathematics which has perhaps been considered more frequently than any other and has a very large literature, presenting a number of different views on disputed points. The authors aim to give a non-partisan presentation of the chief difficulties and results.

The last parts of the great German and French mathematical encyclopedias, which are in the course of publication, are to be devoted to history, philosophy, and didactics. These encyclopedias are likely to create a new era in the history of mathematics in view of the fact that the extensive coöperation which they called forth seemed essential for the purpose of securing a scientific basis for a reliable extensive work on this subject. 


\section{Teaching and Philosophy}

I. Reports of the International Commission on the Teaching of Mathematics.

The publications which have appeared under the general direction of this Commission since its organization in 1904 constitute a very valuable contribution to the literature on the teaching of mathematics. According to the report of the secretary, dated April 1, 1914, there were then twenty-six countries which took part in the work of this Commission, and the total publications aggregated ro,293 pages. The eleven reports published under the general direction of the American members of this Commission aggregated 670 pages. The German reports up to this time were especially extensive, aggregating 3822 pages.* The American reports were published by the United States Bureau of Education. See $\S 6$.

2. Monographs on Topics of Modern Mathematics relevant to the Elementary Field. Edited by J. W. A. Young. New York, Longmans, Green, and Co., rgir. Pp. vii +4 I 6 .

A series of nine monographs relating to mathematics of special interest to teachers of secondary mathematics. The titles and authors are as follows: The foundations of geometry, by $O$. Veblen; Modern pure geometry, by T. F. Holgate; Non-Euclidean geometry, by F. S. Woods; The fundamental propositions of algebra, by E. V. Huntington; The algebraic equation, by G. A. Miller; The function concept and the fundamental notions of the calculus, by G. A. Bliss; The theory of numbers, by J. W. A. Young; Constructions with ruler and compasses, by L. E. Dickson; The history and transcendence of $\pi$, by D. E. Smith.

3. The Teaching of Elementary Mathematics. By D. E. Smith. New York, The Macmillan Co., rgor. Pp. xv +3 I 2.

* H. Fehr, L'Enseignement Mathématique, Vol. 16 (1914), p. I84. 
The value of this volume is greatly increased by the large number of references and by the fact that the history of the various subjects is briefly treated. It is chiefly devoted to the most elementary parts of mathematics, omitting trigonometry and analytic geometry.

\section{The Teaching of Mathematics in the Elementary} and the Secondary Schools. By J. W. A. Young. New York, Longmans, Green, and Co., r907. Pp. xviii +35r.

A discussion of numerous questions which confront the teacher, with emphasis on the conditions in the United States. The present work and the preceding one are somewhat complementary; in particular, the discussions of the history of the various subjects given in the preceding volume are not repeated in the present volume, but the space thus saved is employed for a consideration of difficulties in the subject matter, various methods of presentation, and the material equipment for doing the best work. In Igr 2 this book was translated into Russian and enlarged by A. R. Kulischer.

\section{The Teaching of Mathematics in Secondary Schools.} By Arthur Schultze. New York, The Macmillan Co., I9r2. Pp. $x x+370$.

"The chief object of this book is to contribute towards making mathematical teaching less informational and more disciplinary." It does not contain any direct references to history, material equipment, or the developments in other countries. The space thus saved is used for a more detailed discussion of questions relating to the disciplinary value of mathematics.

6. Lectures on Fundamental Concepts of Algebra and Geometry. By J. W. Young. New York, The Macmillan Co., I9ı. Pp. vi +247 .

A discussion of elementary concepts from the standpoint of more advanced mathematics, with emphasis on the logical con- 
nections and logical processes. This little volume gives an excellent introduction to the philosophy of mathematics.

7. Les étapes de la philosophie mathématique. By L. Brunschvicg. Paris, Felix Alcan, r9r2. Pp. xi + 59r.

Various philosophic questions connected with the development of mathematics are considered, beginning with those of the most ancient times and closing with various modern views

8. Handbuch des mathematischen Unterrichts. By W. Killing and H. Hovestadt. Leipzig, B. G. Teubner, I9ro-13. Two volumes, pp. viii $+45^{6}$ and $\mathrm{x}+472$.

This extensive work aims to present from a logical point of view the fundamental ideas which enter into the theories of elementary mathematics,'and hence it is especially useful to arrive at a thorough understanding of the subject matter with which the teacher of secondary mathematics is concerned.

9. Didaktik des mathematischen Unterrichts. By A. Höfler. Leipzig, B. G. Teubner, r9ro. Pp. xviii + 5og.

This work devotes more attention to practical questions of teaching than the preceding volumes.

Io. Elementarmathematik vom höheren Standpunkt aus. By Felix Klein. Leipzig, B. G. Teubner. Two volumes, I908-o9. Second edition, I9I3-I4.

These lithographed lectures by one of the foremost mathematicians and a leader in the modern reform movements in mathematical teaching, are unusually rich in valuable suggestions relating to modes of presentation. The first volume is devoted to arithmetic, algebra, and analysis, while the subject of geometry is treated in the second volume.

II. Principia Mathematica. By A. N. Whitehead and Bertrand Russell. Cambridge University Press, I9ro- 
A very valuable and extensive work on the logic of mathematics. Volume I appeared in rgro, Volume II in 1912, Volume III in 19r3.

12. Memorabilia Mathematica. By R. E. Moritz. New York, The Macmillan Co., 19r4. Pp. xiv + 4IO.

A collection of 2160 quotations relating to mathematics, arranged under $2 \mathrm{I}$ headings and followed by an extensive index. The quotations from foreign languages appear only in English, with a few exceptions, but references to the original sources follow all the quotations. The many short inspiring quotations are a source of great delight and tend to throw light on many fundamental questions, even if they are sometimes exaggerations, and hence they should not always be taken literally. This is, however, usually true of quotations.

13. On the Study and Difficulties of Mathematics. By A. de Morgan. Chicago, The Open Court Publishing Co., 1902. Pp. vii +288 .

This little book was first published in I83I by the "Society for the Diffusion of Useful Knowledge" and hence it represents views held before some of the modern developments were known. It contains many points of view which are still very helpful, especially for teachers of elementary mathematics.

14. La science moderne et son état actuel. By E. Picard. Paris, Flammarion, 1905. Pp. iv +313 .

This important work has had a very large sale and was translated into Spanish and into German. The latter translation appeared in 1913 under the title "Das Wissen der Gegenwart in Mathematik und Naturwissenschaft." The volume begins with a sketch of the development of mathematical analysis, which is essentially the lecture delivered by Picard at the St. Louis Exposition on September 23, 1904. 
15. The Teaching of Geometry. By D. E. Smith. Boston, Ginn and Company, I9r r. Pp. $v+339$.

This book "stands for vitalizing geometry in every legitimate way; for improving the subject matter in such a manner as not to destroy the pupil's interest." It includes a brief history of geometry and considers leading propositions separately.

16. Essays on Mathematical Education. By G. Carson. Boston, Ginn and Company, r9r3. Pp. v + I39.

Consists mainly of reprints of inspiring essays published in The Mathematical Gazette and elsewhere.

I7. $A$ History of the Teaching of Elementary Geometry. By A. W. Stamper. New York, Columbia University, rgo6. Pp. $x+163$.

Considers the teaching of geometry from the earliest times up to the present and includes a bibliography of sources. The transition of elementary geometry from the university to the secondary schools - is noted. In particular, it is observed on page 97 that it was not until I844 that Harvard required geometry for entrance.

18. The Teaching of Algebra. By T. P. Nunn. London, Longmans, Green, and Company, I9I4. Pp. xiv $+6 \mathrm{r} 6$.

In addition to the usual subjects this book discusses more advanced topics, such as the trigonometry of the sphere, periodic functions, differentiation, integration, etc. In the index a work of $\mathrm{J}$. W. Young is erroneously classed with those of J. W. A. Young. 


\section{AUTHOR INDEX}

(The numbers refer to pages.)

Abel, N. H., 30, 94, 110-11, 188, |Borchardt, C. W., 41 203, 211, 215, 244-5, 247-8, Borel, E., 43, 269-71 $251,255,260-2,265$

Braunmühl, A. von, 284-5

Ahmes, 68, 103, 144, 164, 165, Brioschi, F., 192, 265

$177-8,182,196$

Ahrens, W., 21

Alkhwarismi, 83

Ampère, A. M., 111

Andoyer, H., 69

André, D., 104

Apollonius, 16, 93, 221-4

Archimedes, 14, 16, 76, 93, 166$167,169,171,219-24$

Aristotle, 13, 134

Bachmann, P., 117

Ball, W. W. R., 13, 55, 97, 128, 282-3

Balzer, R., 193

Barlow, P., 280

Barrow, I., 232

Beltrami, E., 265

Beman, W. W., 141, 237, 283

Bernoulli, John, 96, 210, 238

Bertrand, J., 111, 133

Betti, E., 253

Bézout, E., 191

Bliss, G. A., 286

Bôcher, M., 78, 194

Boethius, A. M. T. S., 81

Boncompagni, B., 61

Brunschvicz, L., 288.

Bürk, A., 160

Burkhardt, H., 47

Burns, Josephine E., 77

Cajori, F., 2, 209-10, 282-3

Cantor, G., 125, 140

Cantor, M., 6, 17, 62, 82, 102, $146,152,230,284-5$

Capelli, A., 109

Cardan, H., 94, 184, 189, 230

Carr, G. S., 67, 281

Carson, G., 290

Casey, J., 181

Castelnuovo, G., 54

Cattell, J. M., 33

Cauchy, A. L., 30, 74, 77, 99, 102 , $191-3,211,215,228,243-5$, 248, 261

Cavalieri, B., 171

Cayley, A., 74, 77, 99, 114, 193, $207,215,257-9$

Čebyšëv, P. L., 133

Chasles, M., 111, 219, 266

Cicero, 221

Clairaut, A. C., 104

Collinson, P., 20 
Cramer, G., 191

Crelle, A. L., 40

'Tremona, L., 215, 264-5

Czuber, E., 54

Darboux, G., 266

Davis, C., 280

D'Adhémar, R., 8

D'Alembert, J., 65, 84, 96, 186-7

Dedekind, R., 140, 206

De Morgan, A., 44

D'Ocagne, M., 200

Descartes, R., 8, 9, 59, 60, 95, 136, 184, 186, 199, 201, 215, 228-30 233, 285

Dickson, L. E., 176, 209, 286

Diogenes Laertius, 168

Diophantus, 116, 153, 224-7, 231

Dirichlet, P. G. L., 130, 153-4, 263

Duhamel, J. M. C., 266

Dupuy, P., 252

Eisenstein, G., 242

Eneström, G., 4, 6, 61, 66, 89, 104, 134, 272

Eratosthenes, 131-3

Euclid, 16, 76, 82, 93, 97, 129, $131,134-6,159,160,166,172-$ $173,175,178,216-20,223-4$

Euler, L., 7, 16, 27, 30, 73-5, 104, $131,141,153-4,168,187,210-$ $211,213,215,228,235-9,244$

Euler, P., 238

Fagnano, G. C., 213

Fehr, H., 54, 123, 286

Fermat, P. de, 20, 114-16, 153-4, 176-7, 215, 228, 230-1, 234, 238,257

Ferrari, L., 184
Ferro, Scipione del, 184

Fink, K., 283

Fourier, J. B. J., 2

Franklin, B., 20

Frederick the Great, 119, 239-40

Frenicle de Bessey, B., 20

Frobenius, G., 102, 195, 257

Galois, E., 30, 73, 94, 97, 99, 102, $188,203,215,251-3,255,262-$ 263,265

Gauss, C. F., 2, 6, 7, 16, 30, 55, $95,102,113,117,175-6,186-9$, $192,199,203,215,228,241-3$, 255, 261-2

Gebhardt, M., 1

Gerardin, A., 89

Gergonne, J. D., 41, 252

Gilman, D. C., 254

Girard, A., 170-1, 184, 189

Goldbach, C., 131

Goldziher, C., 277

Grassmann, H., 249

Graup, F., 161

Graves, R. P., 213

Grebe, E. W., 181

Greenhill, G., 54

Grotefend, G. F., 3

Grunert, J. A., 41

Guccia, G. B., 46

Gudermann, C., 255 .

Günther, S., 8, 285.

Hadamard, J., 54

Hagen, J. G., 67, 280

Hall, G. S., 32

Halley, E., 233-4

Hamilton, W. R., 173-4, 212-13, 215, 248-51

Hankel, H., 106-7, 151, 249

Hayashi, T., 24 
Heath, T. L., 129, 164, 219, 223-4 |Laisant, C. A., 29

Hedrick, E. R., 34

Heiberg, J. L., 220

Henry, C., 231

Hermite, C., 190, 215, 260-2

Hero of Alexandria, 178, 227

Hippocrates of Chios, 217

Höffler, A., 288

Hoffmann, J., 161

Holgate, T. F., 286

Holmboe, B. M., 110, 247

Hooke, R., 232

Hospital, G. F. A. de l', 191

Hovestadt, H., 288

Hudde, J., 197, 226

Huntington, E. V., 286

Hutton, C., 280

Jacobi, C. G. J., 192-3, 213, 246247, 261

Johnson, W. W., 153

Jones, W., 168

Jordan, C., 100, 109, 253, 265-6

Karpinski, L. C., 285

Keyser, C. J., 8, 80

Killing, W., 288

Kirkman, T. P., 114

Klein, F., 54, 100, 102, 141, 237, $257,265-7,281,288$

Kowalewski, G., 194

Kowalewski, S., 256

Kronecker, L., 195, 203, 215, 253, 257, 262-3

Kulischer, A. R., 287

Kummer, E. E., 116, 154, 242, 262

Lacroix, S. F., 243

Lagrange, J. L., 2, 16, 30, 94, 98, $119,187,207,215,235,239-41$, 261,265

Lambert, J. H., 167

Lamé, G., 266

Lampe, E., 245-6, 256

Landaw, E., 45, 130

Laplace, P. S., 2, 111, 187, 191

Lebesgue, H., 109

Le Besgue, V. A., 242

Leffler, Anna C., 256

Legendre, A. M., 2, 111-12, 130, $150,154,242$

Lehmer, D. N., 69

Leibniz, G. W., 14, 96, 191, 215, $228,232,234-6,259$

Lemoine, E., 180

Leonardo of Pisa, 132, 149

Lie, S., 95-6, 100, 102, 215-16, 265-8

Lietzmann, W., 115

Lindemann, F., 167, 260

Liouville, J., 40, 140, 242, 252

Lobačevskij, N. I., 125

Lodge, O., 95

Löffler, E., 3

Loria, G., 62

Love, A. E. H., 144

Lovett, E. O., 18

Mackay, J. S., 181

Maclaurin, C., 187

McMahon, P. A., 21, 44

Maillet, E., 110-11

Masson, M., 271

Menæchmus, 222

Mencke, O., 236

Menelaus, 78, 179

Méray, C., 92, 140

Merriman, M., 43, 284

Mersenne, M., 20

Meyer, W. F., 47, 207

Mikami, Y., 283 
Miller, G. A., 286

Mohammed ben Musa, 83

Monge, G., 2, 245, 266

Moore, E. H., 34

Morgan, A. de, 289

Moritz, R. E., 289

Müller, C. H., 5

Müller, F., 5, 37, 73, 96, 107-8, 177,279

Muir, T., 195

Myers, G. W., 5

Nesselmann, G. H., 225

Newton, I., 14, 189, 209, 210-11, $213,215,228,231-5,257,259$

Nuñez, P., 186

Omar Alkhayami, 212

Osgood, W. F., 26

Ostwald, W., 211

Ott, K., 125

Paciuolo, L., 146-7

Pascal, B., 210, 230-1, 236

Pascal, E., 64, 86, 109, 279

Peano, G., 103

Peck, W. G., 280

Peirce, B., 30, 78

Pell, J., 59, 60

Picard, E., 262, 289

Pickering, E. C., 121

Pierpont, J., 7, 100-1

Plato, 157, 222

Poincaré, H., 80, 87, 97, 101, 119, $124,215,268-74,278$

Poncelet, J. V., 266

Proclus, 112, 217

Ptolemy, 68, 82, 112

Pythagoras, 70, 124, 136, 157-8, 163, 172

Quincy, J., 128
Rheticus, G. J., 69

Riccardi, P., 75-6

Richardson, J. M., 162

Romanus, A., 227

Rosen, F., 83

Russell, B., 78, 80, 103, 288

Salmon, G., 209

Schoenemann, T., 205

Schultze, A., 287

Seaver, E. P., 68

Sidway, B., 39

Simson, R., 219

Smith, D. E., 26, 54, 141, 237, $277,283-6,290$

Smith, H., 254

Sommerville, D. M. Y., 278

Spottiswoode, W., 192

Stamper, A. W., 290

Stein, J. P. W., 153

Steiner, J., 85, 215, 245-7, 249

Stifel, M., 211-2

Stringham, I., 34

Sturm, C., 198

Sylow, L., 99

Sylvester, J. J., 31, 40, 106, 114, $193,207,215,253-5,257,259$

Tait, P. G., 212

Tannery, J., 73

Tannery, P., 231

Tartaglia, N., 184

Terquem, O., 61

Theodorus of Cyrene, 135

Thymarides, 183

Torres, L., 200

Tropfke, J., 284

Urban, Pope, 128

Valentin, G., 66, 86-7, 91

Vandermonde, A. T., 98, 191 


\begin{tabular}{|c|c|}
\hline \multirow{4}{*}{$\begin{array}{l}\text { Versluys, J., } 161 \\
\text { Vieta, F., 184, 189, 197, 212, 215, } \\
\quad 226-9,257\end{array}$} & Wieleitner, H., 136, 285 \\
\hline & Wilczynski, E. J., 122 \\
\hline & Wipper, J., 161 \\
\hline & Wölffing, E., 66, 276 \\
\hline $\begin{array}{l}\text { Weber, H., 65, 79, 183, 243, 262- } \\
\quad 263,279\end{array}$ & $\begin{array}{l}\text { Wollfskehl, F. P., } 155 \\
\text { Woods, F. S., } 286\end{array}$ \\
\hline $\begin{array}{l}\text { Weierstrass, K., 15, 92, 125, 140, } \\
\quad 195,215,255-7\end{array}$ & Woodward, R. S., 7, 43, 284 \\
\hline Weigel, E., 235 & Yanney, B. F., 162 \\
\hline Wellstein, J., 65, 183, 243, 279 & Young, J. W., 273, 287 \\
\hline Whitehead, A. N., 103, 288 & Young, J. W. A., 26, 286-7 \\
\hline
\end{tabular}




$$
\text { - }
$$




\section{SUBJECT INDEX}

(The numbers refer to pages.)

Absorption of one mathematical' $\mid$ Arithmetizing of mathematics, subject by another, 92

- - other sciences by pure mathematics, 114

Adaptability of mathematics for service to other sciences, 126

Adjectives most frequently employed with mathematical terms, 107

Algebra, as a thought economizer, 182

- rhetorical syncopated, and symbolic, $215-16$

-, origin of the term, 83

Algebraic analysis, 92,244

- numbers, 140, 262

Alexandrian School, 16, 132

Algorithm, origin of the term, 83

American Journal of Mathematics, 30-1

- Mathematical Society and its Bulletin, 33-5, 46

- - students in Europe, 30

- mathematics, 29

- Men of Science, 123

Analysis used with different meanings, 83-4

Approximate values for $\pi, 143$

Arabian mathematics, 82

Arithmetic taught in the universities, 2 257

Babylonian clay writing tablets, 3

Berlin Academy of Sciences, 235, 239

Bertrand's postulate, 133

Bibliographies of mathematical literature, 86,276

Bibliotheca Mathematica, 4, 61

Binomial theorem, 209

Birthdays of mathematical theories, 212

Bollettino di bibliografia e storia delle scienze matematiche, 62

Brief list of important books on mathematics, 275-90

Bulletin de bibliographie, d'histoire et de biographie mathématique, 61

- des sciences mathématiques, 62

Bulletino di bibliografie e di storia delle scienze matematiche $\mathrm{e}$ fisiche, 61

Calculating machines, 236

Calcutta Mathematical Society and its Bulletin, 24

Cambridge Mathematical Journal, 40 
Centers of mathematical activity, 6

Changes during the nineteenth century, 1

Chicago University, 31-2

Circolo matematico di Palermo and its Rendiconti, 45, 48, 120

Clark University, 31

Classification of mathematical literature, 87

Collected mathematical works, 73

Committee on mathematical tables, 69

Complex number systems, 249

Continuous transformation groups, 100

Convergence of an infinite series, 248

Coöperation in mathematical work, 75

Cosmic or Platonic solids, 72-3

Cramer's Rule, 191

Crelle's Journal of Mathematics, 41-2

Cuneiform inscriptions deciphered, 3

D'Alembert's theorem, 186

Definitions of the term circle, 164

\section{- - - function, 96}

- - - mathematics, 17,78

Democratization of mathematical education, 17

Determinants and their usefulness, 191

Deutsche mathematiker-Vereinigung and its Jahresbericht, 47-8

Developed parts of mathematics and of mathematical history, 12

Different methods of multiplying numbers, 147

- terms representing the same concept, 109

Direct fundamental operations, 145

Divisibility of polynomials, 186

Division of mathematics with respect to development, 14

- - - - - subject matter, 84

Domains of rationality, 202, 262

Dominance of the group concept in recent times, 101

Dominant concepts in mathematics, 91

Edinburgh Mathematical Society and its Proceedings, 46

Elementary mathematics taught in the universities, 1

Elements of Euclid, 129, 131, 134, 136

Encyclopedias and other works of reference, $5,25,63,276$

Entrance requirements at Harvard University, 1

Errors in the mathematical literature, 6, 77, 110, 114, 118

Existence proof of an infinite number of prime numbers, 129

- - - irrational numbers, 138

Extraction of the square root, 141

Fermat numbers, 176

- Prize and the Greater Fermat Theorem, 114, 153

Figure inscribed on tombstone, 209, 221, 243 
First decade and a half of the twentieth century, 22

Foreign associates of National Academies, 121

Founder of modern mathematics, 239

Founders of mathematical theories, 14

Führer durch die Mathematische Literatur, 73, 278

Fundamental developments in algebra, 182-213

- - arithmetic, 129-158

- - - geometry, 159-181

Fundamental operations of arithmetic, 144

- theorem of algebra, 185, 241

General historical questions relevant to mathematics, $78-128$

Gentleman's Diary or Mathematical Repository, 39

Geometry as a group-theory problem, 100

Goldbach's theorem, 131

Grand divisions of mathematics, 81

Group, development of the concept, 97, 240, 265

-, most general definition of the term, 102

Growth of the mathematical literature, 22

Harvard University, 1, 2, 128

Hero's theorem, 178

Historical periodicals on mathematics, 60

History of mathematics defined, 8 - - in the nineteenth century, 7
History of mathematics, value of, 4

Honorary members of mathematical societies, 120

Imaginary as a technical mathematical term, 185

Importance of mathematical discoveries, 132

Incentives for the study of mathematics, 93, 143

Incommensurable quantities, 161

Index du Répertoire Bibliographique des Sciences Mathématiques, 89

Indian Mathematical Society and its Journal, 24

Integers made by God, all else is the work of man, 262

Integrating factor in the solution of differential equations, 238

International Catalogue of Scientific Literature, 66, 90, 277

- Commission on the Teaching of Mathematics, 5, 26, 286

- Mathematical Congresses, 31

Introduction of ordinary complex numbers, 7, 242-3

- - the symbol $i$ for $\sqrt{-1}, 237$

Intuitional method in mathematics, 125

Invariants, 206, 258

Inverse operations of arithmetic, 145

Irrational quantities and irrational numbers, $93,133,160$

Irrationality of $\pi, 167$

Isolation of English mathematicians, 259 
Jahrbuch über die Fortschritte Machines to solve algebraic equader Mathematik, 28, 57, 277

Johns Hopkins University, 31, 254

Journal de l'Ecole Polytechnique, 38

- mathématiques pures et appliquées, 40

- für die reine und angewandte Mathematik, 40-1

Kummer's theory of ideal numbers, 116

Ladies' Diary, 38

Lagrange's theorem, 98

Languages from which mathematical terms came, 108

La Société Mathématique de France and its Bulletin, 44-5

Law and mathematics combined as objects of study, 257

Law governing the selection of mathematical terms, 85

Lemoine or Grebe point, 180

L'Enseignement Mathématique, 27

Leonhard Euler-Gesellschaft, 75

Liber Abaci of Leonardo of Pisa, 132,149

Lines of division between various mathematical subjects, 84

Liouville's Journal, 41

Lists of errors committed by prominent deceased mathematicians, 11

Living mathematicians, 118

Logistica numerosa and logistica speciosa, 184

London Mathematical Society and its Proceedings, 44, 120 tions, 200

Magic squares, 19

Mathematical Adam, 106

- Correspondent, the first American mathematical periodical, 2

+ Handbook, 68

- literature in general, 36-77

- monographs, 42-3

- notation and terminology, 102

- periodicals, 23,37

- research in America, 30, 35

- societies, 43,51

- Society of Spitalfields, 44

- Tables, 68

Mathematics as an educational subject, 125

- not a linear sequence of facts, 36

- Teacher, 27

Mathematischer Bücherschatz, 66, 276

Mathematisches Vokabularium, 66

Matrices and determinants, 194

Maximum area of a convex polyhedron having given sides, 164

Measuring curved lines and curved surfaces, 170

Membership in mathematical societies, 48-9, 121

Methods of work employed by mathematicians, 123, 270

Motives for the development of mathematics, 22, 143

Multiplication by successive doubling, 146

Napier's Rods, or Napier's Bones, 71 
National Academy of Sciences Quarterly Journal of Mathematand its Proceedings, 23, 30, ics, 40 120-1

Nobel prize, 120

Notation, value of a good, 105

Notations Mathématiques, 104

Number of journals containing mathematical articles, 37

- symbols, 152

Numerical and literal equations, 195

Octonary numeration, 153

Papyri containing quadratic equations, 144

Parallel axiom, supposed proofs of, 122

Periodic decimals, 138

Periodicals on periodicals and books on books, 56

Periods in the history of mathematics, 15

$\pi$ as a mathematical symbol, 168

- proved to be a transcendental number, 167, 260

Platonic or cosmic solids, 172

Pons asinorum, 162

Positional system of arithmetic, 151

Practical education and mathematics, 3

Prime numbers, 129

Prizes offered for mathematical work, 114, 121, 272

Pure and applied mathematics, 81

Pure mathematics absorbing other subjects, 114

Quadratic reciprocity in the theory of numbers, 242

Quadrivium, 81

Rational numbers defined, 133, 135

- operations of arithmetic, 142

Reference to the writings of others, 5,42

Regular geometric forms, 171

Repertorio di matematiche superiori, 64,279

Revue semestrielle des publications mathématiques, 58, 277

Rosetta stone discovered, 4

Scholarships and fellowships in the universities, 32

School Science and Mathematics, 27

Search for the truth in mathematical work, 80

Sexagesimal system of notation, 153

Sieve of Eratosthenes, 131

Significance of irrational numbers and their general introduction, 137

Solution of algebraic equations, $94,247,260$

Spanish mathematical society and its periodical, 23

Strongest American university mathematical departments, 33

Sturm's series, 198

Subdivisions of mathematics, 86 Subject Index of the Royal Society of London, 65, 91

Sulba-Sustras, 159

Summa de arithmetica of Paciuolo, 146 
Swiss Society of Naturalists pub- | Transcendental numbers, 140, 167 lishing Euler's Works, 28 Sylow's theorem in the theory of groups, 99

Symbol for zero, 152

Synopsis der höheren Mathematik, 67,280

- of Elementary Results in Pure Mathematics, 67, 281 Systems of notation, 149

Table of Pythagoras, 70

Tablets of Senkereh, 141, 150

Teaching and investigating not necessarily separated, 255,261

Theory of aggregates, 92

- - errors, 113, 242

Three great problems of antiquity, 167

Tôhoku Mathematical Journal, 24

Transactions of the American Mathematical Society, 23, 35, 46

Triangle as a center of study, 177

Tribune publique of the French mathematical encyclopedia, 118

Twenty-five prominent deceased mathematicians, 214

Types of recent mathematical literature, 36

Undefined symbols in mathematics, 79

Usefulness of the history of mathematics, 17

Value of $\pi, 165$

Variable used as an undefined symbol, 79

Who is Who as a source of information in regard to living mathematicians, 123

Women mathematicians, 124 
$T^{H E}$ following pages contain advertisements of books on kindred subjects. 



\section{The Elements of the Theory of Algebraic Numbers}

\section{BY LEIGH WILBER REID}

Professor of Mathematics in Haverford College

With an introduction by DAvid Hilbert, Professor of Mathematics in the University of Göttingen.

By easy stages the author leads a reader, entirely unacquainted with the subject, to an appreciation of some of the fundamental conceptions in the general theory of algebraic numbers. With this object in view, he has treated the theory of rational integers more from the standpoint of the general theory than is usual and has emphasized those properties of these integers which find their analogues in the general theory. The same may be said of the general quadratic realm, which has been treated rather as an example of the general realm of the $n$th degree than simply as of the second degree, as little use as was possible being made of the special properties of the quadratic realm in the proofs. The aim of the book is not only to help make the elements of the theory of numbers the common property of all mathematicians, but also to serve as an introduction to the original works to which reference is made, and to incite to independent activity in the field of the theory of numbers.

\section{THE MACMILLAN COMPANY}

\section{Publishers \\ 64-68 Fifth Arenue \\ New York}




\section{A Foundational Study in the Pedagogy of Arithmetic}

By HENRY BUDD HOWELL, Ph.D.

Principal of Public School No. 27, Jersey City, N. J.

$$
328 \text { pp., } 8 v 0, \$ 1.25
$$

The first part of the book constitutes a very complete résumé of the extensive experimental literature on the subject and makes it readily accessible to the general student. It will serve equally well as a convenient guide to the special student who desires to make a first-hand study of it. The second part forms the author's own research, and is an important contribution both because of its positive results and as a scholarly critique of the technique employed by other investigators.

\section{The Teaching of Mathematics in Secondary Schools}

\section{BY ARTHUR SCHULTZE}

Assistant Professor of Mathematics in New York University, Head of the Mathematical Department, High School of Commerce, New York City.

$370 \mathrm{pp}, 12 \mathrm{mo}, \$ 1.25$

This is a clear-cut, definite and scholarly presentation of the uses of mathematics and of the way to make the subject both practical and interesting to high school students.

\section{The Teaching of Elementary Mathematics}

\section{By DAVID EUGENE SMITH}

Professor of Mathematics in Teachers College, Columbia University

$312 p p, 12 m 0, \$ 1.00$

This book has been prepared with a view to arousing in instructors new ideas concerning the teaching of elementary mathematics, and should be in the hands of every instructor of the subject.

THE MACMILLAN COMPANY

Publishors 64-66 Fifth Avenne Now York 
atosinges

की

int

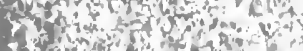

low

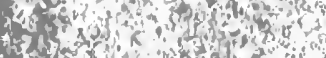

$\pi$.

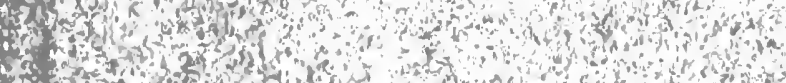

The

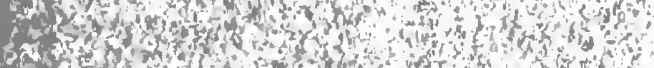

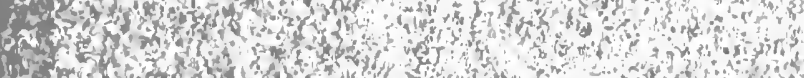

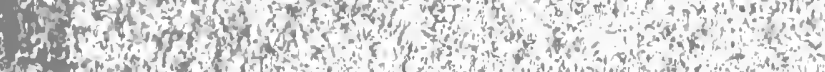

S.

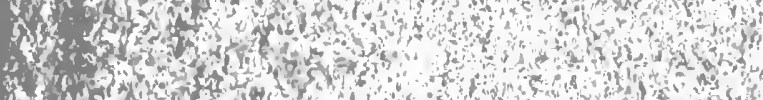

3) 3 (n)

of

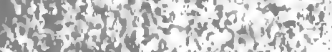

4.

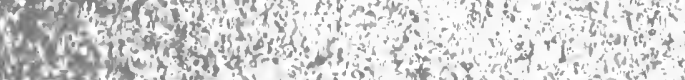

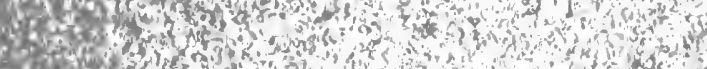

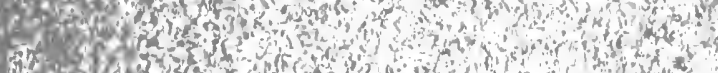

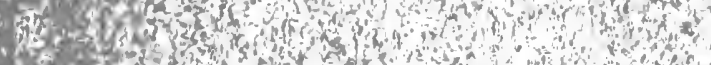

Q⿻

a.dent

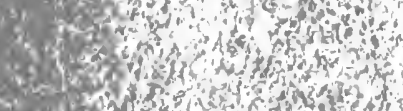

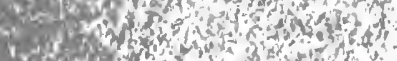

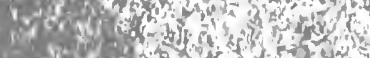

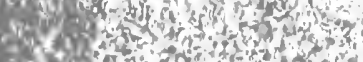

4.

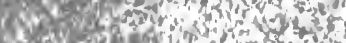

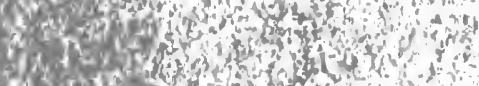

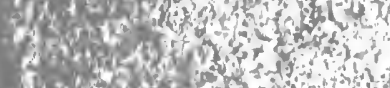

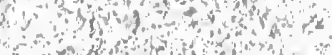

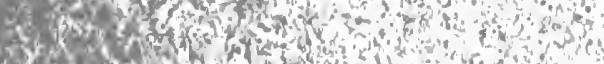


QA

21

M5

\author{
Miller, George Abram \\ Historical introduction \\ to mathematical literature
}

Physical \&

Applied 3ci.

\title{
PLEASE DO NOT REMOVE
} CARDS OR SLIPS FROM THIS POCKET

\section{UNIVERSITY OF TORONTO LIBRARY}


